\title{
Desenvolvimento de um Agente SNMP para Plataformas rodando DOS
}

\section{Renata Cicilini}

Orientador: Prof. Dr. Edson dos Santos Moreira

Dissertação apresentada ao Instituto de Ciências Matemáticas de São Carlos, Universidade de São Paulo, como parte dos requisitos para obtenção do título de Mestre na área de Ciências de Computação e Matemática Computacional 
Aos meus pais,

Antonino e Sueli,

Ao meu irmão e grande amigo,

Gustavo,

pela compreensão, carinho e incentivo durante todos esses anos. 


\section{Agradecimentos}

À Fapesp, Fundação de Amparo a Pesquisa do Estado de São Paulo, ao CNPq e à Capes, pelo apoio financeiro.

Ao Prof. Dr. Edson dos Santos Moreira pela orientação, apoio e incentivo.

À Profa. Dra. Neide Maria Bertoldi Franco pelo constante incentivo.

Aos professores Adilson Gonzaga e Regina H. C. Santana, pelas sugestões.

Ao professor Marcos J. Santana.

Aos professores Nivaldi Calônego Jr. e Onofre Trindade Jr, pelo desenvolvimento das rotinas de interface com o Packet Driver.

A Robert Crosson, pelo esclarecimento de dúvidas sobre a SNMPLIB.

Ao Carrilho, pela amizade e pelas explicaçōes sobre a definição de novas MIBs.

A todos os amigos do ICMSC, em especial ao Welton, Júlio, Rogério, Geraldo, Luis Paulo, Boca, Marquinhos, Tchelo, Hasegawa, Claudinha, Marcelo Stein, Issamy, Morte, Leandro, Elder e Mauricio. Aos meus incriveis amigos: Ana Luisa, Alexandre (Pastel) e Roberto (Fritz), pelos momentos que passamos juntos e que com certeza deixaram saudades. Às minhas inseparáveis amigas Regina(Tata) e Cybelle (Mi), por tudo!

Aos funcionários do ICMSC, em particular: à Beth e à Laura da seção de pósgraduação; à Sonia, ao Angelo e ao Luciano do LDCC; ao José Angelo, à Sandra e ao Paulinho da seção de graduação; ao Eduardo e ao Cabral do LASD; ao Marquinhos do xerox; à Silvana, Sandra e Gi da biblioteca; aos guardas da portaria; à Dna. Dolores e Dna. Maria. À vocês obrigada pelo carinho, atenção e amizade.

A todas as pessoas que sempre me incentivaram meu eterno carinho e gratidão.

Aos meus pais, Antonino e Sueli, pelo exemplo de vida...

Ao Gustavo, por ter sido sempre muito mais que um irmão, revelando-se o grande amigo de todas as horas.

Ao meu padrinho...

À Deus, verdadeira fonte inesgotável de sabedoria e bondade do Universo. 


\section{Resumo}

A tarefa do gerenciamento de redes de computadores tem se tornado complexa, motivando o desenvolvimento de aplicações capazes de auxiliar 0 administrador nas suas funções. Dentre tais aplicações pode-se citar os: sistemas de gerenciamento, agentes, agentes proxy, sistemas monitores e medidores de tráfego.

Neste contexto, este trabalho trata do desenvolvimento de um agente SNMP para plataformas rodando DOS, que pode ser o ponto de partida para a implementação de agentes proxy e demais aplicações de gerenciamento. $O$ agente deve obter informações sobre a sub-rede à qual está conectado. Estas são definidas numa MIB, denominada MIB Net, formada por grupos da MIB padrão Internet, um grupo da MIB RMON e um novo grupo que define um conjunto de objetos relacionados com o fluxo de pacotes por protocolo TCP/IP na sub-rede. $O$ agente exibe os dados obtidos na tela local e permite o acesso aos mesmos por sistemas de gerenciamento que suportem a MIB Net.

No desenvolvimento do agente utiliza-se softwares de domínio público. $\mathbf{O}$ driver de rede adotado é o Packet Driver e a implementação das primitivas do protocolo de gerenciamento SNMP é feita adicionando-se novas rotinas numa biblioteca de primitivas SNMP, a SNMPLIB. O Packet Driver e a SNMPLIB estão disponiveis por Anonymous FTP.

\section{Abstract}

In modern networks, consisted of many hosts and several subnetworks, management functions are becoming complex, demanding the development of applications that can help administrators to perform their tasks. Some examples of these applications are: management systems, agents, proxy agents, monitoring systems and traffic evaluators.

In this context, this work deals with the development of a SNMP agent for DOS platforms, which can provide the basics for implementing proxy agents and other management applications. The agent must get information about the subnetwork in which it is connected in. They are defined on a MIB, called MIB Net, consisted of some Internet Standard MIB groups, the MIB RMON group and a new group that defines a set of objects related to the flow of TCP/IP packets on subnetwork. The agent can show data on a local display and allows access to them by management systems that support MIB Net.

The agent is developed with public domain softwares. The Packet Driver is the network driver used and the SNMP primitives are implemented by adding new routines to a library of SNMP functions, the SNMPLIB. Both Packet Driver and SNMPLIB are available by anomymous FTP. 


\section{Índice}

Lista de Figuras

Capítulo 1 : Introdução

Capítulo 2 : Redes de Computadores 3

2.1. Introdução 3

2.2. Conceitos 4

2.2.1. Estrutura de Rede 4

2.2.2. Topologias e Meios de Transmissão 5

2.2.3. Arquitetura de Rede 7

2.2.4. Redes Locais e Redes a Longa Distância 8

2.3. O Modelo de Referência ISO/OSI 8

2.3.1. Descrição das Camadas $\quad 8$

2.3.2. Serviços 11

2.4. O Conjunto de Protocolos Internet: TCP/IP 12

2.5. Algumas. Tecnologias de Sub-redes de Comunicação 14

2.5.1. O Padrão IEEE 802.x 14

$\begin{array}{ll}\text { 2.5.2. FDDI } & 18\end{array}$

2.5.3. B-ISDN e ATM 19

$\begin{array}{ll}\text { 2.5.4. DQDB } & 22\end{array}$

2.6. Dispositivos de Interconexão de Redes 23

Capítulo 3 : Gerenciamento de Redes 26

3.1. Introdução 26

3.2. O Modelo de Gerenciamento OSI 27

3.2.1. Conceitos Básicos $\quad 27$

3.2.2. O Ambiente de Gerenciamento OSI 27

3.2.3. A Arquitetura de Gerenciamento OSI 28

3.2.4. O Protocolo de Gerenciamento CMIP 30

3.2.5. O Protocolo de Gerenciamento CMOT 31 
3.3. O Modelo de Gerenciamento Internet 32

3.3.1. Histórico $\quad 32$

3.3.2. Conceitos 33

3.3.3. Objetos Gerenciados: o SMI e a MIB 36

3.3.4. Modelo Administrativo $\quad 37$

3.3.5. O Protocolo de Gerenciamento SNMP 38

3.4. A Versão 2 do Modelo de Gerenciamento Internet (SNMPv2) 42

3.5. Comparação entre os Protocolos de Gerenciamento 43

Capítulo 4 : Projeto do Agente SNMP para Plataformas rodando DOS 44

4.1. Introdução $\quad 44$

4.2. Contexto 45

4.3. Informações Contidas na MIB Net 46

4.3.1. Objetos da MIB Padrão Internet para os Protocolos TCP/IP (MIB II) 46

4.3.2. Objetos da MIB para Monitoração Remota da Rede (RMON) 47

4.3.3. Objetos Adicionais definidos na MIB Net 49

4.4. Estrutura da MIB Net no Modelo de Gerenciamento Internet 49

4.5. Um Agente SNMP para Plataformas rodando DOS 51

Capítulo 5 : Implementação $\quad 55$

5.1. Introdução $\quad 55$

5.2. Ambiente de Desenvolvimento $\quad 55$

5.2.1. O Packet Driver $\quad 56$

5.2.2. A Biblioteca SNMPLIB 61

5.3. Implementação de um Agente SNMP para Plataformas rodando DOS 63

5.3.1. Implementação da MIB Net $\quad 64$

5.3.2. O Módulo de Captura $\quad 64$

5.3.3. O Módulo de Tratamento de Primitivas SNMP 67

5.3.4. O Módulo de Interface com o Usuário 68

Capítulo 6 : Conclusões e Trabalhos Futuros 69

Apendice A: A Especificação da MIB Net 72

$\begin{array}{ll}\text { Glossário } & 96\end{array}$

$\begin{array}{ll}\text { Referências Bibliográficas } & 101\end{array}$ 


\section{Lista de Figuras}

Figura 2.1: Estrutura de uma Rede de Computadores 4

Figura 2.2: Topologias de Redes 5

Figura 2.3: Uma Arquitetura de Rede 7

Figura 2.4: O Modelo de Referência ISO/OSI 9

Figura 2.5: Interface entre as Camadas 11

Figura 2.6: $O$ Conjunto de Protocolos Internet $\quad 13$

Figura 2.7: Os Padrões IEEE 802.x

Figura 2.8: Configuração usual da Ethernet 16

$\begin{array}{ll}\text { Figura 2.9: Token Bus } & 17\end{array}$

Figura 2.10: Token Ring 18

Figura 2.11: Interface de Anel Token Ring.

$\begin{array}{ll}\text { (a) Modo de Escuta (b) Modo de Transmissão } & 18 \\ \text { Figura 2.12: FDDI } & 19 \\ \text { Figura 2.13: Multiplexação ATM } & 20\end{array}$

$\begin{array}{ll}\text { Figura 2.13: Multiplexação ATM } & 20 \\ \text { Figura 2.14: Célula ATM } & 20\end{array}$

Figura 2.15: Chaveamento ATM $\quad 21$

Figura 2.16: Modelo de Referência para B-ISDN 21

Figura 2.17: Topologia Open Dual Bus $\quad 22$

Figura 2.18: Topologia Looped Dual Bus 23

Figura 2.19: Exemplo de uma Ponte entre uma rede IEEE 802.3 e uma rede IEEE 802.4 24

Figura 3.1: Modelo Arquitetural de Gerenciamento OSI 29

Figura 3.2: O Conjunto de Protocolos CMIP $\quad 30$

Figura 3.3: Os Serviços CMISE 31

Figura 3.4: O Conjunto de Protocolos CMOT 32

Figura 3.5: O Agente Proxy $\quad 34$

Figura 3.6: Árvore de Identificação ASN.1 36

Figura 3.7: A Arquitetura SNMP 39

Figura 3.8: Obtendo Informações de Gerenciamento do Agente 39

Figura 3.9: Obtendo Informações via Traversal $\quad 40$

Figura 3.10: Atualizando Informações de Gerenciamento no Agente 40

Figura 3.11: Notificando a Ocorrência de um Evento ao Gerente 40 
Figura 4.1: Um Ambiente de Gerenciamento 45

Figura 4.2: A MIB Net na Árvore de Identificação 50

Figura 4.3: O Agente SNMP 51

Figura 4.4: Tarefas Básicas do Agente 53

Figura 5.1: Os Efeitos da Utilização do Packet Driver na Substituição

de Interfaces de Rede

Figura 5.2: Duas Aplicações Sobre uma Mesma Placa de Interface de Rede,

Usando o Packet Driver

Figura 5.3: Uma Aplicação Sobre Duas Placas de Interface de Rede Diferentes, Usando o Packet Driver

Figura 5.4: O Acesso às Rotinas do Packet Driver 59

Figura 5.5: A Biblioteca SNMPLIB 61

Figura 5.6: Tarefas Básicas de um Sistema de Monitoração $\quad 62$

Figura 5.7: A Implementação do Agente SNMP 63

Figura 5.8: A Implementação da Captura das Informações do Grupo ProtoStat 65 


\section{Capítulo 1}

\section{Introdução}

As últimas décadas deste século foram marcadas pela chamada revolução da informação ou ainda revolução da informática. Os primeiros computadores, usados principalmente no processamento aritmético, foram cada vez mais aperfeiçoados, chegando às atuais máquinas multimídia, capazes de manusear voz $\mathrm{e}$ imagens tão bem quanto dados tradicionais. Tais maravilhas conseguiram sair dos filmes de ficção científica graças ao desenvolvimento da microeletrônica, aliada ao surgimento de dispositivos de armazenamento de alta capacidade.

Atualmente, encontra-se computadores nas diversas áreas de atividade humana, desde empresas de grande porte e ambientes acadêmicos, até pequenas casas de comércio, escritórios, consultórios e residências.

Paralelamente ao desenvolvimento desse cenário, surgiram as redes de computadores, interconectando essas máquinas, permitindo a troca de informaçōes e o compartilhamento de recursos. Assim, têm-se redes de âmbito mundial, viabilizando a comunicação entre diversos grupos de interesse, tais como pesquisadores, empresários, governos.

O crescimento desenfreado inerente a esse panorama tem seu preço, motivando uma preocupação comum entre usuários e projetistas de redes: o gerenciamento. Existe um consenso que "gerenciar é preciso" e o resultado é o surgimento de modelos e protocolos de gerenciamento, visando dar suporte ao desenvolvimento de sistemas capazes de auxiliar o responsável por uma rede a gerenciá-la de forma inteligente e eficiente, causando o minimo de transtorno possivel aos usuários. 
A tarefa do gerenciamento tem se tornado cada vez mais abrangente, englobando todo um conjunto de dados capazes de refletir o estado da rede gerenciada. Nesse sentido, um sistema de gerenciamento destaca-se na medida em que obtém uma quantidade maior de informações da rede e as apresenta ao gerente de forma amigável e objetiva ao mesmo tempo, permitindo a visão da rede como um todo e a verificação de seu funcionamento, assim como das redes que a compõe, facilitando a análise e a tomada de decisões.

Este trabalho consiste no desenvolvimento de um agente para plataformas rodando o sistema operacional DOS, segundo o modelo de gerenciamento Internet. $\mathbf{O}$ agente em questão utiliza o protocolo de gerenciamento SNMP, sendo responsável por fornecer, além de algumas informações definidas na base de dados padrão Internet para a máquina que roda - sistema, informações adicionais sobre a sub-rede à qual está conectado. Tais informações formam uma base de dados particular, estando disponiveis para o acesso de sistemas de gerenciamento que implementem tal base. Dentre os objetivos deste trabalho encontra-se a criação da infra-estrutura necessária para o desenvolvimento de agentes e agentes que respondem por outros equipamentos.

Os assuntos abordados pelos capítulos da presente dissertação são citados abaixo.

No Capítulo 2 são apresentados os conceitos básicos referentes à redes de computadores; o Modelo de Referência ISO/OSI; o conjunto de protocolos Internet, mais conhecidos por TCP/IP; as tecnologias de sub-redes de comunicação mais comuns atualmente; e os dispositivos de interconexão de redes.

No Capítulo 3 encontram-se os conceitos de gerenciamento de redes segundo os Modelos de Gerenciamento OSI, Internet versão 1 e Internet versão 2 (SNMPv2).

No Capítulo 4 apresenta-se o projeto do agente SNMP para plataformas rodando DOS, tema deste trabalho.

No Capítulo 5 são abordados aspectos de implementação do agente em questão, incluindo $o$ ambiente de desenvolvimento e a implementação propriamente dita.

Finalmente, o Capítulo 6 apresenta as conclusões e sugestōes para trabalhos futuros. 


\section{Capítulo 2}

\section{Redes de Computadores}

\subsection{Introdução}

Analisando o desenvolvimento tecnológico neste século, percebe-se que a indústria de computadores é uma das mais prósperas e bem sucedidas, ao lado da indústria de telecomunicações com o surgimento das redes telefônicas mundiais, do rádio, da televisão e dos satélites de comunicação. Como resultado da fusão dessas duas áreas surgem as Redes de Computadores, consistindo na interconexão de vários computadores autônomos, muitas vezes através de canais de comunicação antes dedicados exclusivamente à transmissão analógica de voz [TA89].

Ainda nesse contexto, a queda do preço e o aumento crescente das potencialidades do hardware têm ocasionado mudanças na maneira através da qual as informações são obtidas, processadas e usadas. Assim, o modelo computacional de um único computador responsável por todas as tarefas de uma organização tem sido substituido por um grande número de computadores individuais, porém interconectados. Os computadores individuais são mais fáceis de usar e quando interconectados permitem aos usuários isolados o compartilhamento de recursos e a troca de informações. 
Os principais objetivos das redes de computadores são [TA89]:

- compartilhar recursos computacionais geograficamente dispersos;

- permitir alta confiabilidade, através da existência de recursos redundantes;

- reduzir gastos, através da interconexão de computadores de porte menor, o que apresenta vantagem na relação custo/desempenho quando comparada com a utilização de grandes computadores e terminais;

- e ser um meio de comunicação entre as pessoas.

As redes de computadores permitem a comunicação de dados localmente e em áreas geograficamente dispersas, com diferentes requisitos de desempenho e confiabilidade.

São abordados neste capitulo os conceitos básicos referentes às redes de computadores; o Modelo de Referência ISO/OSI; o conjunto de protocolos Internet (TCP/IP); as tecnologias de sub-redes de comunicação mais utilizadas atualmente, a saber: os padrões IEEE 802.x, a rede FDDI, a B-ISDN (Broadband ISDN) a qual utiliza o ATM (Asynchronous Transfer Mode) como estrutura de transporte, as redes DQDB; e finalmente os dispositivos de interconexão de redes.

\subsection{Conceitos}

\subsubsection{Estrutura de Rede}

A figura 2.1 ilustra a estrutura de uma rede de computadores [TA89]. Os computadores individuais que compõe uma rede são chamados de hospedeiros (hosts) e são conectados através de uma sub-rede de comunicação (subnet), cuja tarefa é transferir mensagens de um hospedeiro a outro. Uma sub-rede de comunicação é formada por dois componentes: os elementos chaveadores e os canais de transmissão. Os elementos chaveadores são chamados de IMPs (Interface Message Processors) e são usados para conectar dois ou mais canais de transmissão, recebendo e transmitindo dados através da linha correta.

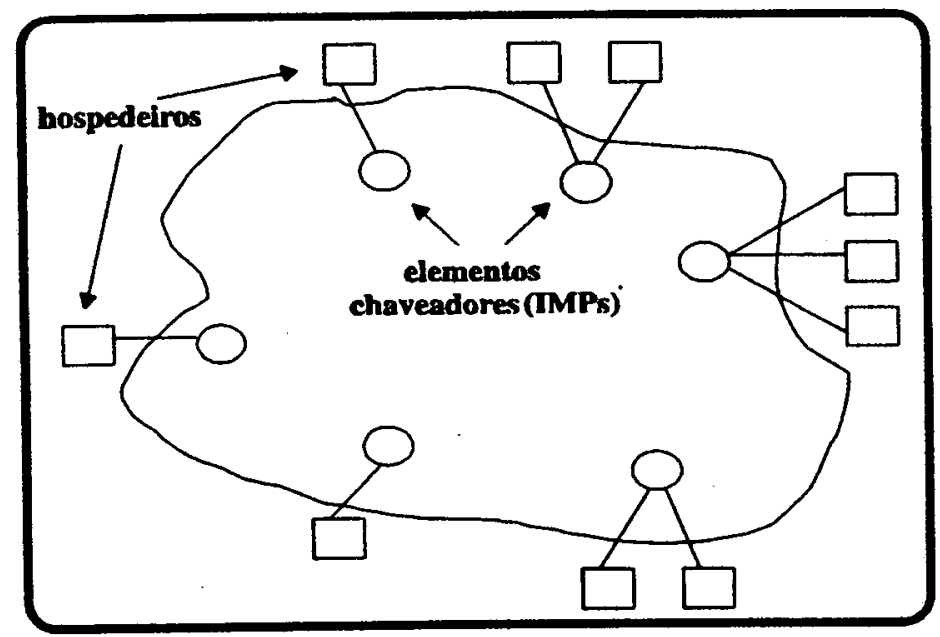

Figura 2.1: Estrutura de uma Rede de Computadores 
Quanto a forma de comunicação, as sub-redes de comunicação podem ser [TA89]:

- ponto a ponto, também chamadas store-and-fonward ou packet-switched, quando a informação é enviada de um IMP para outro podendo passar por vários IMPs no caminho. Cada IMP intermediário recebe a informação, armazena temporariamente e retransmite por um canal de saida; ou

- broadcast, quando usam um único canal de comunicação compartilhado por todos os computadores da rede.

\subsubsection{Topologias e Meios de Transmissão}

Segundo Stallings em [ST84a], a topologia e o meio de transmissão de uma rede são responsáveis por determinar a natureza da rede, ou seja, os dados que podem ser transmitidos, a velocidade e eficiência da comunicação e, consequentemente, as aplicações que a rede pode suportar.

Há uma série de topologias para interconexão dos IMPs, as mais comuns são mostradas na figura 2.2 e descritas a seguir [TA89, GI86]:

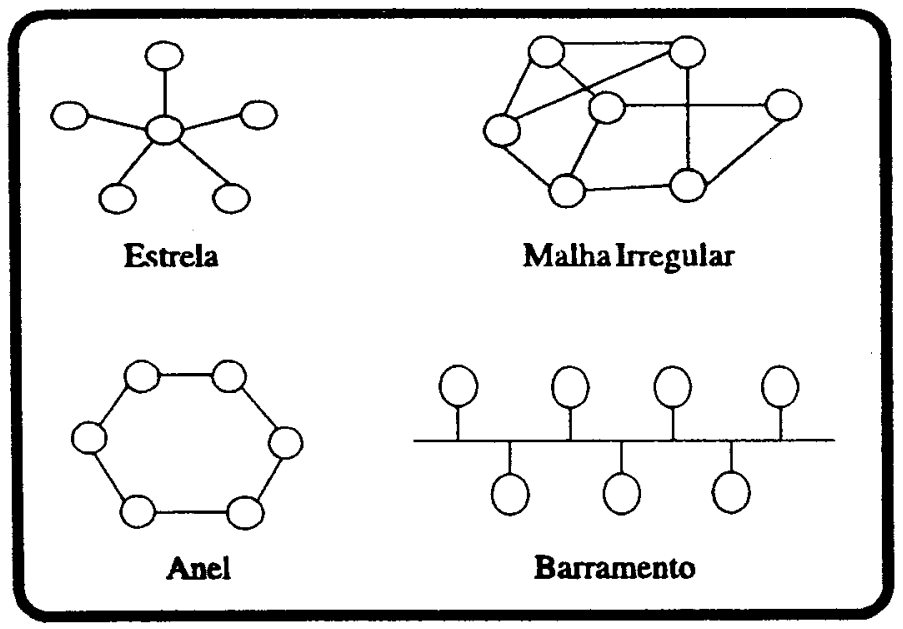

Figura 2.2: Topologias de Redes

$\mathrm{Na}$ topologia em estrela todas as decisões de roteamento são concentradas num IMP central, no qual todos os outros IMPs estão ligados fisicamente. No anel as mensagens são transmitidas unidirecionalmente de IMP a IMP até atingir o destinatário. Dessa forma, cada IMP deve ser capaz de reconhecer seu endereço e copiar as mensagens que the são destinadas.Por outro lado, na topologia em barramento as estações comunicam-se sem a participação dos IMPs intermediários. A única decisão necessária a um IMP é o reconhecimento das mensagens destinadas a ele. A malha irregular é a estrutura mais geral possivel, onde cada IMP pode ser conectado a um número variável de outros IMPs originando uma estrutura irregular.

Existem vários meios físicos usados para transmissão de dados nas redes de computadores [TA89,G186]: 


\section{Par Trançado}

É um meio de transmissão constituido por dois fios metálicos, geralmente de cobre, enrolados em espiral com o objetivo de evitar interferências elétricas externas. É usado principalmente para transmissão a velocidades menores. Apresenta certa suscetibilidade a interferências. Tem conquistado uma parte expressiva do mercado devido ao baixo custo e à versatilidade oferecida na instalação dos equipamentos em decorrência da utilização dos mesmos dutos que conduzem os cabos telefônicos.

\section{Cabo Coaxial}

Trata-se de um meio de transmissão muito comum, assim como o par trançado. A estrutura do cabo coaxial permite alta capacidade de transmissão e boa imunidade a interferências externas.

Existem duas formas de conectar computadores a um cabo coaxial. A primeira é cortar o cabo e introduzir uma junção $T$, a qual conecta as duas partes do cabo e fornece um terceiro fio que deve ser conectado ao computador; enquanto que a segunda é usar uma vampire tap, a qual perfura o cabo atingindo seu núcleo. A vantagem da vampire tap reside em não precisar cortar o cabo.

A utilização de cabos coaxiais como meio de transmissão em redes de computadores está associada ao grande número de redes em barramento. Um exemplo típico é a Ethernet, discutida na seção 2.4.1.

\section{Fibra Ótica}

O desenvolvimento da indústria ótica tornou possivel a transmissão de dados como pulsos de luz. Um pulso de luz pode ser associado a um bit 1 e a ausência de luz a um bit 0 . As vantagens de um sistema de transmissão ótico são a alta capacidade de transmissão alcançada em decorrência da alta frequência da luz, aliada ao pequeno diâmetro e à baixa suscetibilidade a interferências. Superando-se as limitações financeiras e técnicas, as topologias com fibras óticas tornam-se cada vez mais comuns, sendo muito usadas como backbone em redes locais. Além disso, a existência de uma rede de fibra ótica viabiliza a comunicação multimídia, permitindo a transmissão de voz, imagens e dados simultaneamente. Como exemplo tem-se a FDDI, discutida na seção 2.4.2.

As sub-redes de comunicação que tradicionalmente usam cabo coaxial, como a Ethernet, têm procurado atualizar seus padrões visando incorporar o uso de fibras óticas. A grande vantagem nestes casos não é a velocidade, mas sim a grande confiabilidade adicionada pela alta imunidade a ruídos aliado ao fato do sinal ótico poder se propagar a distâncias maiores sem o uso de repetidores.

\section{Satélites de Comunicacão}

Pode-se imaginar um satélite como um repetidor de microondas no céu, sendo capaz de "escutar" uma porção do espectro, amplificar o sinal recebido e retransmití-lo em outra freqüência, para evitar interferência do sinal recebido. Apresenta uma capacidade de 
transmissão razoável quando comparado aos demais meios de transmissão. É usado nas redes a longa distância.

\subsubsection{Arquitetura de Rede}

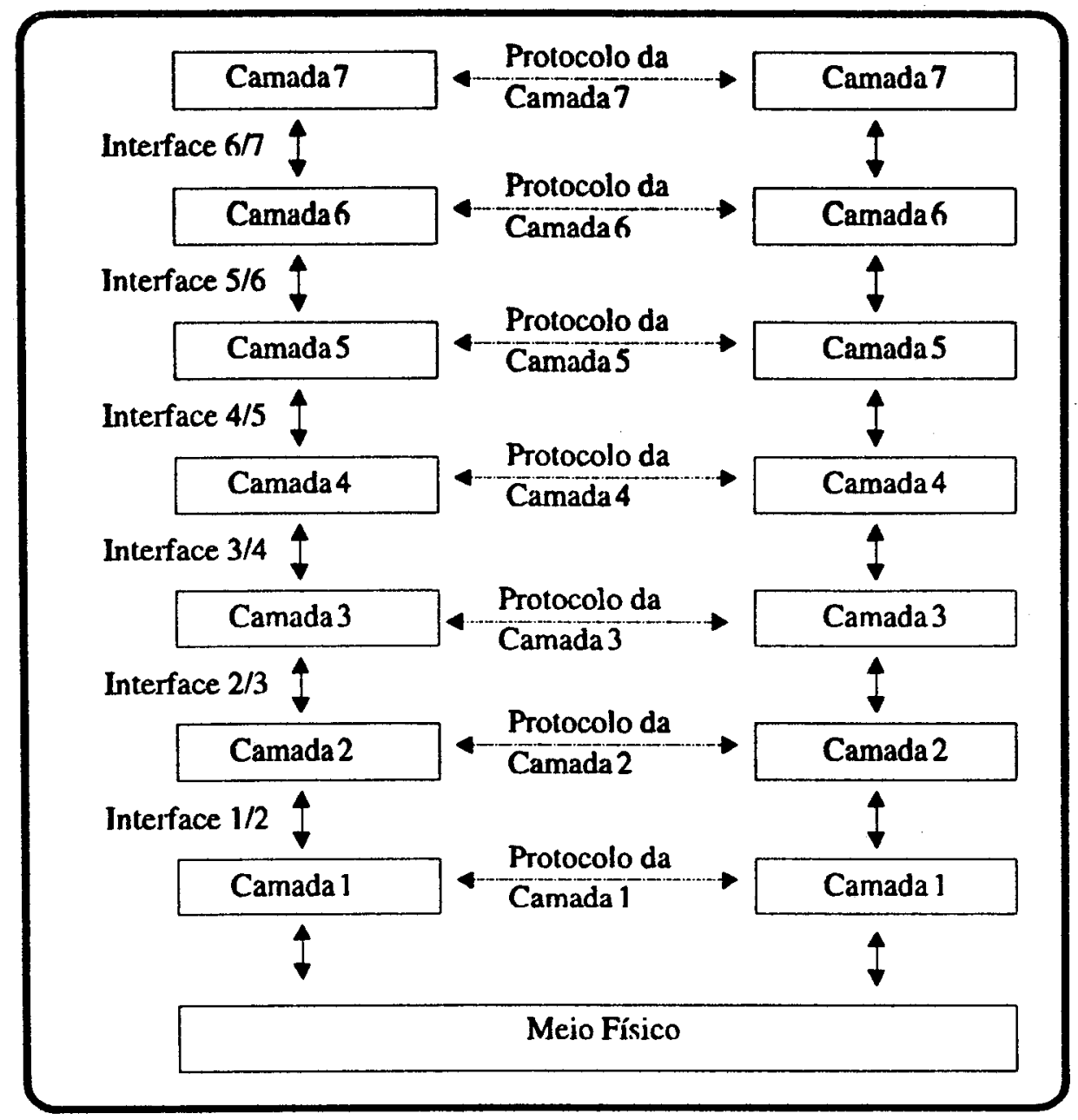

Figura 2.3 : Uma Arquitetura de Rede

As redes atuais são estruturadas em camadas sobrepostas, como ilustrado na figura 2.3, de modo que uma determinada camada oferece um conjunto de serviços à camada superior. Assim, cada camada fica responsável por "esconder" da camada superior os detalhes das camadas inferiores [TA89].

A camada $\mathbf{N}$ de uma máquina comunica-se com a camada $\mathbf{N}$ da outra máquina seguindo um conjunto de regras denominado protocolo da camada $N$ [TA89]. Esta comunicação é virtual, poịs na realidade, os dados são transferidos para as camadas inferiores juntamente com informações de controle até atingir o meio fisico, através do qual a comunicação é estabelecida. Analogamente, estes dados e informações de controle são transferidos para as camadas superiores da máquina destino, até atingir a camada correspondente. 
Entre cada par de camadas adjacentes tem-se uma interface, responsável por definir os serviços e primitivas que serão fornecidos à camada superior [TA89]. Um dos principais objetivos de um projetista de redes é definir uma interface clara entre as camadas, fazendo com que cada uma execute um conjunto de funções bem definidas. $\mathbf{O}$ número de camadas, 0 nome e as funções desempenhadas por cada uma delas varia de acordo com a rede.

Ao conjunto de camadas e protocolos denomina-se arquitetura da rede [TA89]. A especificação da arquitetura de uma rede deve conter informações que permitam construir software e hardware para cada camada seguindo o protocolo apropriado.

\subsubsection{Redes Locais e Redes a Longa Distância}

Uma rede de computadores a longa distância, WAN ( Wide Area Network ou ainda Long Haul Network), interconecta recursos computacionais numa área geográfica extensa. Uma WAN consiste na interconexão de IMPs. As WANs são, predominantemente, redes store-and-forward e não oferecem altas taxas de transmissão [TA89].

Uma rede local de computadores, LAN (Local Area Network), interconecta computadores e recursos computacionais numa área geográfica limitada. Nas LANs o IMP, geralmente, é incorporado à placa de interface da rede. Além disso, as LANs são predominantemente redes broadcast, oferecem altas taxas de transmissão e pequena taxa de erros [TA89,ST84a].

\subsection{O Modelo de Referência ISO/OSI}

\subsubsection{Descrição das Camadas}

A partir de meados da década de 70, a demanda e a complexidade dos sistemas de comunicação aumentavam visivelmente, não havendo uma metodologia ou algo equivalente capaz de orientar o desenvolvimento de padrões para protocolos de comunicação e muito menos de classificar os já existentes [KN88]. Nesse contexto, da mesma forma que princípios de programação estruturada eram essenciais no desenvolvimento de softwares complexos, alguma metodologia análoga deveria auxiliar o desenvolvimento de sistemas de comunicação. Surge assim, uma estrutura de sete camadas constituindo uma abstração do sistema real. A especificação destas sete camadas permite implementações diversas, mas define rigidamente o comportamento do sistema resultante, o que certamente é a chave para a interconexão de sistemas. Trata-se do Modelo de Referência para Interconexão de Sistemas Abertos (OSI, Open Systems Interconnection Reference Model) proposto pela ISO (International Standard Organization). 0 conceito de sistemas abertos está relacionado ao objetivo principal do OSI, ou seja, definir padrões que viabilizem a comunicação entre computadores de diferentes fabricantes [KN88].

O modelo OSI não deve ser visto como uma arquitetura de rede, pois preocupa-se apenas com as funções que cada camada deve desempenhar, não especificando os 
protocolos e serviços usados por cada uma delas. A ISO entretanto, tem produzido padrões para todas as camadas, embora não façam parte do modelo em si [TA89].

A figura 2.4 mostra as sete camadas do modelo OSI, descritas a seguir [TA89].

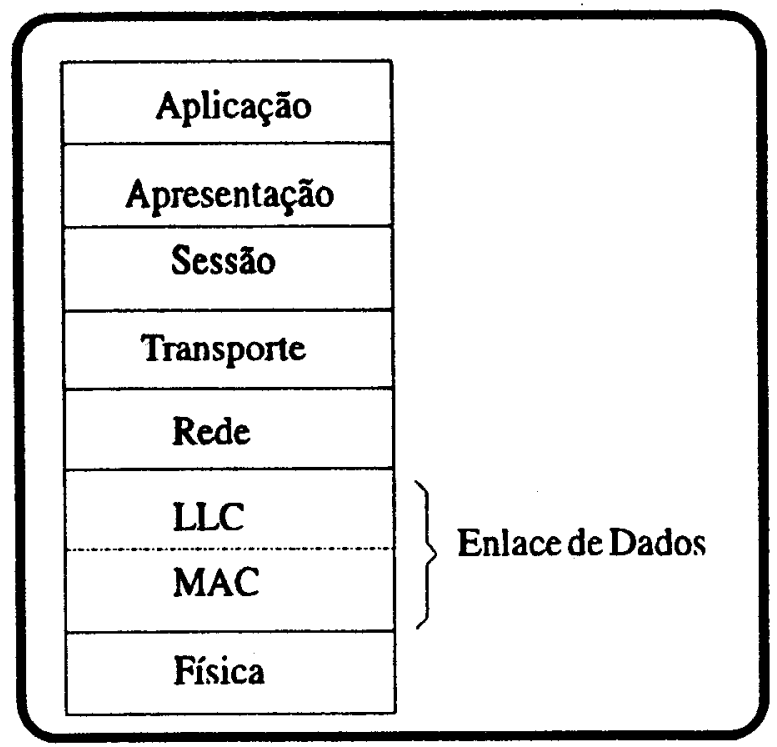

Figura 2.4: O Modelo de Referência ISO/OSI

\section{Camada Física}

É responsável pela transmissão dos bits através de um canal de comunicação. Nesta camada, as decisões de projeto estão relacionadas com as interfaces elétricas e mecânicas e com o meio físico de transmissão que está abaixo da camada física.

\section{Camada de Enlace de Dados (Data Link)}

Tem por finalidade facilitar a transmissão, além de gerar um conjunto de dados sem erros de transmissão para a camada superior: a camada de rede. Para realizar sua tarefa, trabalha na máquina fonte organizando os dados em frames que são transmitidos seqüencialmente. É responsável também por processar os frames de avisos de recebimento enviados pela máquina destino.

São tarefas da camada de enlace de dados:

- criar e reconhecer as fronteiras dos frames ;

- resolver problemas causados por frames danificados, perdidos ou duplicados durante a transmissão;

- sincronizar as velocidades de transmissão e recepção, de modo que o buffer do receptor tenha espaço suficiente para armazenar os dados que estão sendo transmitidos no momento;

- resolver problemas gerados quando a linha é usada para transmissão em ambas as direções.

A camada de enlace de dados constitui-se por duas subcamadas: a subcamada de Controle de Acesso ao Meio, MAC (Medium Access Control) e a subcamada de Controle 
de Enlace Lógico, LLC (Logical Link Contro). A primeira define o método de acesso ao meio, comunicando-se com as camadas superiores através da subcamada LLC, a qual executa as funções de enlace de dados independentes do meio e do controle de acesso ao meio (MAC) [SC88].

\section{Camada de Rede} deve:

É responsável por gerenciar a operação da sub-rede de comunicação; para tanto

- cuidar do roteamento dos pacotes;

- controlar congestionamentos;

- gerenciar os problemas resultantes da interconexão de redes heterogêneas.

\section{Camada de Transporte}

Possui como função principal receber dados da camada de sessão, particioná-los em unidades menores se necessário, transferi-los para a camada de rede e assegurar que todas partes da mensagem chegarão corretamente no destinatário. Portanto, é responsabilidade sua o estabelecimento de conexões.

Trata-se da primeira camada end-to-end, ou seja, ao contrário das camadas inferiores onde os protocolos eram entre a máquina fonte e seus vizinhos imediatos, agora os protocolos são entre a máquina fonte e a destino.

\section{Camada de Sessão}

Permite que os usuários em máquinas diferentes estabeleçam sessões entre elas. Alguns serviços da camada de sessão são:

- gerenciar o tráfego, ou seja, o acesso ao canal de comunicação;

- fazer o gerenciamento de token, uma forma de evitar que dois usuários executem uma operação crítica ao mesmo tempo, sendo que somente o usuário de posse do token tem permissão para executar a operação;

- eliminar problemas na transferência de arquivos extensos, introduzindo pontos de verificação nos dados; assim, se houver algum problema na rede durante a transferência, somente os dados transmitidos após o último ponto de verificação deverão ser transmitidos novamente. Trata-se do serviço conhecido como sincronização.

\section{Camada de Apresentação}

Fornece certas funções necessárias para a solução de problemas tão freqüentes que não compensaria deixá-las a cargo do usuário. Preocupa-se também com a sintaxe e a semântica da informação transmitida e com aspectos relevantes para a representação da informação, como por exemplo, conversões da representação específica do computador para a representação padrão usada na rede. 


\section{Camada de Aplicação}

Apresenta um conjunto de protocolos adicionais que são, geralmente, necessários. $\mathrm{Na}$ maioria das vezes, é responsável por solucionar problemas como por exemplo incompatibilidade entre equipamentos na rede.

\subsubsection{Serviços}

Denomina-se entidades os elementos ativos de cada camada e entidades pares as entidades da mesma camada, porém em máquinas diferentes. As entidades da camada $\mathrm{N}$ implementam os serviços usados pela camada $\mathrm{N}+1$, usando os serviços da $\mathrm{N}-1$. Os serviços ficam disponiveis em SAPs (Service/Access/Points), ou seja, a camada $\mathrm{N}+1$ acessa os serviços oferecidos pela camada N nos SAPs da camada N [TA89].

A comunicação entre duas camadas é ditada por um conjunto de regras que define a interface entre as mesmas. Numa interface típica, a entidade da camada $\mathrm{N}+1$ passa um IDU (Interface Data Unit) para a entidade da camada N através do SAP, mostrado na figura 2.5 . O IDU é formado pelo SDU (Service Data Unit), que é a informação passada para a entidade par, e alguma informação de controle, responsável por facilitar o trabalho da camada inferior. Na transmissao, a entidade da camada $\mathrm{N}$ particiona o SDU e cada uma de suas partes recebe um cabeçalho, sendo transmitida como um PDU (Protocol Data Unit). 0 cabeçalho do PDU é usado pelas entidades pares para, de fato, implementar seu protocolo. Assim, as entidades da camada $\mathrm{N}$ comunicam-se através dos $\mathrm{N}$-PDUs, segundo o protocolo da camada $\mathrm{N}$ [TA89].

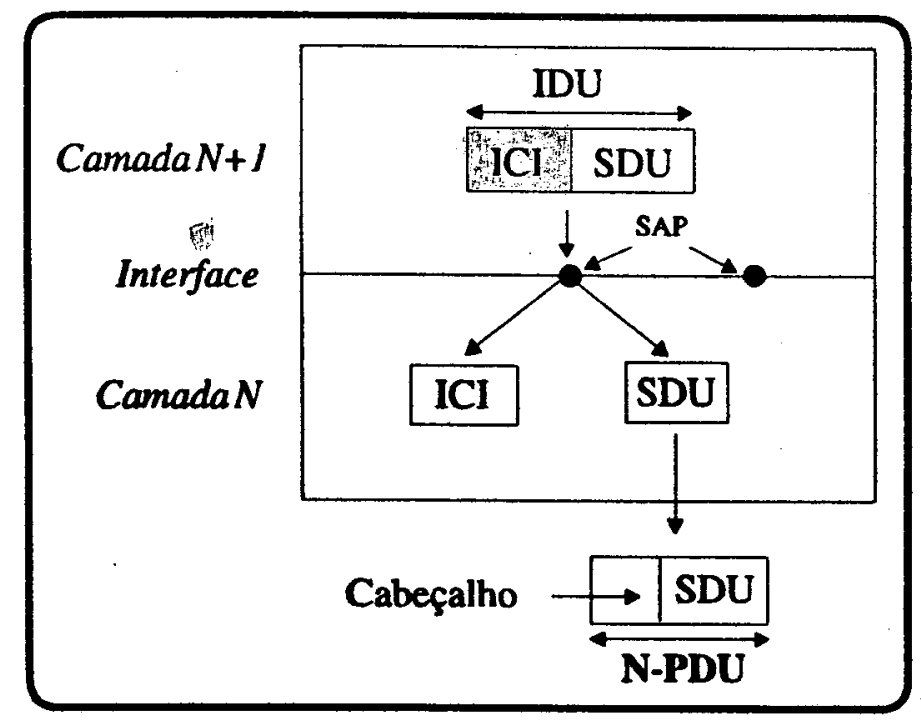

Figura 2.5: Interface entre as Camadas.

Existem dois tipos de serviços: orientados a conexão e sem conexão. Num serviço orientado à conexão o usuário do serviço deve estabelecer uma conexão, usá-la, ou seja, transmitir os dados e em seguida encerrá-la. Um exemplo típico deste tipo de serviço é o 
sistema telefônico. Por outro lado, num serviço sem conexão os pacotes de dados são tratados independentemente, significando que uma determinada seqüência de pacotes enviada de uma máquina para outra pode percorrer caminhos diferentes, perdendo inclusive alguns pacotes [CO91a]. Um exemplo típico é o sistema postal .

Os serviços podem também ser classificados quanto a qualidade em: confiáveis e não confiáveis. Os serviços confiáveis são implementados, geralmente, através de avisos de recebimento (acknowledgements), onde o receptor da mensagem é responsável por enviar uma "resposta" a quem enviou, confirmando o recebimento da mensagem.

Exemplificando, transferências de arquivos usam geralmente um serviço orientado à conexão e confiável; enquanto que a transmissão de voz usa, quase sempre, um serviço orientado à conexão e não confiável, pois os avisos de recebimento podem introduzir um atraso na transmissão inaceitável nesse tipo de aplicação.

\subsection{O Conjunto de Protocolos Internet : TCP/IP}

Uma internet significa a interconexão de duas ou mais sub-redes. $\mathrm{O}$ fenômeno internetworking tem ganho destaque na medida em que as redes de computadores tornam-se mais populares. A maior vantagem de uma internet é permitir a interconexão de redes de grupos específicos com hardware qualquer, ou seja, a independência da tecnologia de rede utilizada. A rede mais conhecida que satisfaz os requisitos acima é a Internet, também conhecida como DARPA Internet ou TCP/IP Internet [CO91a]. A Internet foi desenvolvida pela DARPA (Defense Aduanced Research Projects Agency) do Departamento de Defesa dos Estados Unidos e serve como base para a conexão da maioria das instituições de pesquisa incluindo universidades e laboratórios governamentais nos Estados Unidos e no resto do mundo.

A tecnologia Internet inclui um conjunto de padrões responsáveis por especificar a comunicação entre os computadores e também um conjunto de convenções para interconexão de redes e roteamento. Tal tecnologia é frequentemente referenciada como TCP/IP, os dois protocolos mais conhecidos dentro do conjunto de protocolos desenvolvido pela DARPA para constituir a base da Internet [CO91a, S091].

O TCP/IP tem sido muito utilizado nas redes modernas, sendo a Internet um exemplo característico da sua adequação sobre uma grande variedade de tecnologias de subrede de comunicação. 


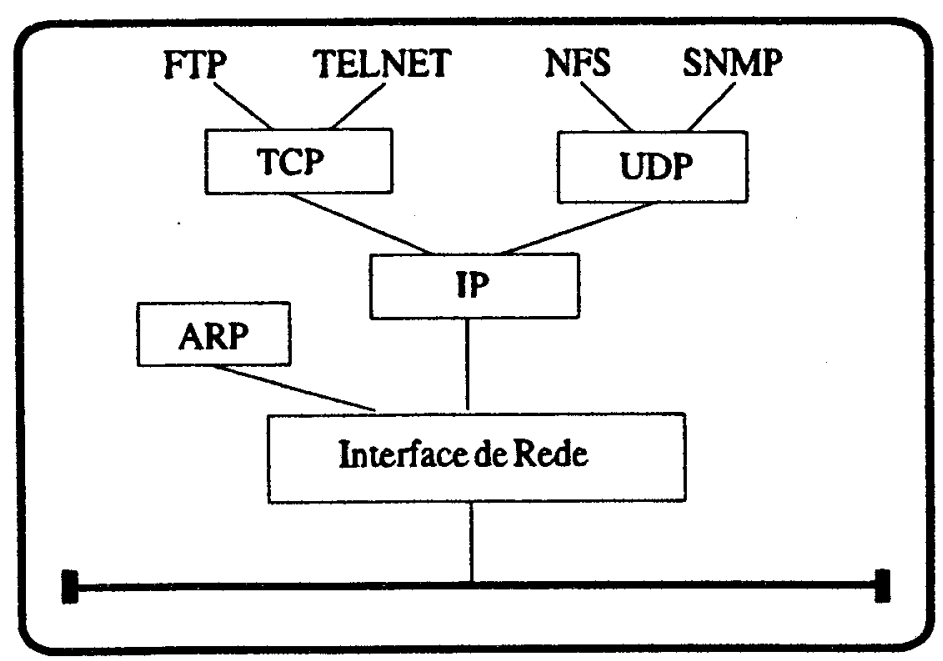

Figura 2.6: O Conjunto de Protocolos Internet

A figura 2.6 ilustra o conjunto de protocolos Internet. A tarefa da camada de interface de rede é a transmissão dos dados na rede fisica, correspondendo às duas camadas inferiores do modelo OSI: a camada fisica e a de enlace de dados [R091].

O protocolo IP (Internet Protocol) define a unidade básica de transferência e 0 formato exato para a transmissão de dados na Internet, além de estabelecer um conjunto de regras que especificam o processamento dos pacotes e a maninulação de erros. No entanto, a essência do IP é o roteamento de pacotes, justificando sua função básica: a interconexão de redes. Constitui um mecanismo não confiável e sem conexão para a transmissão de dados [C091a, SO91].

Outro protocolo importante é o ARP. A tarefa do ARP (Address Resolution Protocol) é a tradução de endereços IP em endereços físicos. A tradução é feita na transmissão de pacotes IP, pois neste momento tem-se o endereço destino IP mas não o correspondente endereço fisico, imprescindivel para montar o cabeçalho a nivel de MAC [SO91,PL82]. O mapeamento de endereços constitui a fronteira entre o protocolo das camadas superiores, que manipulam apenas endereços IP, e as camadas inferiores onde se encontra o driver, que manipula somente endereços fisicos [CO91b].

O protocolo TCP (Transmission Control Protocol) fornece um serviço de transporte confiável e orientado à conexão, do qual dependem muitas aplicações que exigem garantia de transmissão e não podem preocupar-se com time-outs e retransmissões [SO91]. Alguns exemplos são o FTP (File Transfer Protocol) e o TELNET, descritos abaixo. Por outro lado, a confiabilidade garantida pelo TCP tem um preço: faz com que este seja mais complexo internamente e requisite mais CPU e rede que o UDP.

O UDP (User Datagram Protocol) é um protocolo de transporte alternativo, diferente do TCP pois fornece um serviço não confiável e sem conexão, não assegurando a transmissão dos dados [SO91, CO91a]. Por outro lado, implementa um serviço de comunicação ágil e rápido.Como exemplo de aplicações que usam o UDP têm-se o NFS (Network File System) e o SNMP (Simple Network Management Protocol). Tanto o TCP quanto o UDP usam o IP para transmitir as mensagens na Internet e oferecem serviços às aplicações do usuário.

Descreve-se a seguir algumas aplicações mais comuns [SO91]: 


\section{TELNET}

Permite o login remoto através do TCP, sendo uma aplicação antiga e muito usada. Suas implementaçðes trabalham, geralmente, entre sistemas operacionais diferentes.

\section{$\underline{\text { FTP }}$}

Os comandos definidos no FTP permitem copiar arquivos de uma máquina para outra. É uma aplicação tão usada e antiga quanto o TELNET e também usa o TCP.

\section{NFS}

Desenvolvido primeiramente pela SUN Microsystems, usa o UDP e permite montar os sistemas de arquivos UNIX em vários computadores; dessa forma, uma estação de trabalho sem disco pode acessar o disco do servidor como se fosse um disco local.

\section{$\underline{\text { SNMP }}$}

Implementado sobre o UDP, é usado pelas estações responsáveis pelas tarefas de gerenciamento da rede. Este protocolo será detalhado na seção 3.3.5.

\subsection{Algumas Tecnologias de Sub-redes de Comunicação}

\subsubsection{O Padrão IEEE 802.x}

O IEEE (Instituto dos Engenheiros Elétricos e Eletrônicos dos Estados Unidos) desenvolveu um conjunto de padrões para redes locais denominados coletivamente IEEE 802. Os padrões são divididos em partes publicadas em livros separados. O IEEE 802.1 contém a introdução ao conjunto de padrões e define as primitivas de interface. $\mathrm{O}$ IEEE 802.2 descreve o protocolo da subcamada superior da camada de enlace de dados: a LLC (Logical Link Control), a qual usa os serviços da subcamada MAC (Medium Access Control) para fornecer serviços às camadas superiores. Os padrões IEEE 802.3, $802.4 \mathrm{e}$ 802.5 definem três métodos de acesso ao meio para redes locais: o CSMA/CD (Carrier Sense Multiple Access/Collision Detection ), o token bus e o token ring, respectivamente [TA89]. Estes padrões incluem a camada fisica e o protocolo de MAC, sendo compativeis a nivel de LLC, como ilustrado na figura 2.7 [SC88]. 


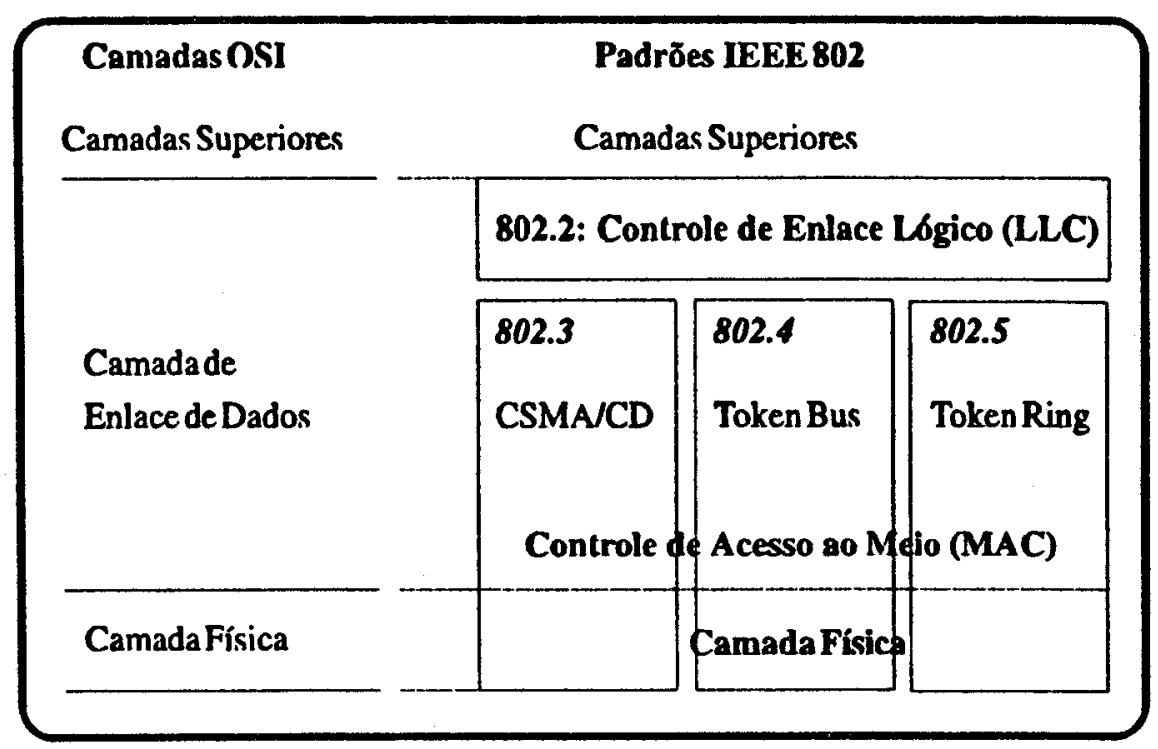

Figura 2.7: Os Padrões IEEE 802.x

\section{O Padrão IEEE 802.3 e a Ethernet}

O padrão IEEE 802.3 permite suportar o método de controle de acesso ao meio CSMA/CD numa sub-rede de comunicação em barramento, descrevendo uma familia de sistemas CSMA/CD 1-persistente rodando tipicamente a $10 \mathrm{Mbps}$ em diversos meios de transmissão [TA89].

Quando se descreve o padrão IEEE 802.3, um fato importante deve ser considerado: antes do 802.3, a XEROX construiu um sistema CSMA/CD 2.94 Mbps para conectar 100 estações de trabalho num cabo de $1 \mathrm{~km}$, o qual foi denominado Ethernet. Devido ao sucesso do projeto, a XEROX, a DEC e a INTEL desenvolveram o padrão Ethernet $10 \mathrm{Mbps}$, o qual foi a base para o 802.3. Logo, a Ethernet é a implementação mais comum do padrão IEEE 802.3 [TA89].

A figura 2.8 mostra a configuração usual da Ethernet [ME76]. O transceiver fica preso ao cabo, sendo responsável pela deteç̧ão da portadora e de colisões. $O$ cabo de interface conecta o transceiver à placa de interface do computador, podendo ter um comprimento de até $50 \mathrm{~m}$. A placa de interface por sua vez, deve gerenciar a transmissão e recepção de pacotes para e do transceiver, agrupar os dados no formato do pacote apropriado; computar o checksum dos pacotes transmitidos, e verificar os checksums dos pacotes recebidos. O ether é, geralmente, um cabo coaxial com o comprimento máximo de $500 \mathrm{~m}$; no entanto, os repetidores permitem que a rede estenda-se fisicamente a distâncias maiores sendo capaz de receber, amplificar e retransmitir sinais em ambas as direções. Um sistema pode conter múltiplos segmentos de cabo e múltiplos repetidores, mas dois transceivers não podem estar mais que $2.5 \mathrm{~km}$ separados e nenhum caminho entre dois transceivers pode atravessar mais que quatro repetidores. 


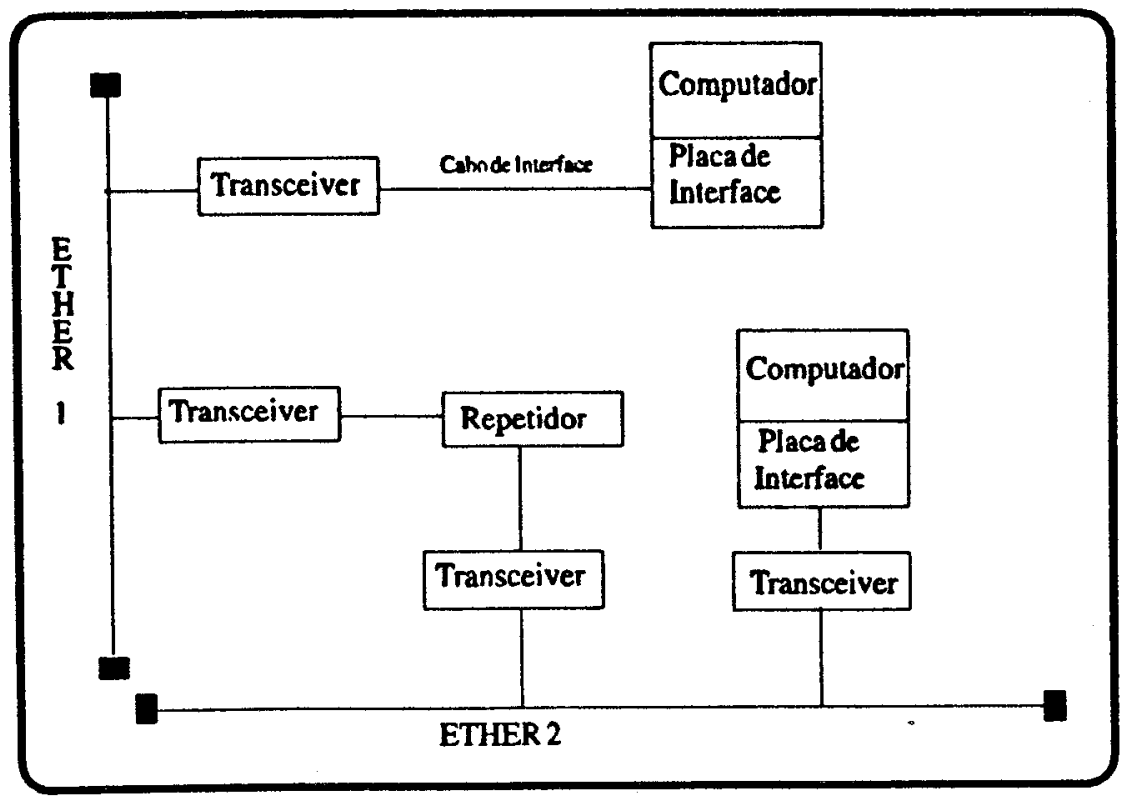

Figura 2.8: Configuração usual da Ethernet.

O método de acesso ao meio usado é o CSMA/CD (Carrier Sense Multiple Access/Collision Detection) 1-persistente. Nesse tipo de sistema quando uma estação deseja transmitir dados, esta deve primeiro verificar se o meio está ocupado; se estiver, a estação espera até que fique livre, caso contrário transmite 0 pacote. $O$ método é dito ser 1-persistente porque a estação transmite com probabilidade 1 sempre que encontra 0 canal livre [TA89].

Uma colisão, sobreposição de sinais, ocorre quando dois ou mais transceivers detectam o canal livre e iniciam a transmissão simultaneamente. A fim de garantir a integridade dos dados na transmissão, o transceiver verifica sua porta de entrada enquanto transmite pela porta de saída: se os sinais forem diferentes, houve colisão. Nesse caso, a transmissão do pacote é automaticamente cancelada e um breve sinal é transmitido para notificar a ocorrência de colisão às outras estações. Depois de transmitido o sinal, a estação espera um tempo aleatório e tenta novamente.

\section{O Padrão IEEE 802.4: Token Bus}

No padrão IEEE 802.4, ilustrado na figura 2.9, as estações são conectadas logicamente em forma de anel, enquanto que fisicamente a topologia adotada é 0 barramento ou árvore [TA89]. Cada estação pode pertencer ou não ao anel lógico; em caso afirmativo, possui uma posição definida dentro da sequência, sendo o último membro seguido pelo primeiro. Cada estação conhece a identidade da estação sucessora e predecessora. Como meio físico, a Token Bus utiliza um cabo coaxial broadband de 75-ohms e pode ter velocidade de transmissão de 1, 5, e 10 Mbps [TA89]. 


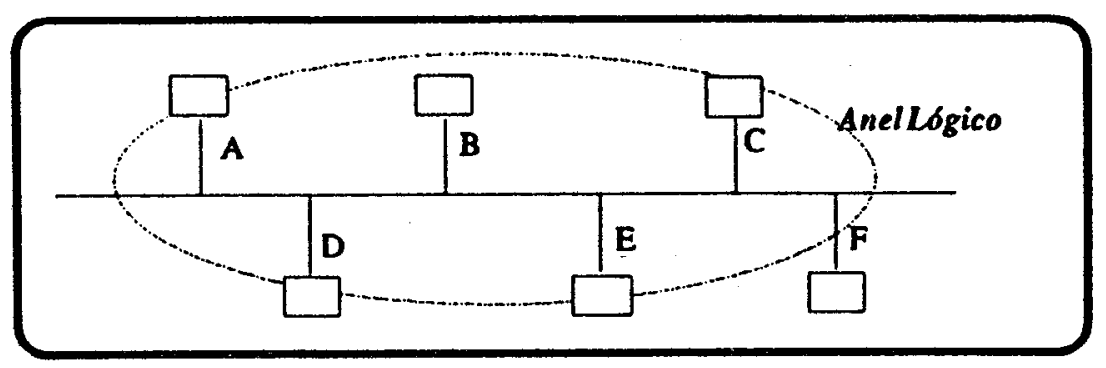

Figura 2.9: Token Bus

Quando o anel lógico é inicializado, a estação de posição mais alta pode enviar o primeiro pacote. Depois disso, a permissão para transmissão é passada ao sucessor desta estação, através de um pacote especial: o token. $\mathrm{O}$ token propaga-se no anel lógico de modo que uma estação pode transmitir somente se estiver de posse do mesmo; logo, como sempre uma única estação estará com o token, não haverá colisões. Quando o tempo designado a uma estação esgotar-se ou a transmissão for finalizada, o token é passado para a próxima estação de acordo com a sequência lógica [TA89]. Desde que o cabo é um meio inerentemente broadcast, cada estação recebe os pacotes, descartando os que não estiverem endereçados a ela.

Uma vantagem do Token Bus sobre a Ethernet é a sua capacidade de suportar prioridades. São definidas quatro classes de prioridades, $0,2,4$, e 6 , sendo 0 a prioridade mais baixa e 6 a mais alta.

O quadro descrito acima exige um conjunto mínimo de funções de manutenção, que devem ser realizadas por uma ou mais estações do barramento. Dentre estas funções pode-se citar: a adição e remoção de estações do anel; o gerenciamento de falhas e a inicialização do anel. $\mathbf{O}$ tratatamento de tais funções é descrito por Stallings em [ST84b] e por. Tanenbaum em [TA89].

\section{O Padrão IEEE 802.5: Token Ring}

A Token Ring é provavelmente a técnica mais antiga de controle de acesso ao meio em redes com topologia em anel. Proposta originalmente em 1969, tornou-se popular e transformou-se no padrão 802.5 pela IEEE [ST84b].

O anel, como mostrado na figura 2.10, é formado por uma coleção de interfaces conectadas por linhas ponto a ponto [TA89]. Cada bit que chega numa interface é copiado num buffer de 1 bit, e em seguida copiado novamente para o anel. Enquanto está no buffer, o bit pode ser inspecionado e possivelmente modificado, sendo que este período de cópia introduz um atraso de 1 bit em cada interface. 


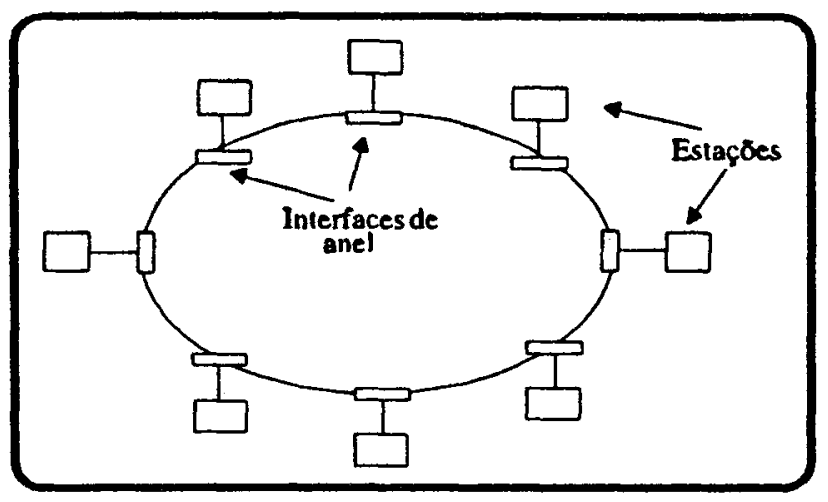

Figura 2.10: Token Ring

Como na Token Bus, a Token Ring tem a vantagem de possuir esquema de prioridades, o que garante sua adequação a aplicações em tempo real.

0 método de acesso ao meio da Token Ring baseia-se na utilização de um pequeno pacote, o token, que circula no anel quando todas as estações estão desocupadas. Quando uma estação precisa transmitir um pacote, ela espera pela passagem do token e retira-o do anel antes de iniciar a transmissão. As interfaces de anel possuem dois modos de operação: 0 modo de transmissão e de escuta. No modo de escuta os bits que chegam na interface são copiados com um atraso de 1 bit, como ilustrado na figura 2.11 (a) e descrito anteriormente. 0 modo de transmissão, mostrado na figura 2.11(b), é acionado depois da retirada do token do anel, sendo que neste caso a interface transmissora deve ser responsável por transmitir os bits e retirá-los do anel. Logo após a recepção do último bit do pacote a estação deve colocar o token no anel novamente e voltar ao modo de escuta [TA89].

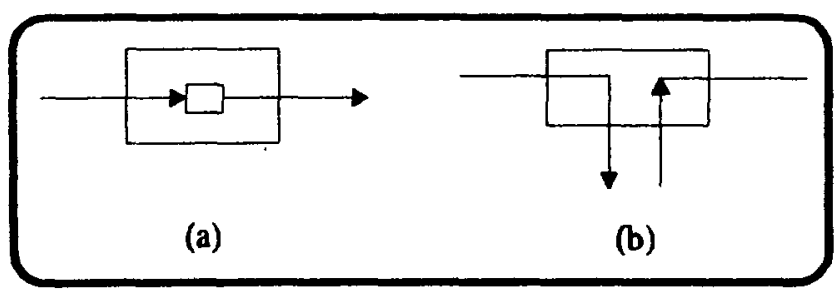

Figura 2.11: Interface de Anel Token Ring. (a) Modo de Escuta (b) Modo de Transmissão

Com a existência de apenas um token, somente uma única estação pode transmitir num dado instante, solucionando o problema do acesso ao meio, analogamente à Token Bus.

\subsubsection{FDDI}

A FDDI (Fiber Distributed Data Interface) é uma rede local de fibra ótica com alta performance, rodando a $100 \mathrm{Mbps}$ sobre distâncias de até $200 \mathrm{~km}$, com até 1000 estações conectadas [RO90b, TA89].

Embora possa ser utilizada da mesma forma que as LANs padrão 802, é na maioria das vezes adotada como backbone conectando várias LANs graças a sua alta capacidade de 
transmissão. Possui uma taxa de erros muito baixa, da ordem de um erro a cada $2.5 \times 10^{10}$ bits.

O meio fisico da FDDI consiste de dois anéis de fibra ótica, um transmitindo no sentido horário e o outro no sentido anti-horário, como mostrado na figura 2.12. Se um deles quebra, o outro pode ser usado. Se ambos quebram no mesmo ponto, os dois anéis podem ser agrupados num único anel com aproximadamente o dobro de comprimento. Cada estação contém chaves que podem ser usadas para agnupar os dois anéis ou isolar as estações com problemas.

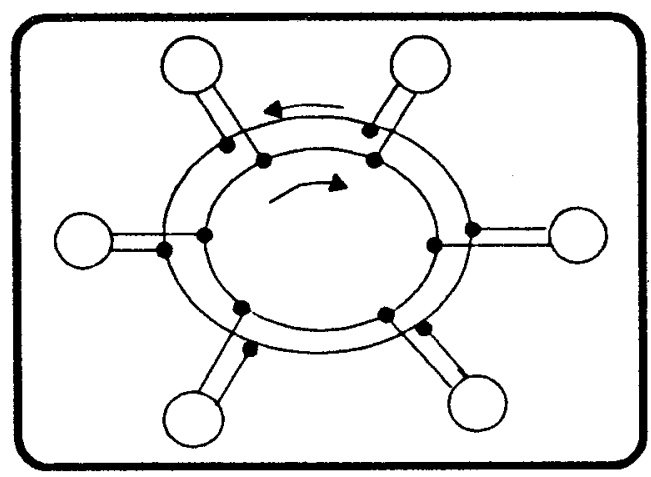

Figura 2.12: FDDI

$O$ método de acesso ao meio da FDDI baseia-se no padrão IEEE 802.5. Para transmitir, a estação deve capturar o token, transmitir o pacote e removê-lo quando este voltar do anel. Há uma diferença entre a FDDI e a token ring. Na token ring, a estação não pode gerar um novo token até que seu pacote tenha circulado por todo o anel e voltado. No entanto na FDDI, com potencialmente 1000 estações e $200 \mathrm{~km}$ de extensão, o tempo gasto na espera do pacote pode ser substancial. Logo, a estação coloca novamente o token no anel imediatamente após o término da transmissão dos dados; sendo que num anel grande, vários pacotes podem coexistir [TA89].

\subsubsection{B-ISDN e ATM}

Durante muito tempo a infraestrutura de comunicação a nivel mundial tem sido fundamentada, principalmente, no sistema telefônico, projetado para transmissão analógica de voz. Tal sistema tem se mostrado insuficiente e até mesmo obsoleto com a crescente demanda de novos serviços envolvendo som, dados e imagem.

Nesse contexto, surge a ISDN(Integrated Services Digital Network) definida pelo CCITT (International Telegraph and Telephone Consultative Committee) como uma rede que fornece conectividade end-to-end e suporta uma grande variedade de servicos, envolvendo ou não voz, a qual os usuários podem acessar através de um conjunto limitado de interfaces padrão usuário-rede [HA89, KE90].

As principais recomendaçбes ISDN foram aprovadas em 1984 pelo CCITT [TA89]. Nesse momento já havia um consenso de que a ISDN pela sua própria definição deveria evoluir com a finalidade de permitir a total integração dos chamados serviços broadband, 
tais como tele-conferência, vídeo-telefonia, telefax, transmissão digital de informações a altas velocidades, etc. Em 1985 foi criado o Task Group on Broadband Aspects of ISDN, com o objetivo de encontrar soluções flexíveis e eficientes para a transmissão das diversas mídias (som, imagem e dados). Define-se assim a B-ISDN (Broadband ISDN) que usa como estrutura de transporte o ATM (Asynchronous Transfer Mode), modo de transferência assincrona [HA89].

O ATM é uma técnica de multiplexação e chaveamento, sendo as conexões multiplexadas através de pequenos pacotes de tamanho fixo denominados células [BO92]. A figura 2.13 mostra a multiplexação segundo o ATM e a figura 2.14 a estrutura básica de uma célula ATM.

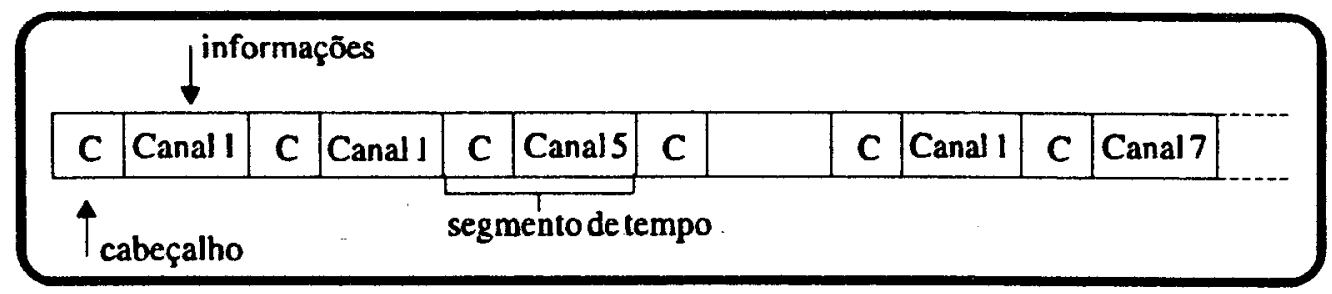

Figura 2.13: Multiplexação ATM

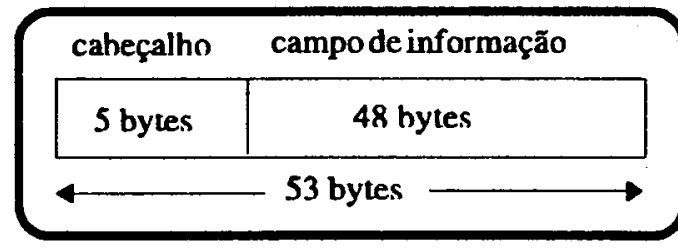

Figura 2.14: Célula ATM

A célula ATM constitui-se por 5 bytes de cabeçalho e 48 bytes de dados, totalizando 53 bytes. No cabeçalho encontra-se um rótulo responsável pela especificação das informações de roteamento [BO92]. A utilização do rótulo ao invés do endereço explícito deve-se ao tamanho reduzido e fixo da célula.

O ATM utiliza dois conceitos: canal virtual e caminho virtual. Um canal virtual estabelece uma conexão lógica entre dois usuários e o caminho virtual define uma rota fonte-destino através da rede, de modo que vários canais virtuais podem ser agrupados e podem utilizar o mesmo caminho virtual [BA93]. $O$ rótulo encontrado no cabeçalho da célula ATM, também chamado de campo de roteamento, é composto pela união de dois campos: o identificador de canal virtual (VCI, Virtual Channel Identifier) e o identificador de caminho virtual (VPI, Virtual Path Identifier). 


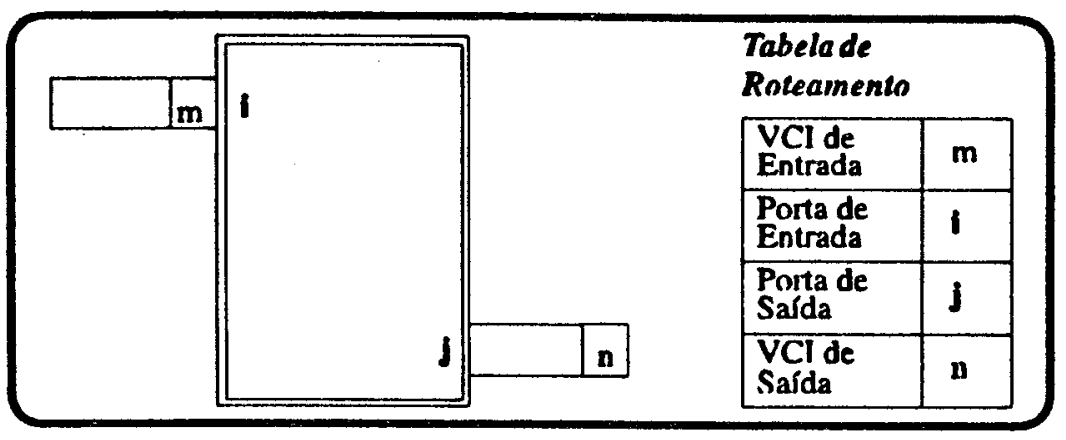

Figura 2.15: Chaveamento ATM

O processo de chaveamento dar-se-á como descrito a seguir e ilustrado na figura 2.15. Quando uma célula chega numa porta $i$ com um rótulo $m$, a unidade de chaveamento em questão consulta uma tabela de roteamento determinando a porta de saída $j$ e o novo rótulo $n$. A célula é então transmitida, sendo o novo rótulo usado pela próxima unidade de chaveamento encontrada por ela. As tabelas de roteamento devem ser inicializadas antes da transmissão, podendo ser pré-definidas ou alocadas dinamicamente. A transmissão das células exige sempre o estabelecimento de uma conexão [B092].

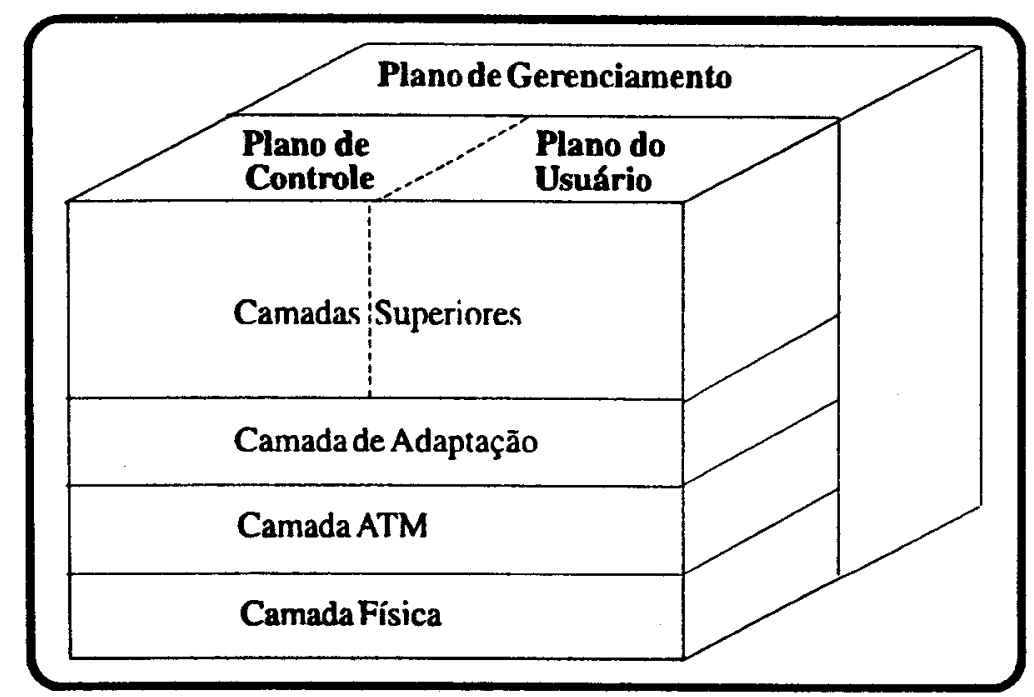

Figura 2.16: Modelo de Referência para B-ISDN

A figura acima apresenta o modelo de referência definido para a B-ISDN [BA93]. A camada ATM é independente dos serviços suportados pelas camadas superiores, sendo responsável pelo transporte de células através de um sistema de transmissão que constitui a camada fisica. A camada de adaptação é dependente do serviço e tem por finalidade mapear as informações das camadas superiores em células ATM, ou ainda coletar dados das células ATM e fornecê-los às camadas superiores.

O modelo de referência define também três planos: o plano do usuário, responsável pela transmissão das informações do usuário e correspondente controle; o plano de controle, responsável por exemplo pelo estabelecimento de conexões; e finalmente, o plano 
de gerência envolvendo o gerenciamento do sistema e a coordenação dos planos, assim como o gerenciamento das camadas incluindo os recursos e parâmetros de cada uma delas.

\subsubsection{DQDB}

A crescente demanda por redes de computadores com alta largura de banda, interconectando várias máquinas e atingindo grandes distâncias, originou as chamadas redes metropolitanas, MANs (Metropolitan Area Networks). Uma MAN interconecta LANs e outras máquinas abrangendo, tipicamente, uma área de $50 \mathrm{~km}$ de diâmetro [ZU90, YA93, KR93].

$O$ interesse nas MANs deve-se a três fatores [RO90c]:

- o mercado, devido à necessidade de redes de alta velocidade capazes de interconectar LANs de maneira eficaz;

- a disponibilidade de aplicações para computação distribuída e arquiteturas clienteservidor, justificando a utilização de redes de alta velocidade $e$

- os avanços tecnológicos, permitindo a redução de custos.

O protocolo DQDB (Distributed Queue Dual Bus) é o padrão IEEE 802.6 para MANs. Dentre as áreas de aplicação das redes DQDB destaca-se: a implementação de backbones para LANs com baixa velocidade; a utilização no contexto das redes B-ISDN; e a utilização como rede de mútiplos serviços capaz de dar suporte à aplicações multimídia distribuídas [YA93].

Existe uma forte relação entre os padrões IEEE 802.6 e B-ISDN. Esta relação é o resultado da interação entre os grupos de especificação de tais padrões, visando a integração das redes padrão IEEE 802.6 num ambiente B-ISDN. O exemplo mais expressivo desta interação é a modificação feita no padrão IEEE 802.6 para se adequar à estrutura da célula ATM, usado como mecanismo de transporte na B-ISDN. A integração entre MANs IEEE 802.6 e B-ISDN é abordada por Byrne em [BY91].

Uma rede DQDB constitui-se por dois barramentos unidirecionais de alta velocidade, com tráfego em direções opostas passando por cada estação. Para que a rede seja estável, os barramentos devem ter velocidades iguais. Os nós são conectados em ambos os barramentos existindo, no entanto, apenas um caminho de transmissão entre quaisquer dois nós, visto que os barramentos são unidirecionais [YA93].

Existem duas topologias para uma rede DQDB: a open dual bus, mostrada na figura 2.17 e a looped dual bus, mostrada na figura 2.18. As duas topologias permitem a reconfiguração na ocorrência de falhas em nós ou ligações.

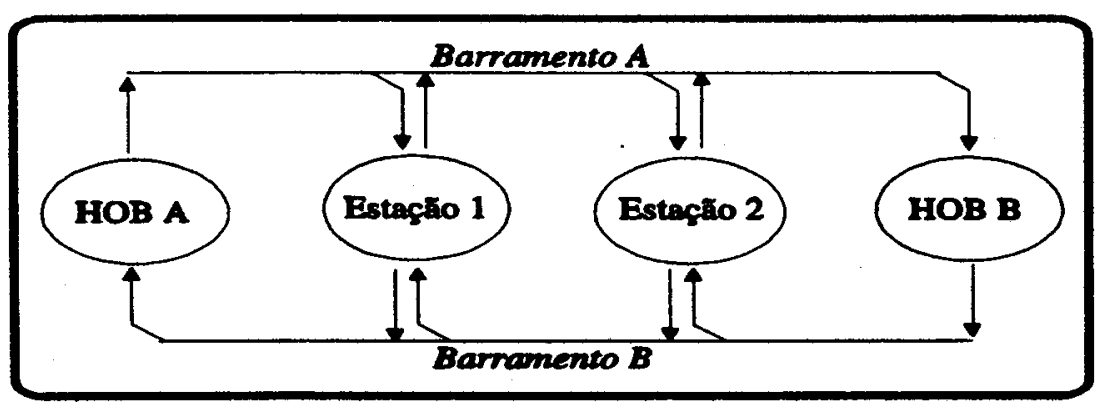

Figura 2.17: Topologia Open Dual Bus. 


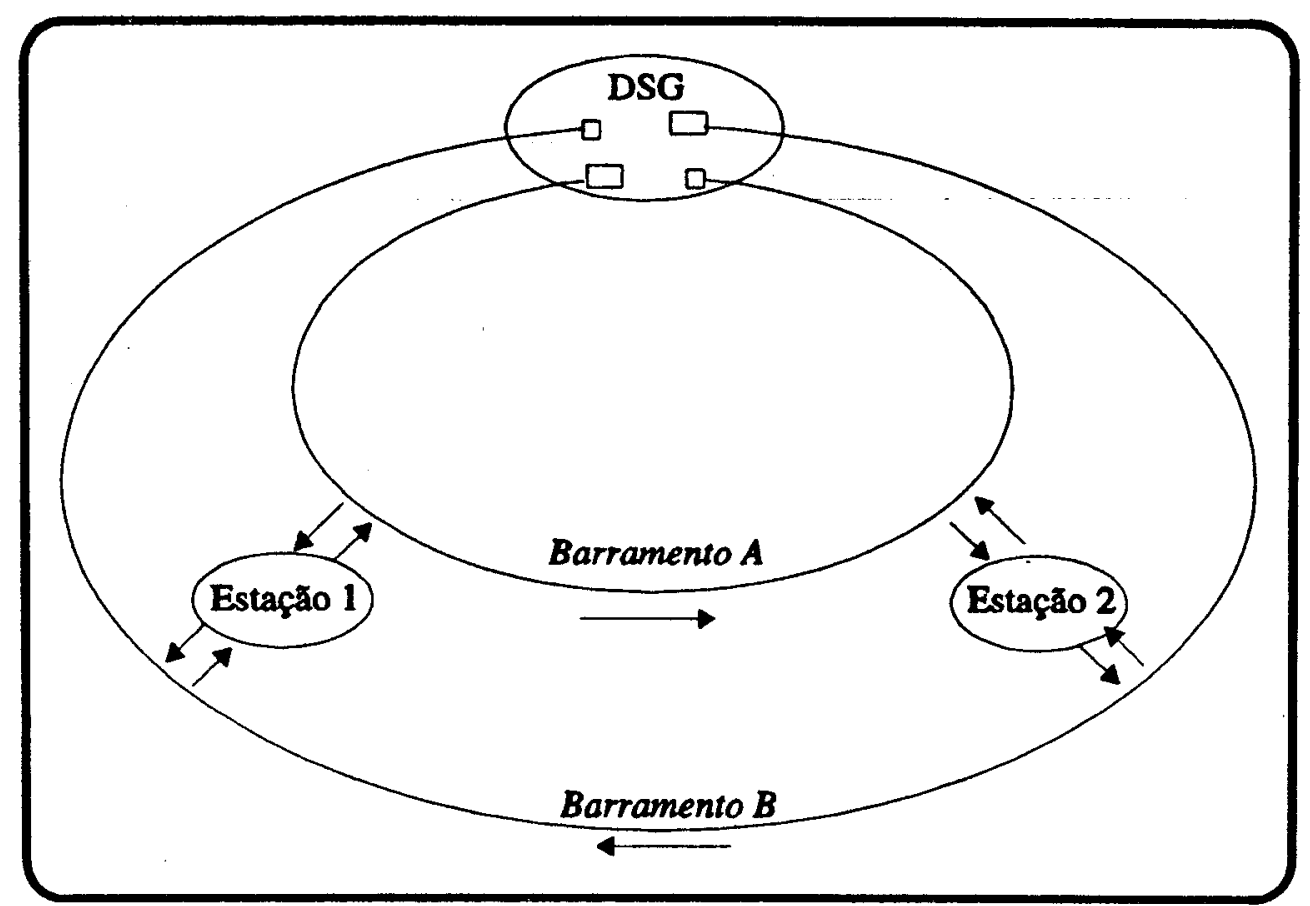

Figura 2.18: Topologia Looped Dual Bus.

A estrutura de transmissão usada por uma rede DQDB baseia-se em slots. Uma sequência de pequenos slots de tamanho fixo é gerada frequentemente pelo nó da extremidade do barramento, chamado de Head of Bus (HOB). Os slots DQDB propagam-se no sentido do barramento (dowstream) e são eventualmente descartados pelo nó situado no final deste. Na topologia looped dual bus a geração de slots para os dois barramentos é feita por um único nó, chamado Default Slot Generator (DSG) [YA93].

$\mathrm{O}$ acesso ao barramento é controlado por um algoritmo de filas distribuídas que ordena o acesso segundo a politica First Come First Served (FCFS). Tal esquema é descrito em [ZU90].

\subsection{Dispositivos de Interconexão de Redes}

Após a introdução dos conceitos de sub-redes de comunicação e de internetworking, deve-se considerar os dispositivos necessários para interconectar redes de características diferentes. Tais diferenças podem estar em vários níveis, resultando em quatro grupos de dispositivos de interconexão.

A nivel de camada fisica tem-se os repetidores, dispositivos de baixo nivel capazes de amplificar sinais elétricos; são usados, por exemplo, no padrão IEEE 802.3 para aumentar o comprimento do cabo [TA89]. 
As pontes (bridges) viabilizam a interconexão a nivel de enlace de dados. São dispositivos store-and-forward, sendo responsáveis por receber um frame, passá-lo para a camada de enlace de dados e enviá-lo numa sub-rede de comunicação diferente. Podem fazer pequenas alterações no frame, mas somente no que diz respeito até a camada de enlace de dados [TA89].

As pontes compatibilizam MACs diferentes e portanto são muito usadas na interconexão de LANs 802. Considere a figura 2.19. A máquina $\mathbf{A}$ transmite um pacote com cabeçalho LLC e o cabeçalho MAC, nesse caso o 802.3. Na rede, o pacote passa por uma ponte, cujo MAC 802.3 retira o cabeçalho e passa o pacote para a subcamada LLC. Neste exemplo, a outra rede conectada à ponte é uma 802.4, logo o pacote é passado para o MAC 802.4, recebe o novo cabeçalho, sendo transmitido na nova rede. Uma ponte conectando $n$ LANs distintas terá $n$ MACs e $n$ camadas fisicas, uma para cada rede [TA89].

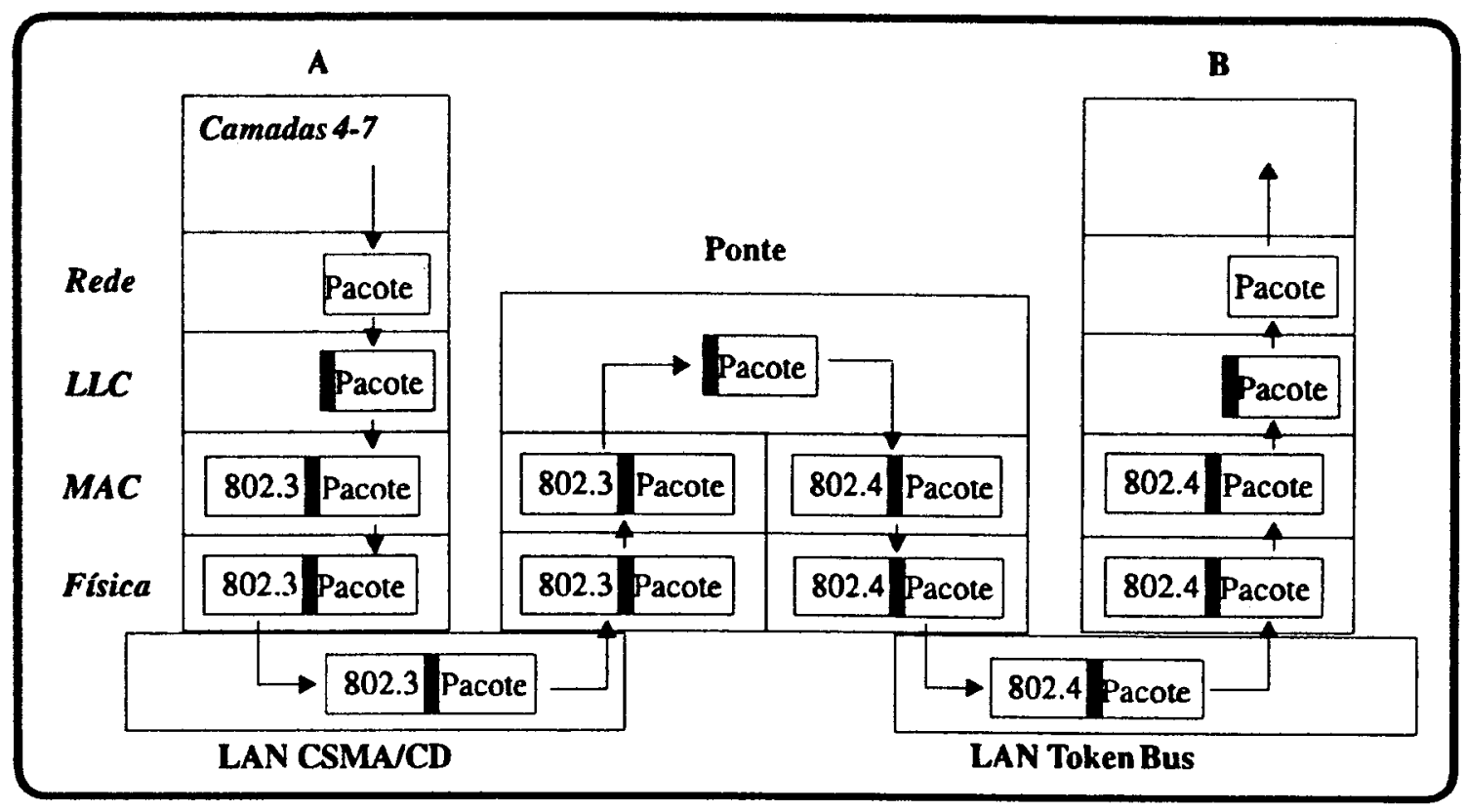

Figura 2.19: Exemplo de uma Ponte entre uma rede IEEE 802.3 e uma rede IEEE 802.4

Os roteadores, também chamados de gateways, são os dispositivos de interconexão no nível da camada de rede. Um roteador pode conectar redes com formatos de endereçamento incompativeis [TA89], ou ainda ser capaz de escolher um entre vários caminhos disponíveis para a transmissão do pacote, segundo uma política de roteamento pré-definida [SE88].

Os dispositivos encontrados acima da camada de transporte são chamados de conversores de protocolos, cuja finalidade é justamente fazer a conversão entre protocolos diferentes com o mínimo de perdas possivel. Muitas vezes encontra-se na literatura o termo gateway associado aos dispositivos de interconexão de modo geral [TA89]. 
No escopo do gerenciamento de redes, as pontes e os roteadores são dispositivos muito importantes. As pontes trabalham em modo promíscuo, o que lhes permite 0 acesso a todos os dados que trafegam na rede. Nesse sentido, podem armazenar informações sobre o estado global da rede ou ainda manter estatisticas tais como o tráfego num determinado ramo ou numa estação específica, erros, etc. Os roteadores por sua vez, podem manter estatísticas que permitam avaliar a qualidade do serviço de interconexão disponivel, ou ainda que auxiliem o gerente da rede na definição de rotas alternativas e na previsão de congestionamentos [BE88]. 


\section{Capítulo 3}

\section{Gerenciamento de Redes}

\subsection{Introdução}

É visivel a invasão das redes de computadores na sociedade facilitando a comunicação e o compartilhamento de recursos computacionais. Tais redes tendem a crescer atingindo grandes dimensões, constituindo-se de várias sub-redes que podem ser de tecnologias diferentes, usar protocolos distintos ou ainda equipamentos de diversos fabricantes. Surge assim o conceito de internet, associado à interconexão de redes de computadores [R091] e discutido no capitulo 2.

$O$ problema inicial consiste em viabilizar a troca de informações entre as diversas subredes possibilitando enxergá-las como uma única rede de comunicação. Esta é a tarefa associada aos protocolos de comunicação [KL88].

Tendo solucionado esse problema, surge outro não menos complexo, que consiste em como gerenciar essas redes. Para tanto, o usuário deve ser capaz de:

- monitorar a rede, obtendo dados em tempo real sobre a performance e o tráfego na rede;

- diagnosticar problemas de comunicação e

- reconfigurar a rede atendendo às mudanças nas necessidades do usuário ou no ambiente. 
O problema do gerenciamento atinge maiores dimensões quando se trata de redes extensas, heterogêneas e que, em decorrência disto, podem estar sobre administraçōes diferentes.

Nota-se que uma tecnologia de gerenciamento especifica a um determinado ambiente seja inútil em ambientes de caráter tão heterogêneo. Precisa-se então de um conjunto comum de ferramentas capaz de gerenciar os diversos recursos de comunicação dispersos. Assim, aparecem conjuntos de protocolos de gerenciamento, como o SNMP (Simple Network Management Protocol) associado à Internet, já em sua segunda versão; o CMIP (Common Management Information Protocol) desenvolvido pela ISO e o CMOT (CMIP over TCP/P), uma solução para 0 gerenciamento de redes TCP/IP baseada no CMIP. Neste capitulo pretende-se discutir tais conjuntos de protocolos, apresentando as características básicas e a filosofia de cada um, além de uma breve comparação entre eles.

\subsection{O Modelo de Gerenciamento OSI}

\subsubsection{Conceitos Básicos}

Considerando o problema de gerenciamento, a ISO (International Standards Organization) sentiu necessidade de viabilizar o gerenciamento de sistemas que usam os protocolos OSI (Open Systems Interconnection). As atividades da ISO englobam a inclusão de gerenciamento no Modelo de Referência e a especificação de protocolos de suporte à troca de informações de gerenciamento entre sistemas abertos, como é o caso do CMIP (Common Management Information Protocol) [KL88].

O gerenciamento proposto pela ISO visa fornecer meios para a monitoração e controle dos recursos da rede, representados como objetos gerenciados. Entende-se por objetos gerenciados os recursos do sistema ou da rede: um modem, uma tabela de roteamento IP ou uma conexão TCP, por exemplo [WA89].

A filosofia de gerenciamento OSI engloba o gerenciamento de recursos OSI (as camadas), do sistema em si e da rede de comunicação.

O gerenciamento de redes OSI é constituído de estações de gerenciamento e elementos a serem gerenciados na rede. Nas estações de gerenciamento encontra-se processos de aplicação denominados gerentes, enquanto que nos elementos da rede a serem gerenciados encontra-se processos de aplicação denominados agentes. Os termos gerente e agente são usados com certa frequência para designar sistemas gerenciadores e sistemas gerenciados, respectivamente. Assim, - gerenciamento da rede é feito através da cooperação entre gerente e agente, trocando informações de controle e monitoração da rede úteis ao gerenciamento da mesma e de seus componentes [WA89].

\subsubsection{O Ambiente de Gerenciamento}

O ambiente de gerenciamento OSI é constituido de ferramentas e serviços necessários para controlar e supervisionar as atividades de interconexão e os objetos gerenciados associados. 
Para retratá-lo, têm-se três modelos [KL88,WA89]:

- Modelo Organizacional, o qual descreve o gerenciamento OSI administrativamente,ou seja, através de dominios de gerenciamento e sistemas de gerenciamento dentro de um dominio. $\mathbf{O}$ conceito de domínio reforça a criação de sistemas de gerenciamento distribuídos, com alto nivel de cooperação e hierarquia bem definida;

- Modelo de Informação, o qual estabelece normas para a definição dos objetos gerenciados e seus respectivos inter-relacionamentos, classes, atributos, açōes e nomes. As informaçōes de gerenciamento são armazenadas numa base de informações de gerenciamento, chamada frequentemente apenas de MIB (Management Information Base). Para que tais informações sejam acessadas pelo protocolo de gerenciamento, são definidas convenções que permitem a descrição e identificação única das informações na MIB; estas convenções são chamadas de estrutura da informação de gerenciamento ou SMI (Structure of Management Information);

- e Modelo Funcional, o qual particiona o problema do gerenciamento em cinco áreas funcionais, ou subsistemas de gerenciamento, que podem interagir entre si. Define-se assim o:

- Gerenciamento de Falhas, responsável por detectar problemas na rede de comunicação e no ambiente OSI, incluindo mecanismos para detectar, isolar e corrigir falhas da rede;

- Gerenciamento de Nomes e Configuração, responsável por controlar a configuração da rede, como por exemplo os softwares instalados e os sistemas operacionais utilizados nas diversas máquinas da rede;

- Gerenciamento de Performance, responsável por dar suporte à monitoração e avaliação da performance da rede;

- Gerenciamento de Contabilidade, responsável por coletar e processar dados relacionados a utilização de recursos na rede;

- Gerenciamento de Segurança, responsável por administrar os serviços de controle de acesso aos recursos de comunicação.

\subsubsection{A Arquitetura de Gerenciamento OSI}

O modelo arquitetural de gerenciamento OSI é, ilustrado na figura 3.1 e discutido por Klerer em [KL 88]. O gerenciamento OSI é feito através de funções de gerenciamento de sistemas, de funções de gerenciamento da camada $\mathrm{N}$ e da operação do protocolo da camada $\mathrm{N}$. 


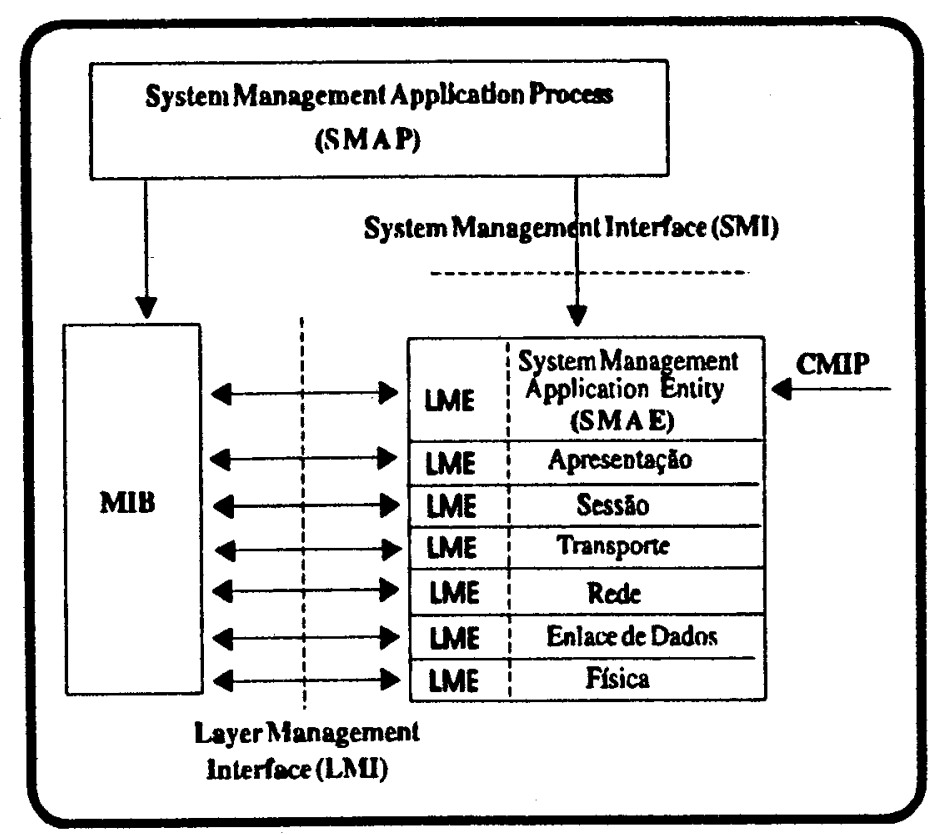

Figura 3.1: Modelo Arquitetural de Gerenciamento OSI

As funções de gerenciamento de sistemas garantem a operação continua do sistema como um todo, permitindo a adaptação às mudanças no ambiente ou nas necessidades do usuário. Estas funções são executadas pelo processo de aplicação responsável pelo gerenciamento do sistema, System Management Application Process (SMAP).

A entidade de aplicação do gerenciamento de sistemas, Systems Management Application Entity (SMAE), é responsável pela comunicação com outras entidades de gerenciamento a nível de aplicação. Logo, a troca de informações de gerenciamento, ou seja a comunicação, dá-se através de protocolos da camada de aplicação capazes de manipular informações referentes às camadas individuais ou ao sistema inteiro. $O$ protocolo de gerenciamento CMIP define as regras para a troca de informações de gerenciamento, sendo acessado pela SMAE na camada de aplicação.

As funções de gerenciamento da camada $\mathbf{N}$ devem assegurar a integridade dos protocolos da camada e permitir alterações nos parâmetros da mesma visando a adequação a mudanças do ambiente ou das necessidades do usuário. Essas funçð̃es afetam a camada como um todo e não somente uma única instância de comunicação; sendo executadas pelo processo de gerenciamento da camada $\mathrm{N}$, que pode ser um processo individual ou parte de um SMAP integrado. As entidades de gerenciamento da camada N, Layer Management Entity (LME), comunicam-se entre si através do protocolo de gerenciamento do sistema ou dos protocolos de gerenciamento da camada $\mathrm{N}$.

Finalmente, a operação do protocolo da camada $\mathbf{N}$ possui funções que permitem alterar um conjunto particular de parâmetros usados numa instância de comunicação ou no gerenciamento da mesma; portanto, as modificações efetuadas através do protocolo da camada $\mathbf{N}$ são restritas a uma determinada instância de comunicação, sendo que o sistema retorna ao estado anterior quando esta for encerrada. 


\subsubsection{O Protocolo de Gerenciamento CMIP}

Como visto anteriormente, a comunicação de informações de gerenciamento é feita através das entidades da camada de aplicação, as quais fornecem um determinado conjunto de serviços às aplicações superiores [WA89, TA89].

Neste contexto, o gerenciamento de redes proposto pela ISO baseia-se nos seguintes protocolos de aplicação: ACSE, ROSE e CMIS/CMIP, organizados como ilustrado na figura 3.2 e descritos sucintamente a seguir [WA89].

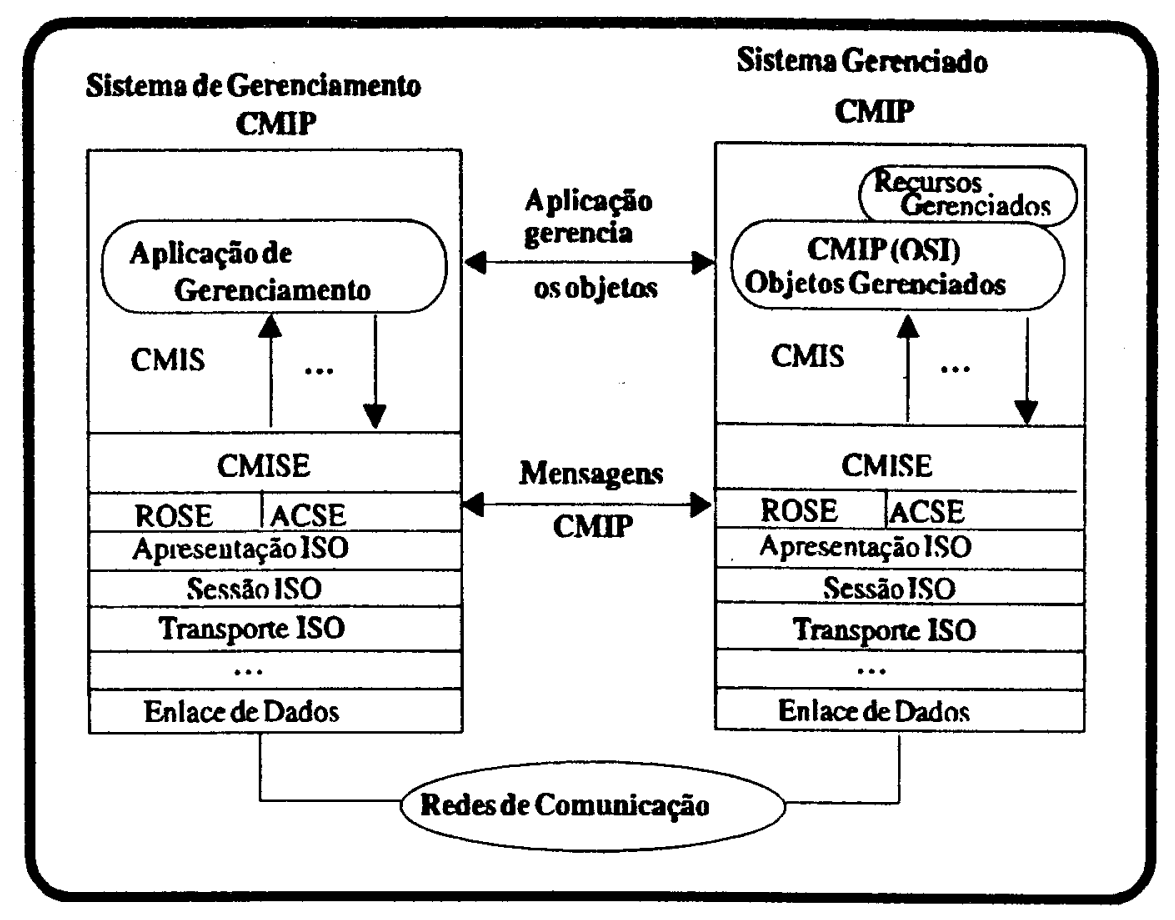

Figura 3.2: O Conjunto de Protocolos CMIP

\section{ACSE : Association Control Service Element}

Para que operações de gerenciamento sejam executadas usando o CMIP, uma associação deve ser estabelecida entre duas entidades de aplicação. Tais associações são estabelecidas e liberadas usando o protocolo ACSE.

\section{ROSE : Remote Operation Service Element}

O protocolo ROSE permite a execução de uma operação remotamente; sendo que o CMIP usa os serviços orientados a transação fornecidos por ele para fazer requisições e obter respostas (request-response), usando também o mecanismo de retorno de erros do mesmo.

\section{CMISE : Common Management Information Service Element}

O CMISE, também citado na literatura como CMIS/CMIP (Common Management Information Service / Common Management Information Protocol), contém os serviços de gerenciamento, sendo usuário do ROSE e do ACSE. Fornece serviços para notificação de eventos, obtenção e manipulação de dados de gerenciamento, os quais são relacionados a seguir, podendo ser com ou sem confirmação, como ilustrado na figura 3.3. 


\begin{tabular}{|l|l|}
\hline \multicolumn{1}{|c|}{ Serviço } & \multicolumn{1}{c|}{ Tipo } \\
\hline M-INITLLISE & confirmado \\
M-TERMINATE & confirmado \\
M-ABORT & não confirmado \\
M-EVENT-REPORT & confirmado/não confirmado \\
M-GET & confirmado \\
M-SET & confirmado/năo confirmado \\
M-ACTION & confirmado/não confirmado \\
M-CREATE & confirmado \\
M-DELETE & confirmado \\
\hline
\end{tabular}

Figura 3.3: Os Serviços CMISE

- M_INITIALIZE: estabelece uma associação com um usuário CMISE remoto, atendendo ao pedido de um usuário CMISE, para troca de informações de gerenciamento. Entende-se por usuário CMISE a parte do processo de aplicação que usa o CMISE.

- M_TERMINATE : libera uma associação.

- M_ABORT : aborta uma associação.

- M_EVENT_REPORT: notifica um evento ocorrido com um objeto gerenciado a um usuário CMISE remoto.

- M_GET: obtém informações de gerenciamento de um usuário CMISE remoto.

- M_SET: requisita a modificação de informações de gerenciamento pelo usuário CMISE remoto.

- M_ACTION: requisita a execução de uma ação a um usuário CMISE remoto.

- M_CREATE: requisita a criação de outra instância do objeto gerenciado a um usuário CMISE remoto.

- M_DELETE: requisita a eliminação de uma instância de um objeto gerenciado a um usuário CMISE remoto.

Além dos serviços acima, o CMISE possui um serviço adicional: o M_LINKED_REPLY, usado para fornecer várias respostas a uma única requisição [KL88, WA89].

\subsubsection{O Protocolo de Gerenciamento CMOT}

Com o objetivo de determinar a estratégia a ser adotada no gerenciamento de redes TCP/IP, o IAB (Internet Activities Board) realizou uma reunião em 1988, resultando em duas propostas: o SNMP e o CMOT; que seriam desenvolvidas paralelamente, a primeira destinada a ser uma solução a curto prazo e a segunda uma eventual solução a longo prazo [BE90]. O SNMP (Simple Network Management Protocol) será discutido na seção 3.3.3, enquanto que o conjunto de protocolos de gerenciamento CMOT (CMIP over TCP/IP) será abordado a seguir.

O CMOT baseia-se no modelo de gerenciamento OSI, indicando como este pode ser usado para gerenciar redes TCP/IP [WA89], ou ainda, permitindo que o protocolo de gerenciamento proposto pela ISO, o CMIP, seja usado sobre ambientes TCP/IP [BE90].

O CMOT segue os modelos, serviços e protocolos definidos pela ISO. Os modelos são os definidos pelo ambiente de gerenciamento OSI, descritos na secão 3.2.2 . Os serviços são os fornecidos pelo CMIS e os protocolos de aplicação, aqueles definidos para o gerenciamento OSI: ACSE, ROSE e CMIS/CMIP; ambos descritos na seção 3.2.4. 


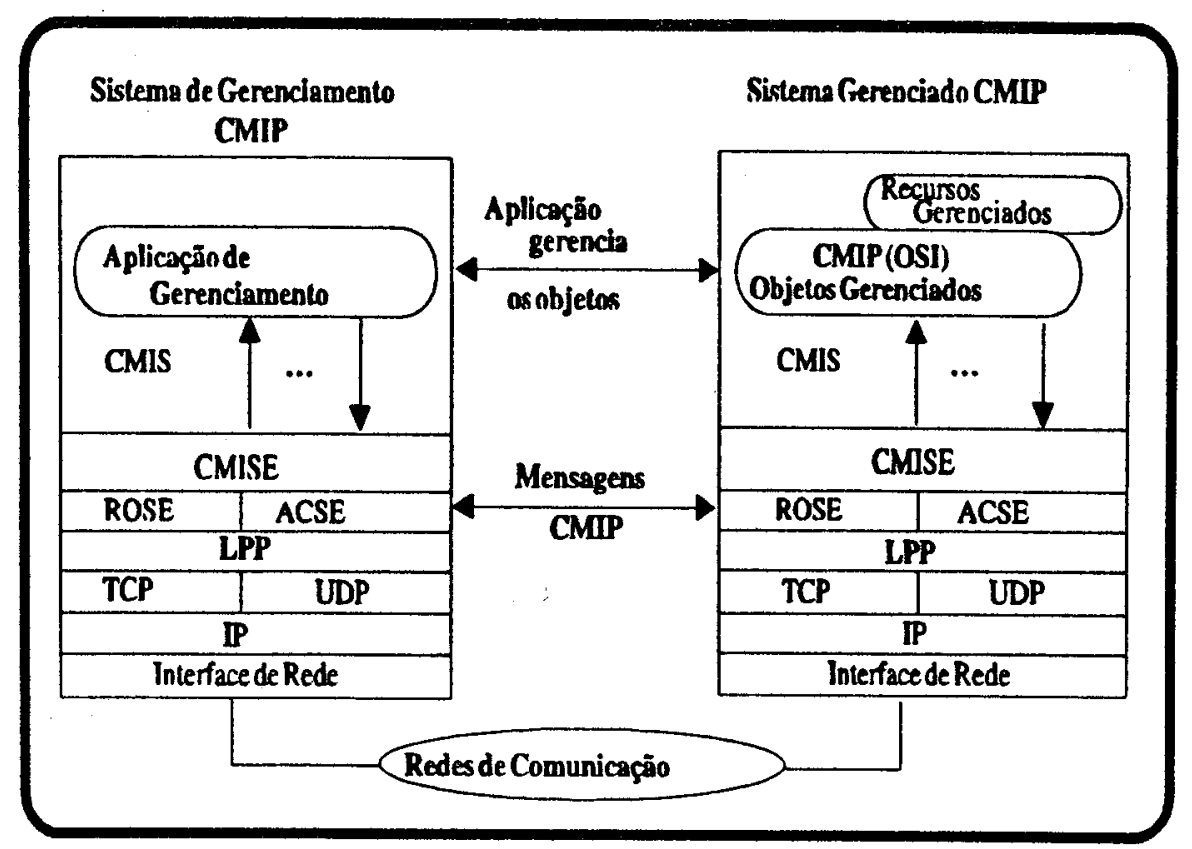

Figura 3.4: O Conjunto de Protocolos CMOT

Como ilustrado na figura 3.4, o ACSE, o ROSE e o CMIS/CMIP são implementados sobre o TCP/UDP/IP, o que é possivel graças ao protocolo LPP (Lightweight Presentation Protocol) que permite o uso dos serviços de apresentação OSI sobre os protocolos de transporte Internet (TCP e UDP) [WA89].

O CMOT inclui o conceito de gerenciamento proxy, útil nos casos onde o gerente é incapaz de gerenciar alguns dispositivos, seja por problemas de segurança, administrativos ou por protocolos e mecanismos de comunicação incompativeis [WA89]. Este conceito será melhor explorado na seção 3.3.2.

\subsection{O Modelo de Gerenciamento Internet}

\subsubsection{Histórico}

A partir de meados dos anos 80 , observou-se o crescimento desenfreado do número de redes conectadas a Internet, originando uma discussão a cerca do gerenciamento da mesma [R091a]. Assim, em 1987, surgiram três propostas: o SGMP (Simple Gateway Monitoring Protocol), o HEMS (High-Level Entity Management System), e o CMOT (CMIP over TCP/IP); além de muitas controvérsias. Visando resolver o problema, o IAB (Internet Activities Board) organizou uma reunião em fevereiro de 1988, resultando em duas soluções: a primeira, o SNMP (Simple Network Management Protocol) seria desenvolvida a partir do SGMP, destinada a ser uma solução a curto prazo para o problema do gerenciamento das redes baseadas em TCP/IP; e a segunda, concentraria-se no desenvolvimento do CMOT, discutido na seção 3.2 .5 e destinada a ser uma solução alternativa a longo prazo. 
Neste momento, têm-se duas soluçōes que deveriam ser compatíveis; logo, um modelo de gerenciamento comum às duas propostas deveria ser elaborado, surgindo em agosto de 1988 o chamado Modelo de Gerenciamento de Redes Internet. Como parte deste encontrava-se dois documentos responsáveis pela definição das informaçzes de gerenciamento: o SMI (Structure of Management Information) e a MIB (Management Information Base), ambos projetados visando a compatibilidade entre os dois modelos de gerenciamento: o Internet e o OSI [CA90].

Em abril de 1989, o SNMP se tornaria um padrão De Facto para o gerenciamento de redes baseadas em TCP/IP em decorrência da aceitação dos fabricantes, de produtos de rede ou não, assim como do número de sistemas desenvolvidos. Por outro lado, o CMOT não alcançava tamanho sucesso, pois não apresentava implementações "reais", deixando o SNMP como a única solução. Reconheceu-se, então, a impossibilidade de elaboração de um modelo de gerenciamento compativel a ambos os protocolos: os requisitos dos modelos OSI e Internet são bem diferentes; sendo decidido em nova reunião do IAB, em junho de 1989, a utilização de modelos distintos. Com isso, os requisitos de compatibilidade do SMI e da MIB também foram suspensos, permitindo que o modelo operacional, Internet, adicionasse novos itens à MIB aproximando-se das necessidade reais da comunidade Internet [CA90].

O Modelo de Gerenciamento de Redes Internet constitui-se:

- pelo SMI (Structure and Identification of Management Information) para redes baseadas em TCP/IP, responsável por descrever as estruturas comuns e o esquema de identificação para a definição das informações usadas no gerenciamento destas redes [RO90a];

- pela MIB (Management Information Base) para gerenciamento de redes baseadas em TCP/IP, responsável por descrever os objetos gerenciados [MC90a];

- e pelo SNMP, protocolo de gerenciamento usado para gerenciar tais objetos [CA90].

\subsubsection{Conceitos}

\section{Um Modelo Básico}

Um sistema de gerenciamento de redes constitui-se de três componentes: vários nós gerenciados, pelo menos uma estação de gerenciamento e um protocolo de gerenciamento [RO91a].

Os nós gerenciados podem ser: um host system, como por exemplo uma estação de trabalho, um servidor ou uma impressora; um gateway system ou um media device (dispositivo associado ao meio), como uma ponte por exemplo. Os dispositivos pertencentes às três categorias citadas acima possuem um ponto em comum: têm algum nível de "capacidade" de rede, sendo que os dois primeiros implementam os protocolos Internet, enquanto que o terceiro caracteriza-se pela dependência do meio. Cada nó gerenciado possui um processo agente responsável por executar as funções de gerenciamento requisitadas pela estação de gerenciamento [CA90].

A estação de gerenciamento é um host system que executa o protocolo e as aplicações de gerenciamento; enquanto que o protocolo de gerenciamento é usado como suporte à troca de informações de gerenciamento entre a estação e o agente, assumindo formas diferentes de acordo com o paradigma de gerenciamento adotado. $O$ paradigma utilizado pelo modelo Internet é o remote debugging, onde cada nó gerenciado contém um conjunto de variáveis, sendo a monitoração feita através da leitura dessas variáveis e o controle através da alteração do valor das 
mesmas [RO91a].

Além das operaçōes de leitura e escrita, há duas outras: a traversal e a trap. A traverșal permite à estação de gerenciamento determinar quais as variáveis suportadas por um nó gerenciado, sendo útil também na consulta de tabelas, como por exemplo a tabela de roteamento IP. A trap permite ao nó gerenciado notificar um evento extraordinário à estação de gerenciamento [R091a].

Para explicar melhor a operação trap, observa-se a existência de dois métodos para notificação de eventos à estação de gerenciamento: trap e polling. No método baseado em traps, quando um evento extraordinário ocorre, este é notificado à estação de gerenciamento. A vantagem é a notificação imediata e a desvantagem a necessidade de muitos recursos para a geração das traps. Dentre tais recursos destaca-se o tempo de processamento do nó gerenciado e a sobrecarga na rede, caso uma grande quantidade de traps seja gerada. Assim, para a utilizacão deste método deve-se estabelecer limites para a geração de traps, o que por sua vez, compromete o nó gerenciado. Concluindo, o método em questão pode causar grande impacto na performance tanto do nó gerenciado como da rede. No método basedo em polling, o nó gerenciado é consultado periodicamente pela estacão de gerenciamento. A vantagem é a visão global mantida pela estação de gerenciamento, o que não acontece no trap. A desvantagem reside na dificuldade em determinar quais nós consultar e com qual frequência [RO91a].

$\mathrm{O}$ modelo Internet usa o chamado trap-directed polling, ou seja, quando um evento extraordinário ocorre, o nó gerenciado envia ưma única trap simples à estação de gerenciamento, a qual a partir dá, interage com o nó gerenciado com o objetivo de determinar a natureza e a extensão do problema [R091a]. Através deste método, o impacto nos nós gerenciados é pequeno, o impacto na rede é reduzido e os problemas são tratados num intervalo de tempo adequado.

Antes de concluir a discussão sobre o modelo básico de gerenciamento, um conceito importante deve ser considerado: o gerenciamento proxy, também incorporado ao protocolo CMOT descrito na seção 3.2.5. Olhando mais detalhadamente as redes atuais, percebe-se a existência de dispositivos "estranhos", ou seja, que não podem ser gerenciados, como por exemplo aqueles associados ao meio (pontes, repetidores); porque não aparelhos de som, num futuro próximo; ou ainda host systems e gateway systems que não implementam o conjunto de protocolos usado pela estação de gerenciamento. Para solucionar tal problema, o modelo de gerenciamento Internet define um agente especial: o agente proxy, ilustrado na figura 3.5. Assim, quando a estação precisa gerenciar um destes dispositivos "estranhos", ela acessa o agente proxy enviando a identificação do dispositivo em questão. $O$ agente proxy, então, traduz as interações do protocolo da estação de gerenciamento para as interações entendidas pelo dispositivo "estranho". Caso o dispositivo gerenciado implemente um protocolo de gerenciamento diferente, o proxy age como um gateway de aplicacão [R091a].

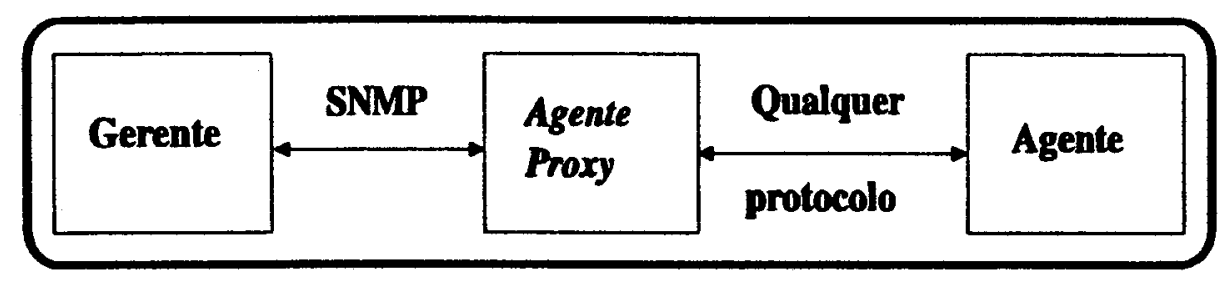

Figura 3.5: O Agente Proxy 
O agente proxy pode assumir também a função de caching de informaçōes de gerenciamento, com o objetivo de aliviar a carga nos nós gerenciados em ambientes onde determinadas informações de gerenciamento devem ser obtidas com certa frequência, mesmo que não apresentem frequentes alterações. Nesse sentido, 0 agente proxy pode ser inserido entre o nó gerenciado e as estações de gerenciamento com a finalidade de manter as informações desejadas [RO91a].

\section{O Axioma Fundamental}

O Modelo de Gerenciamento Internet baseia-se no seguinte axioma [RO91a]:

"O impacto de adicionar o gerenciamento de redes

aos nós gerenciados deve ser minimo, refletindo

o menor denominador comum."

\section{Representação dos Dados}

Considerando a complexidade das estruturas de dados usadas pelos protocolos a nível de aplicação, torna-se necessário um certo grau de formalismo na descrição de tais estruturas. Ao formalismo em questão chama-se sintaxe abstrata, a qual é usada na definição dos dados independentemente de estruturas e restrições de máquina [RO91a].

Associada à idéia de sintaxe abstrata, tem-se a noção de sintaxe de transferência, responsável por definir uma forma de transmissão não ambígua dos dados na rede [RO9la]. Geralmente, existem várias sintaxes de transferência para uma única sintaxe abstrata; no entanto, o OSI definiu um par formado por uma sintaxe abstrata e uma sintaxe de transferência; sendo um subconjunto destas usado no modelo Internet. Trata-se da ASN.1 (Abstract Syntax Notation One), uma linguagem para definição de estruturas de dados independente de máquina; e do $\mathbf{B E R}$ (Basic Encoding Rules), um conjunto de regras para codificação dos dados para transmissão [RO91a]. [RO91a]:

No contexto do gerenciamento, a linguagem ASN.1 é usada com dois objetivos distintos

- definir os formatos dos PDUs manipulados pelo protocolo de gerenciamento e

- definir os objetos que serão gerenciados.

Por outro lado, o BER é usado para codificar as definições ASN.1 para transmissão. Usando o BER, cada tipo ASN.1 é codificado como três campos [R091a]:

Identificador: indica o tipo ASN.1, através de um identificador associado a cada tipo definido em ASN.1;

Comprimento: indica o comprimento do valor ASN.1 codificado no campo seguinte; Valor: contém o valor ASN.1 codificado;

Os tipos ASN.I e as codificações dos valores de cada tipo são apresentados por Rose em [R091a]. 


\subsubsection{Objetos Gerenciados: o SMI e a MIB}

\section{SMI Internet}

O SMI Internet (Structure of Management Information) é responsável por descrever as estruturas comuns e o esquema de identificação usado na definição das informações de gerenciamento usadas para a gerência de redes TCP/IP [RO90a]. Inclui também a descrição de um modelo de informação de objeto para o gerenciamento de redes, assim como um conjunto de tipos genéricos usados para descrever informações de gerenciamento. As estruturas são definidas formalmente na linguagem ASN.1.

Cada objeto gerenciado é especificado segundo o SMI através de uma macro ASN.1, a qual inclui: o nome, a sintaxe, 0 nivel de acesso (read-only, read-write, write-only, notaccessible), e uma informação relacionada a obrigatoriedade de implementação do objeto (mandatory, optional, obsolete) [R091a]. O nome ou identificador de objeto é a forma de se identificar unicamente um determinado objeto [CA90], sendo formado por uma sequência de números inteiros não negativos obtidos percorrendo-se a árvore ilustrada na figura a séguir.

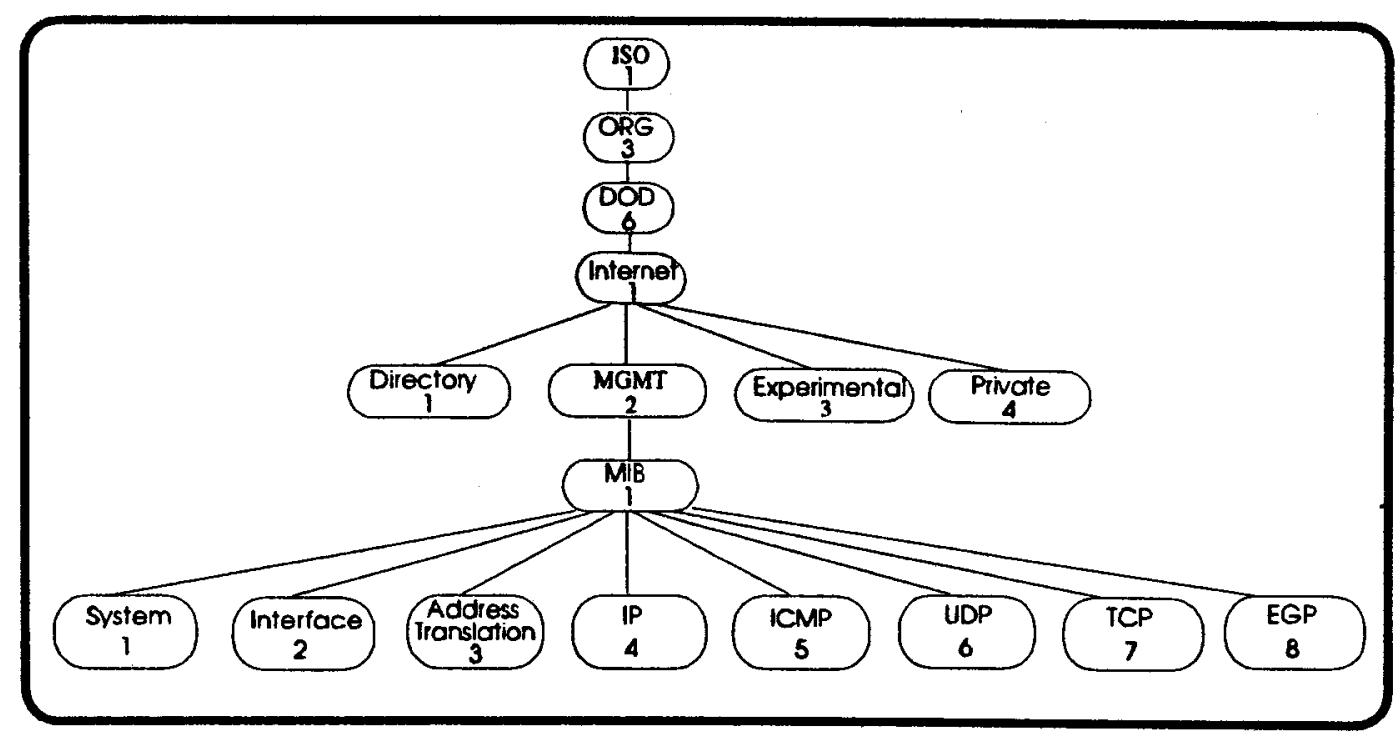

Figura 3.6: Árvore de Identificação ASN.1

A sintaxe de um determinado objeto define a estrutura correspondente ao tipo do objeto. Tal estrutura é definida através de construções ASN.1 [CA90].

\section{MIB Internet}

A base de informações de gerenciamento Internet, MIB Internet (Management Information Base), descreve os objetos a serem implementados pelos nós gerenciados que possuem o conjunto de protocolos Internet.

Todos os dispositivos que constituem nós gerenciados devem implementar a MIB padrão Internet. No entanto, nem todos os nós implementam todas as funções do conjunto de protocolos Internet [R091a]. Visando solucionar tal problema, a MIB divide os objetos em grupos, significando que se um determinado nó possuir as funções de um grupo, deverá implementar 
todos os objetos gerenciados do grupo em questão. O modelo Internet permite ainda a definição de novos objetos em caráter experimental ou para avaliação.

A MIB padrão Internet MIB I, definida em [MC90], possui oito grupos de objetos, enquanto que a MIB padrão MIB II, definida em [R091c], possui dois grupos adicionais sendo compativel com o SMI e a MIB I. Os grupos que constituem a MIB I e os adicionais definidos na MIB II são [RO91a]:

System: armazena informações genéricas sobre a configuração e deve ser implementado em todos os nós gerenciados. São exemplos de informações desse grupo: a descrição do dispositivo e quanto tempo o agente está no ar.

Interface: contém informações genéricas sobre as entidades da camada de interface, tais como o tipo da interface e o endereço físico. Deve ser implementado em todos os nós gerenciados.

Address Translation: contém informações sobre o mapeamento de endereços fisicos em endereços Internet. Deve ser implementado em todos os nós gerenciados. Foi considerado obsoleto na MIB II.

IP : armazena informações relacionadas com o protocolo IP e deve ser implementado em todos os nós gerenciados. São exemplos de informações definidas neste grupo: o total de datagramas descartados graças a erros e informações de roteamento.

ICMP : contém 26 contadores realcionados com as mensagens definidas pelo protocolo ICMP. Também deve ser implementado em todos os nós gerenciados:

TCP : deve ser implementado em todos os nós gerenciados que implementam TCP. São exemplos de informações deste grupo: o número de conexões ativas e uma tabela responsável por armazenar informações sobre as entidades de aplicação que estão usando o TCP.

UDP : deve ser implementado em todos os nós gerenciados que implementam o UDP. Contém informações genéricas no contexto do protocolo UDP, tais como: total de datagramas enviados e uma tabela, adicionadá na MIB II, usada para armazenar informações sobre as entidades que estão usando o UDP.

$\boldsymbol{E G P}$ : deve ser implementado em todos aqueles nós gerenciados que implementam o EGP (Exterior Gateway Protocol).

Transmission : sendo adicionado na MIB II, armazena informações de MIBs específicas do meio de transmissão.

SNMP : adicionado na MIB II, este grupo constitui-se por um conjunto de objetos gerenciados relacionados às entidades de aplicação SNMP. São exemplos desse tipo de informação o total de PDUs recebidos com cada tipo de erro.

\subsubsection{Modelo Administrativo}

O modelo administrativo usado pelo SNMP define as políticas de autenticação e autorização usadas entre as entidades de aplicação SNMP [R091a].

Nesse contexto, deve-se introduzir o conceito de comunidade como sendo a relação entre um agente SNMP e um ou mais gerentes. Uma comunidade SNMP é identificada por uma cadeia de octetos, que constitui o nome da comunidade. 
Uma mensagem SNMP é formada por duas partes:

- o nome da comunidade e algumas informações adicionais importantes para a validação da entidade fonte como membro da comunidade em questão e

- os dados, incluindo a operação SNMP e os operandos associados.

O mecanismo de autenticação usado pelo SNMP é muito simples: uma entidade fonte é considerada autenticada se o nome da comunidade especificado na mensagem enviada pela mesma for reconhecida pela entidade destino.

Por outro lado, o mecanismo de autorização consiste em verificar o nível de acesso que é permitido a uma determinada entidade, já autenticada. Para tanto, é levado em conta o modo de acesso definido para cada objeto na MIB, assim como o modo de acesso definido pela comunidade para cada objeto pertencente a uma visão. Visão é o nome dado a um subconjunto de objetos visiveis para uma determinada comunidade [RO91a].

\subsubsection{O Protocolo de Gerenciamento SNMP}

O protocolo de gerenciamento SNMP é usado na comunicação de informações de gerência entre as estações de gerenciamento e os agentes, implementados nos nós gerenciados [CA90]. Baseia-se no Modelo de Gerenciamento Internet e, portanto, segue os conceitos definidos no mesmo, inclusive o Axioma Fundamental. Logo, o objetivo principal é ser um protocolo simples e que requisite poucos recursos para ser implementado eficientemente. Usa um serviço de transporte sem conexão, permitindo à estação de gerenciamento determinar o nível apropriado de retransmissão com a finalidade de acomodar perdas e sobrecargas na rede [RO91a]. O padrão SNMP especifica a transmissão através do UDP, no entanto, as mensagens SNMP podem ser transmitidas por qualquer mecanismo de transporte que suporte fluxo bidirecional e capacidade de endereçamento (addressability); com isso, o SNMP tem sido implementado diretamente sobre a Ethernet, sobre o Xerox Network Service (XNS) e o IPX da Novell, por exemplo [SC89]. 


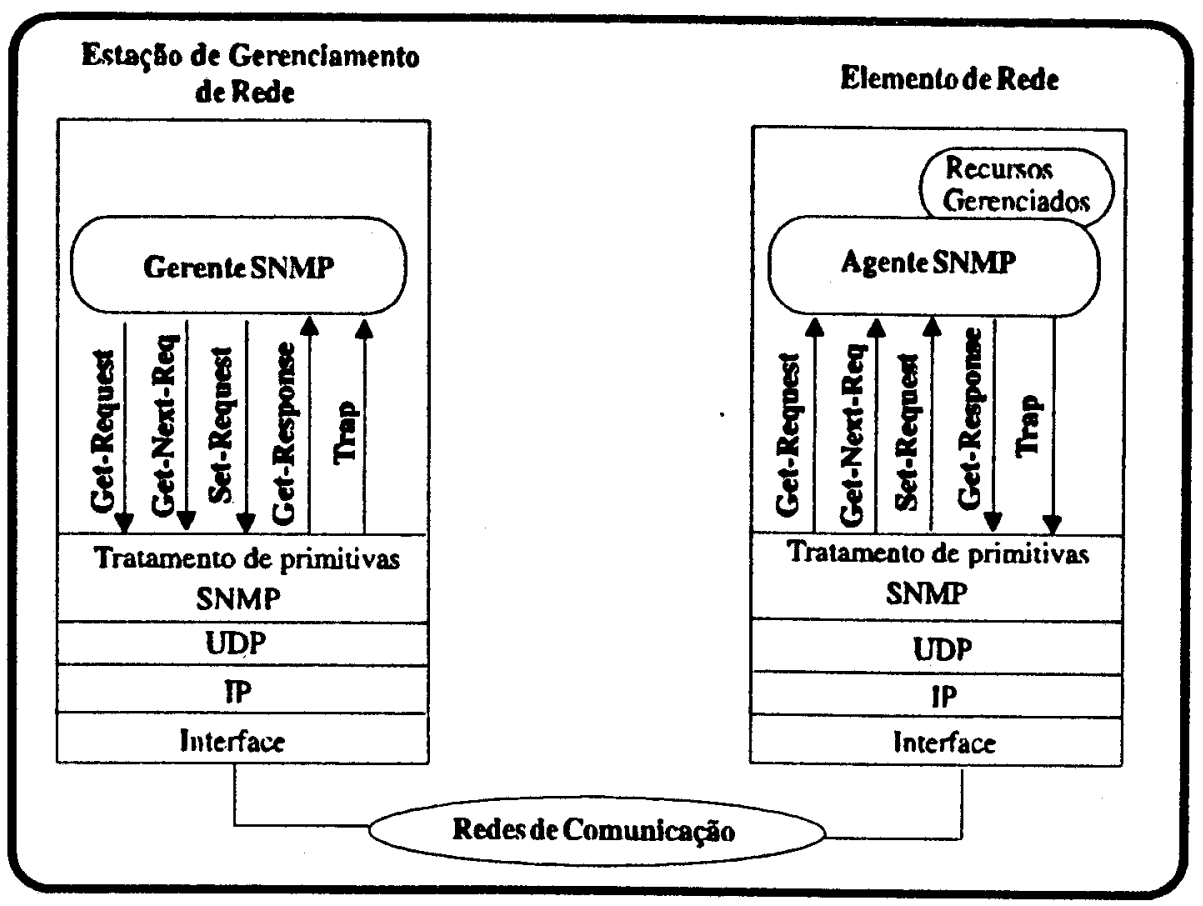

Figura 3.7: A Arquitetura SNMP

O protocolo SNMP, ilustrado na figura 3.7, usa interações request-response análogas ao CMIP embora com um número menor de operações, descritas a seguir [R091a] :

- GET : usada para recuperar informações específicas de gerenciamento;

- GET_NEXT : usada para recuperar informações de gerenciamento via traversal, como percorrer tabelas por exemplo;

- SET : usada para manipular informações de gerenciamento;

- TRAP : usada para notificar eventos extraordinários.

Existem cinco primitivas responsáveis por executar as operações acima: get-request, getresponse, get-next-request, set-request e trap; às vezes referenciadas como operações na literatura.

Quatro interações são possíveis entre essas primitivas:

O gerente obtém informações de gerenciamento do agente, usando a primitiva get-request. Caso alguma variável não exista, a primitiva get-response retorna o erro. Caso contrário, retorna o valor correspondente a cada variável especificada na get-request.

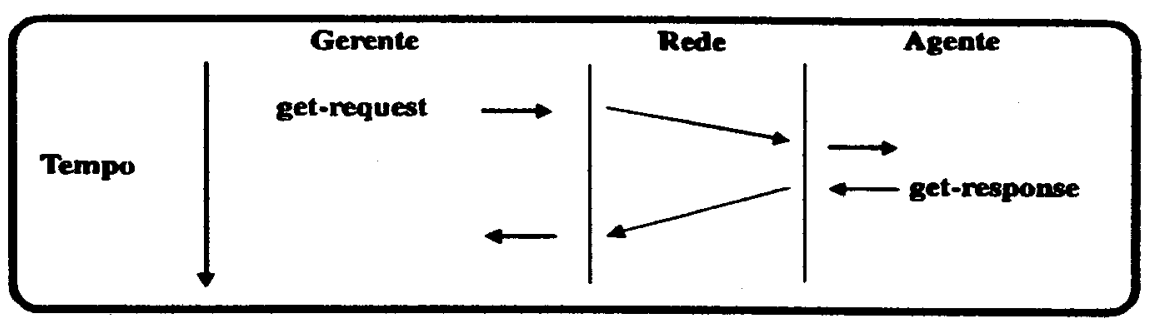

Figura 3.8: Obtendo Informações de Gerenciamento do Agente 
O gerente atravessa uma porção da visão do agente. Nesse caso, para cada variável especificada na primitiva get-next-request, a get-response retorna o valor correspondente à instância que a sucede.

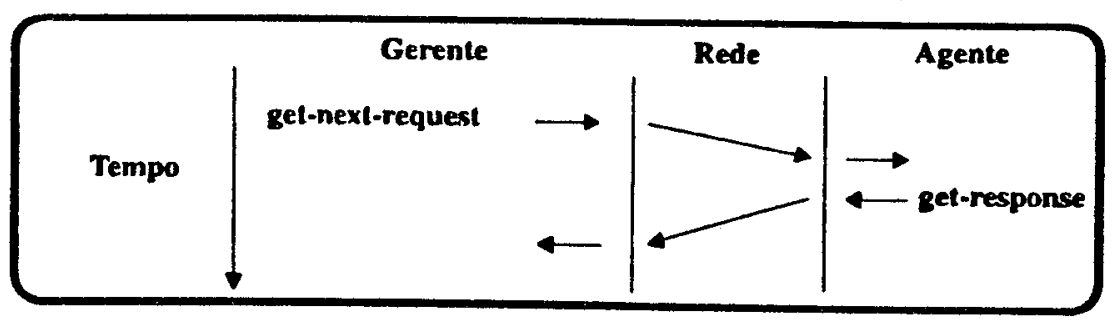

Figura 3.9: Obtendo Informações via Traversal

O gerente atualiza informaçōes de gerenciamento no agente, usando a primitiva set-request. Caso alguma variável não exista, não permita a escrita, ou ainda o novo valor seja inconsistente, a get-response retorna os erros correspondentes. Caso contrário, todas as variáveis especificadas na set-request são alteradas de acordo com os novos valores, sendo gerada uma get-response idêntica à set-request.

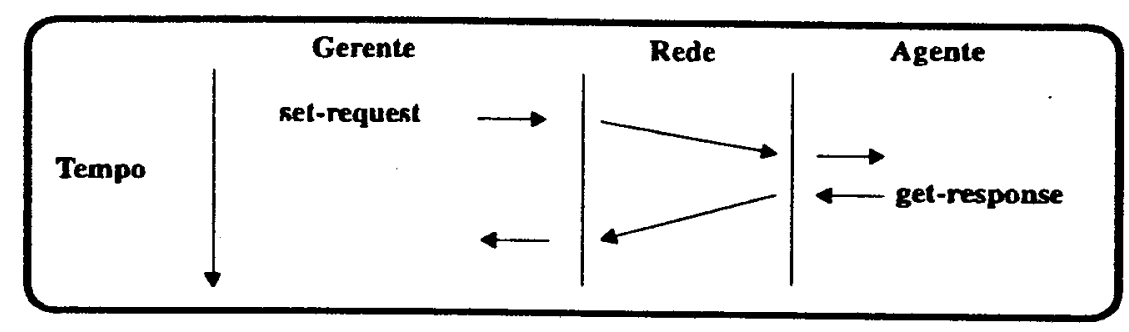

Figura 3.10: Atualizando Informações de Gerenciamento no Agente

O agente notifica um evento extraordinário, enviando uma trap aos gerentes identificados por ele.

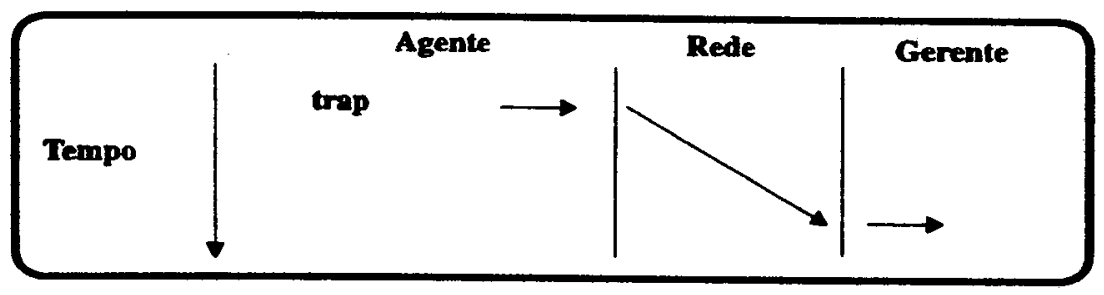

Figura 3.11: Notificando a Ocorrência de um Evento ao Gerente

Como o protocolo de gerenciamento é um protocolo de aplicação, as entidades de aplicação comunicam-se através da troca de mensagens, sendo cada mensagem representada num único datagrama UDP usando o BER [CA90].

Uma mensagem SNMP é formada por um identificador de versão, um nome de comunidade SNMP e um PDU (Protocol Data Unit). A entidade SNMP recebe todas as mensagens na porta UDP 161, exceto as traps, as quais são recebidas na porta UDP 162. 
Todas as implementações do SNMP devem incluir os cinco PDUs: GetRequest, GetNextRequest, GetResponse, SetRequest e Trap.

Existem basicamente dois tipos de PDUs SNMP definidos em ASN.1: aquele usado para a maioria das operaçoes, e o trap-PDU usado para as traps.

Descreve-se a seguir os campos do PDU mais genérico, usado para as primitivas GetRequest, GetNextRequest, GetResponse e SetRequest [CA90, R091a]. Os detalhes de cada campo no contexto dos referidos PDUs são apresentados por Case em [CA90].

request-id: trata-se de um valor inteiro usado pelo gerente para diferenciar as requisições pendentes. Este campo permite à entidade SNMP relacionar uma determinada resposta à requisição correspondente dentre as várias requisições pendentes. Pode também ser usado como mecanismo de deteç̧ão de mensagens duplicadas.

error-status: quando diferente de zero indica a ocorrência de problemas no tratamento da requisição. Pode assumir os seguintes valores:

- too-big: quando o agente não consegue armazenar os resultados da operação numa única mensagem SNMP;

- noSuchName: quando a operação requisitada inclui uma variável desconhecida;

- badValue: quando a operação requisitada especifica a sintaxe ou valor incorretos para a variável que deseja modificar;

- readOnly: quando a operação requisitada inclui a alteração de uma variável à qual não é permitida esse tipo de operação;

- genErr: outros erros.

error-index: quando diferente de zero, indica qual variável gerou erro. Este campo é diferente de zero somente para os erros: noSuchName, badValue e readOnly.

variable bindings: consiste numa lista de variáveis e correspondentes valores. Para alguns PDUs interessa apenas o nome da variável, e não o seu valor, como é o caso do

GetRequest. Nesses casos, os campos referentes ao valor da variável devem ainda seguir a sintaxe ASNl e codificação, podendo assumir um valor nulo (NULL).

O PDU que transmite as traps é formado pelos seguintes campos [CA90, R091a]:

enterprise: trata-se da identificação do agente;

agent-addr: endereço do agente;

generic-trap: inclui um dos seguintes eventos:

coldStart: significa que 0 agente está reinicializando-se de modo que sua configuração ou implementação pode ser alterada;

warmStart: significa que o agente está reinicializando-se sem alterar sua configuração ou implementação;

linkDown: indica o reconhecimento de uma falha num dos canais de comunicação representados na configuração do agente;

linkUp: indica que um dos canais de comunicação representados na configuração do agente está funcionando.

authenticationFailure: indica a chegada de uma mensagem que não foi

autenticada;

egpNeighborloss: indica que o par EGP está inativo;

enterpriseSpecific: indica a ocorrência de um evento extraordinário, identificado

no campo specific-trap. 
specific-trap: quando diferente de zero, identifica uma trap enterpriseSpecific.

time-stamp: o tempo passado desde a última reinicialização da entidade e a geração de uma trap.

variable-bindings: consiste numa lista de variáveis contendo informações sobre a trap.

\subsection{A Versão 2 do Modelo de Gerenciamento Internet (SNMPv2)}

A versão 2 do modelo de gerenciamento Internet, chamada de SNMP versão 2 (SNMPv2), originou-se do modelo de gerenciamento Internet descrito na seção 3:3 [CA93a], constituido pelos mesmos conceitos básicos. Nesta seção apresenta-se as principais caracteristicas do SNMPv2, comparando sempre que possivel com o SNMPv1.

O SMI para o SNMPv2 apresenta algumas diferenças em relação ao modelo Internet original, sendo dividido em três partes: definição de módulos de informação, definição de objetos gerenciados e definição de notificações. Considerando a árvore ASN.1 da figura 3.6, o SMI para o SNMPv2 define dois ramos adicionais na sub-árvore internet: security e snmpv2 [CA93c].

O SNMPv2 define uma nova interação, além daquelas citadas e ilustradas na seção 3.3.5, onde um gerente SNMPv2 pode requisitar informações de gerenciamento de outro gerente SNMPv2, através de uma nova primitiva: a InformRequest [CA93e]. Outra primitiva adicional é a GetBulkRequest que permite a transferência de grande volume de dados, incluindo a recuperação rápida e eficiente de grandes tabelas.

No SNMPv2 a notificação de erros via GetResponse é mais detalhada, graças a um número maior de erros notificados nos campos error-status e error-index, além da inclusão de campos opcionais na definição da lista de variáveis [CA93e].

Como no modelo de gerenciamento Internet original, o SNMPv2 pode ser mapeado sobre vários conjuntos de protocolos; no entanto, o mapeamento sobre o UDP é o preferido [CA93f].

A MIB para o SNMPv2 define os objetos gerenciados que descrevem o comportamento de uma entidade SNMPv2 [CA93g]. Por outro lado, a MIB gerente-gerente define um conjunto inicial de objetos gerenciados que descrevem o comportamento de uma entidade SNMPv2 que atua como gerente [CA93h].

O modelo administrativo para o SNMPv2 é baseado no uso de identificações distintas para pares que trocam mensagens SNMPV2. O novo modelo não usa o conceito de comunidade, identificando de maneira não ambigua o fonte e o destino desejado para a mensagem SNMPv2, o que permite melhores mecanismos de controle de acesso e segurança [GA93a].

O objetivo do modelo administrativo para o SNMPv2 é definir o comportamento de uma party SNMPv2: um ambiente de execução virtual e conceitual, onde as operações são restritas, por segurança e outros fatores, a um subconjunto administrativamente definido de operações possíveis de uma entidade SNMPv2 particular [GA93a]. Uma entidade SNMPv2 age como uma party SNMPv2 sempre que processa uma mensagem SNMPv2, sendo restrita ao conjunto de operações definidas para esta party.

Cada party SNMPv2 possui um único protocolo de autenticação e um único protocolo de privacidade associados. $O$ protocolo de autenticação define um mecanismo através do qual 
informações de gerenciamento transmitidas por uma party possam ser seguramente identificadas como sendo originárias daquela party. $O$ protocolo de privacidade fornece mecanismos para garantir que informaçð̄es de gerenciamento transmitidas por uma determinada party sejam protegidas contra revelação [GA93b]. Os objetos gerenciados correspondentes às propriedades de uma party são definidos na party MIB [MC93].

O SNMPv2 é um super conjunto do modelo de gerenciamento Internet original. Para atingir a coexistência a nivel de protocolo, o gerente deve suportar SNMPvl e SNMPv2. Desse modo, quando a aplicação precisa comunicar-se com um determinado agente, o gerente deve consultar uma base de dados local para verificar qual versão do protocolo está sendo usada. Com o objetivo de garantir a transparência a nivel de aplicações de gerenciamento, o gerente deve mapear as operações: agindo como um agente proxy. Por outro lado, um agente SNMPv2 pode ser implementado e configurado para agir como um agente proxy entre um gerente SNMPv2 e um agente SNMPvl. Os aspectos relacionados à coexistência entre os dois modelos são discutidos em [CA93b].

\subsection{Comparação entre os Protocolos de Gerenciamento}

O SNMP é o protocolo de gerenciamento com maior índice de aceitação de mercado, o que pode ser constatado através das inúmeras aplicações desenvolvidas. A maioria dos dispositivos de rede já implementam o SNMP, e aqueles que não o fazem podem ser gerenciados por agentes proxy com MIBs particulares. Esta liberdade concedida pelo modelo de gerenciamento Internet, aliada a facilidade de implementação do protocolo, tem sido a maior responsável pelo sucesso do SNMP. A facilidade de implementação do SNMP deve-se ao fato de possuir um conjunto menor de operações, além de não exigir excepcionais recursos de processamento e memória. A utilização do SNMP no desenvolvimento de aplicações de gerenciamento torna a tarefa mais simples e rápida do que a utilização do CMIP, basicamente devido a "cultura" SNMP adquirida através dos vários softwares já desenvolvidos. Visando solucionar alguns problemas polêmicos levantados no SNMPv1, como por exemplo a recuperação de grandes volumes de dados e as questōes de segurança, o SNMPv2 foi definido.

O CMIP, por sua vez, vem ganhando impulso, apresentando uma especificação mais sedimentada que o SNMP. Um problema do CMIP é a existência de poucas aplicações desenvolvidas, o que se deve às dificuldades de implementação inerentes ao CMIP.

Atualmente, verifica-se a concretização da idéia citada no início da histórica discussão sobre os protocolos de gerenciamento: o SNMP seria uma solução a curto prazo, enquanto que o CMIP seria a solução a longo prazo [BE90, FI91]. Seguindo essa tendência, observa-se os esforços concentrados em discussões sobre os padrões OSI, incluindo a coexistência e interoperabilidade entre os protocolos OSI e Internet [NI90]. Nesse contexto, a polêmica SNMP e CMIP pode estar com os dias contados, considerando-se a hipótese dos dois protocolos trabalharem juntos no gerenciamento de redes. 


\section{Capítulo 4}

\section{Projeto do Agente SNMP para Plataformas rodando DOS}

\subsection{Introdução}

De acordo com o modelo de gerenciamento Internet, discutido na seção 3.3 , o gerencimento de uma rede dá-se através da troca de informações de gerenciamento entre agentes, agentes proxy e estações de gerenciamento, que fazem o papel de gerentes, utilizando um protocolo de gerenciamento, o SNMP. 0 modelo prevê ainda, uma base de dados, a MIB, onde são armazenadas as informações específicas relacionadas a um determinado componente ou conjunto de componentes da rede.

Neste capítulo descreve-se o projeto de um agente segundo o modelo de gerenciamento Internet. Trata-se de um agente SNMP para computadores, rodando DOS, conectados a uma rede ethernet. São tarefas do agente obter informações sobre a sub-rede à qual está conectado e deixálas disponiveis para o acesso por sistemas de gerenciamento. Para tanto, define-se uma MIB particular formada por informações previstas na MIB Internet para os protocolos TCP/IP, por informações de uma MIB RMON para informações a baixo nivel, e por informações adicionais definidas neste projeto. 
Fazem parte do projeto a implementação das operações do protocolo necessárias para o desenvolvimento de um agente, o levantamento das informações e a coleta das mesmas, assim como a definição de uma MIB particular, contendo o conjunto de todas as informações.

\subsection{Contexto}

O agente, tema deste trabalho, desempenha importante papel num ambiente de gerenciamento, coletando informações sobre a sub-rede à qual está conectado e mostrando-as localmente, o que facilita a detecção de problemas na sub-rede; ou ainda mantendo-as numa MIB particular, a MIB Net, viabilizando a obtenção das mesmas por um sistema de gerenciamento que implemente tal MIB. Então, o sistema atua como agente da máquina onde está instalado, e agente proxy da sub-rede à qual está conectado. Mantendo-se um agente em cada sub-rede, um sistema de gerenciamento pode consultá-los periodicamente, permitindo que o administrador da rede tenha uma visão global do funcionamento da mesma observando o comportamento das diversas subredes que a compõe.

O sistema de gerenciamento pode ser, por exemplo, aquele em desenvolvimento no ICMSC [MO94]. Trata-se de um sistema gerenciador de redes de computadores com recursos multimidia, denominado MultiView, que tem como objetivo básico auxiliar o administrador da rede em suas tarefas de monitoração e controle. Para tanto, o sistema deve fornecer, através de uma interface gráfica, informações sobre estatísticas, configuração, roteamento, mapas da rede e mecanismos para divulgação de mensagens escritas ou faladas para os usuários. Um exemplo de ambiente de gerenciamento é ilustrado na figura 4.1, considerando-se a rede de computadores do campus USP de São Carlos.

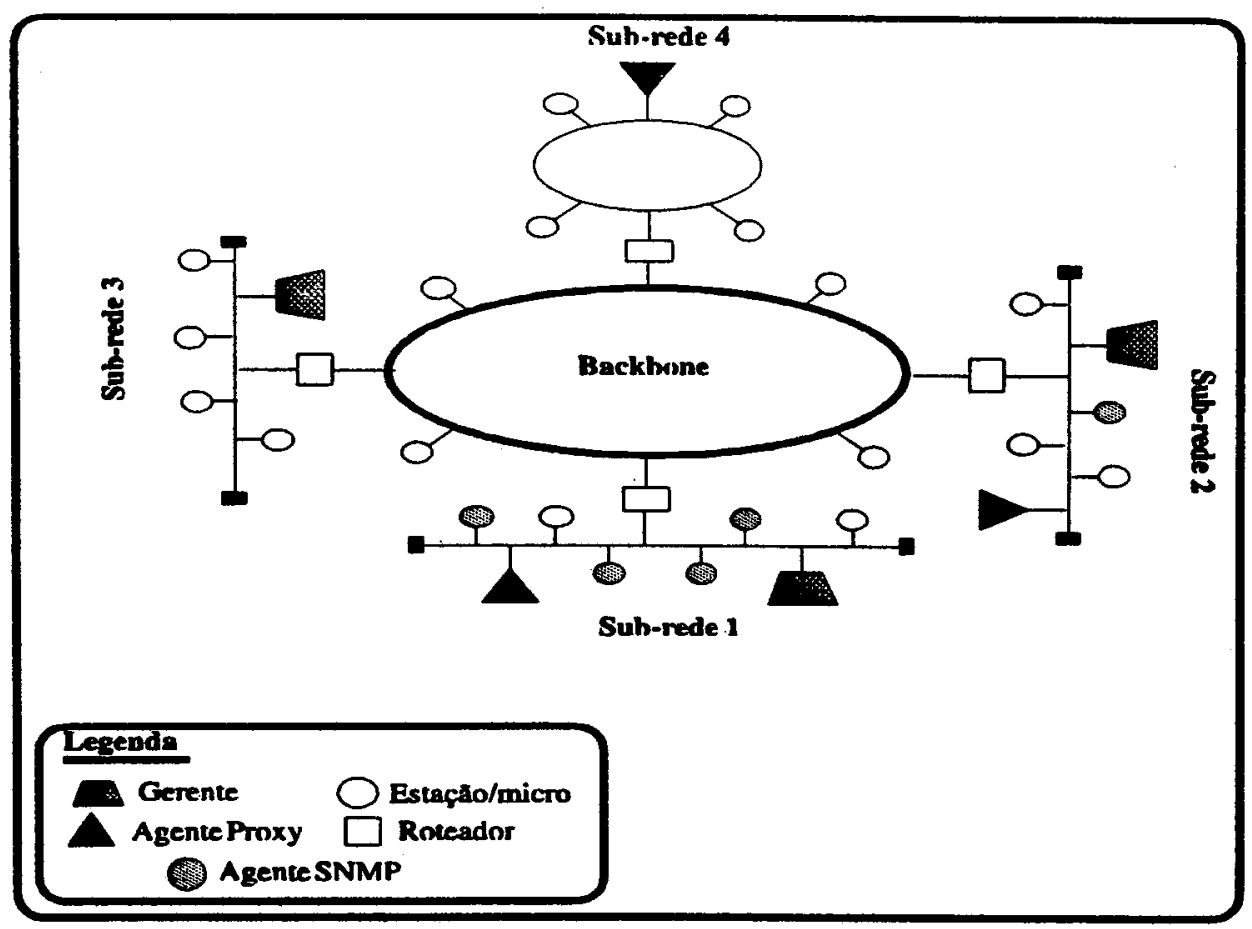

Figura 4.1: Um Ambiente de Gerenciamento 


\subsection{Informações Contidas na MIB Net}

A obtenção de dados relacionados à sub-rede à qual o agente está conectado constitui um dos objetivos do sistema proposto. Tais dados devem ser relevantes a ponto de refletir o comportamento da sub-rede, auxiliando nas tarefas de análise do funcionamento da mesma, como por exemplo, a análise de tráfego. Logo, um estudo das informações suportadas pelas MIBs já existentes torna-se necessário, com o objetivo de detectar dados já definidos e importantes, bem como definir um conjunto de informações adicionais que satisfaçam os requisitos do projeto.

\subsubsection{Objetos da MIB Padrão Internet para os Protocolos TCP/PP (MIB II)}

A MIB II, como descrito na seção 3.3.3, possui os seguintes grupos de objetos: System, Interfaces, IP, ICMP , TCP , UDP, EGP, Transmission e SNMP. Os objetos mantidos pela MIB II e relacionados com o projeto pertencem aos grupos System e Interfaces, sendo descritos a seguir [MC91a, RO91a]:

\section{Grupo System}

sysDescr: descrição do dispositivo;

sysObjectID: identificação do software do agente;

sysUpTime: há quanto tempo o agente está em execução;

sysContact: nome da pessoa responsável;

sysName: nome do dispositivo;

sysLocation: localização fisica do dispositivo;

sysServices: serviços oferecidos pelo dispositivo.

\section{Grupo Interfaces}

Formado por um objeto que armazena o número de placas de interface presentes na máquina e por uma tabela contendo as informações sobre cada uma dessas placas de interface, através dos seguintes objetos:

ifIndex: número da interface;

ifDescr: descrição da interface;

ifType: tipo de interface;

ifMTU: tamanho do MTU;

ifSpeed: velocidade de transmissão em bits/segundo;

ifPhysAddress: endereço físico;

ifAdminStatus: estado desejado para a interface;

ifOperStatus: estado corrente da interface;

iflastChange: há quanto tempo a interface mudou de estado;

ifinOctets: total de octetos recebidos do meio;

iflnUcastPkts: pacotes unicast passados para o protocolo da camada superior . 
iflnNUcastPkts: pacotes broadcast ou multicast passados para o protocolo da camada superior. ifnnDiscards: pacotes descartados devido a limitaçōes de recursos;

ifnnErrors: pacotes descartados devido a erro de formato;

iffnUnknownProtos: pacotes recebidos de protocolos não suportados ou desconhecidos .

ifOutOctets: total de octetos enviados para o meio;

ifOutUcastPkts: pacotes unicast recebidos do protocolo da camada superior .

ifOutNUcastPkts: pacotes broadcast ou multicast recebidos do protocolo da camada superior.

ifOutDiscards: pacotes descartados devido a limitações de recursos;

ifOutErrors: pacotes descartados devido a erro de formato;

ifOutQLen: tamanho do pacote da fila de saida;

irSpecific: ponteiro para uma MIB específica, relacionada à interface.

\subsubsection{Objetos da MIB para Monitoração Remota da Rede (RMON)}

A MIB RMON (Remote Network Monitoring MIB) consiste num ramo da MIB padrão MIB II, definindo objetos para representar informações obtidas por dispositivos de monitoração remota da rede [WA91]. Tais dispositivos, geralmente stand-alone, são instrumentos que tem por objetivo gerenciar a rede. Por exemplo, uma dada organização pode usar vários deles, um por subrede, para gerenciar sua rede. Além disso, consultando-os, sistemas de gerenciamento podem obter informações sobre uma rede geograficamente remota. A RMON define um conjunto de objetos relacionados com a camada de acesso ao meio, tendo sido projetada para intefaces Ethernet, permitindo a definição de objetos semelhantes para outras interfaces de rede.

Os objetos da MIB RMON são definidos em nove grupos, sendo a implementação de cada um deles opcional. Os grupos System e Interfaces da MIB II devem ser obrigatoriamente implementados. Os nove grupos da MIB RMON são os seguintes:

Statistics: contém estatíticas sobre cada interface monitorada neste dispositivo.

History: armazena amostras estatísticas periódicas sobre a rede para posterior consulta.

Alarm: periodicamente obtém amostras estatísticas de variáveis do dispositivo, comparando-as com limites pré-estabelecidos. Se a variável ultrapassa o limite, um evento é gerado. Este grupo exige a implementação do grupo Event.

Host: contém estatísticas sobre cada host detectado na rede. Os hosts são detectados mantendose uma lista dos enderefos fisicos fonte e destino vistos em pacotes recebidos em bom estado através do modo de recepção promíscua.

HostTopN: usado para preparar relatórios que descrevem os hosts que lideram uma lista ordenada constituida por uma de suas estatísticas. As estatísticas disponiveis são amostras de uma de suas estatísticas base num intervalo especificado pela estação de gerenciamento. Este grupo exige a implementação do grupo Host.

Matrix: armazena estatisticas sobre "conversas" entre conjuntos de dois endereços.

Filter: permite detectar pacotes que satisfaçam um determinado "filtro". Os pacotes detectados podem ser capturados ou ainda gerar um evento.

Packet Capture: permite a captura de pacotes. Este grupo exige a implementação do grupo Filter. Event: controla a geração e notificação de eventos pelo dispositivo. 
Dentre os grupos acima, o grupo Statistics torna-se especialmente importante no escopo do presente projeto. As informações estatísticas mantidas no grupo Statistics são relacionadas a todos os pacotes que passam na rede à qual a interface está conectada. Este grupo é formado por uma tabela, com uma entrada por placa de interface ethernet do dispositivo monitorado. Os objetos definidos em cada entrada são [WA91]:

etherStatsIndex: um valor que identifica unicamente a entrada correspondente a interface.

etherStatsDataSource: identifica a fonte de dados que esta entrada é configurada para analisar. Pode ser qualquer uma das placas ethernet do dispositivo.

etherStatsDropEvents: total de eventos nos quais os pacotes são descartados por falta de recursos. Este número não é necessariamente o número de pacotes descartados, mas sim o número de vezes em que tal situação ocorreu.

etherStatsOctets: número de octetos recebidos, inclusive dos pacotes com erros.

etherStatsPkts: total de pacotes recebidos, incluindo os com erros.

etherStatsBroadcastPkts: total de pacotes recebidos sem erros e com endereços broadcast.

etherStatsMulticastPkts: total de pacotes recebidos sem erros e com endereços multicast. Não inclui os pacotes broadcast.

etherStatsCRCAlignErrors: total de pacotes recebidos com comprimento entre 64 e 1518 octetos, que não estavam com o número total de octetos no comprimento ou que apresentavam erro no FCS (Frame Check Sequence).

etherStatsUndersizePkts: total de pacotes recebidos com menos de 64 octetos .

etherStatsOversizePkts: total de pacotes recebidos com mais de 1518 octetos.

etherStatsFragments: total de pacotes recebidos que não estavam com o número total de octetos no comprimento ou que apresentavam erro no FCS, e com menos de 64 octetos de comprimento.

etherStatsJabbers: total de pacotes recebidos com mais de 1518 octetos, que não estavam com o número total de octetos no comprimento ou que apresentavam erro no FCS.

etherStatsCollisions: a melhor estimativa do total de colisões deste segmento Ethernet.

Os seguintes objetos contabilizam o total de pacotes, incluindo os com erro, de acordo com o número de octetos:

etherStatsPkts640ctets

etherStatsPkts65to1270ctets

etherStatsPkts128to2550ctets

etherStatsPkts256to5110ctets

etherStatsPkts512to10230ctets

etherStatsPkts1024to15180ctets

etherStatsOwner: entidade que configurou esta entrada e usa os recursos associados à ela. etherStatsStatus: 0 estado desta entrada. 


\subsubsection{Objetos Adicionais definidos na MIB Net}

Os objetos definidos pela MIB Il estão relacionados ao número de pacotes recebidos pela interface, ou seja, pacotes à ela endereçados ou que passam por ela, no caso dos gateways. Logo, todas as informações sobre fluxo de pacotes são, na verdade, locais. Já os objetos da MIB RMON são definidos levando-se em conta TODOS os pacotes que passam na sub-rede. No entanto, referem-se apenas ao protocolo de acesso ao meio.

As informaçōes mantidas na MIB Net por sua vez, devem permitir a monitoração da subrede a vários níveis, considerando todos os pacotes que passam pelo meio fisico da máquina onde se encontra o agente, dando informações inclusive sobre os protocolos TCP/IP de alto nivel e outros protocolos como NOVELL e LAN Manager, por exemplo. Neste contexto, a MIB Net inclui os grupos System e Interfaces da MIB II, o grupo Statistics da MIB RMON, e ainda define um novo grupo de objetos, o ProtoStat, que contém as informações estatísticas sobre o fluxo de pacotes dos protocolos TCP/IP na sub-rede.

Os objetos do grupo ProtoStat são descritos a seguir:

statArpPkts: total de pacotes ARP detectados na sub-rede; statIcmpPkts: total de pacotes ICMP detectados na sub-rede; statTcpPkts: total de pacotes TCP detectados na sub-rede; statUdpPkts: total de pacotes UDP detectados na sub-rede; statSnmpPkts: total de pacotes SNMP detectados na sub-rede; statUnknownProtoPkts: total de pacotes de protocolos desconhecidos, ou seja não TCP/IP, detectados na sub-rede;

Posteriormente, o grupo ProtoStat poderá incorporar estatísticas de outros protocolos, como NOVELL por exemplo. O conjunto de objetos da MIB Net pode ser estendido de várias maneiras: implementando outros grupos da MIB II ou da MIB RMON, ou ainda definindo novos grupos.

\subsection{Estrutura da MIB Net no Modelo de Gerenciamento Internet}

$O$ agente SNMP descrito coleta informações não previstas na MIB padrão TCP/IP, o que resulta na definição de um novo grupo de objetos, a ser suportado pelo agente, permitindo o armazenamento das informações e a consulta por sistemas de gerenciamento. Neste projeto define-se uma nova MIB, a MIB Net, definida de maneira modular, permitindo o acesso a outras MIIBs, como a MIB padrão TCP/IP por exemplo, e facilitando a inclusão de novas informações.

Para definir uma nova de MIB, deve-se [R091a]:

- identificar a natureza da MIB de acordo com os objetivos do projeto e requisitar um número de identificação único para a mesma segundo sua classificação. Considerando a árvore ASN.1 mostrada na figura 3.6, uma nova MIB pode ser colocada na sub-árvore experimental ou no ramo enterprises da sub-árvore private.

- definir um esqueleto para a MIB;

- e definir os objetos da MIB, segundo o SMI do modelo Internet [RO90a]. 
A MIB Net deve requisitar sua identificação na sub-árvore enterprises, o que resultaria numa identificação do seguinte tipo:

MIB-NET \{ iso(1) org(3) dod(6) internet(1) private(4) enterprises(1) mibnet (XX)\}

Assim, a MIB Net permite a definição de novos grupos de objetos e ainda 0 acesso aos objetos definidos na MIB padrão TCP/IP, MIB Il, e na MIB RMON, como pode ser visto na figura 4.2 .

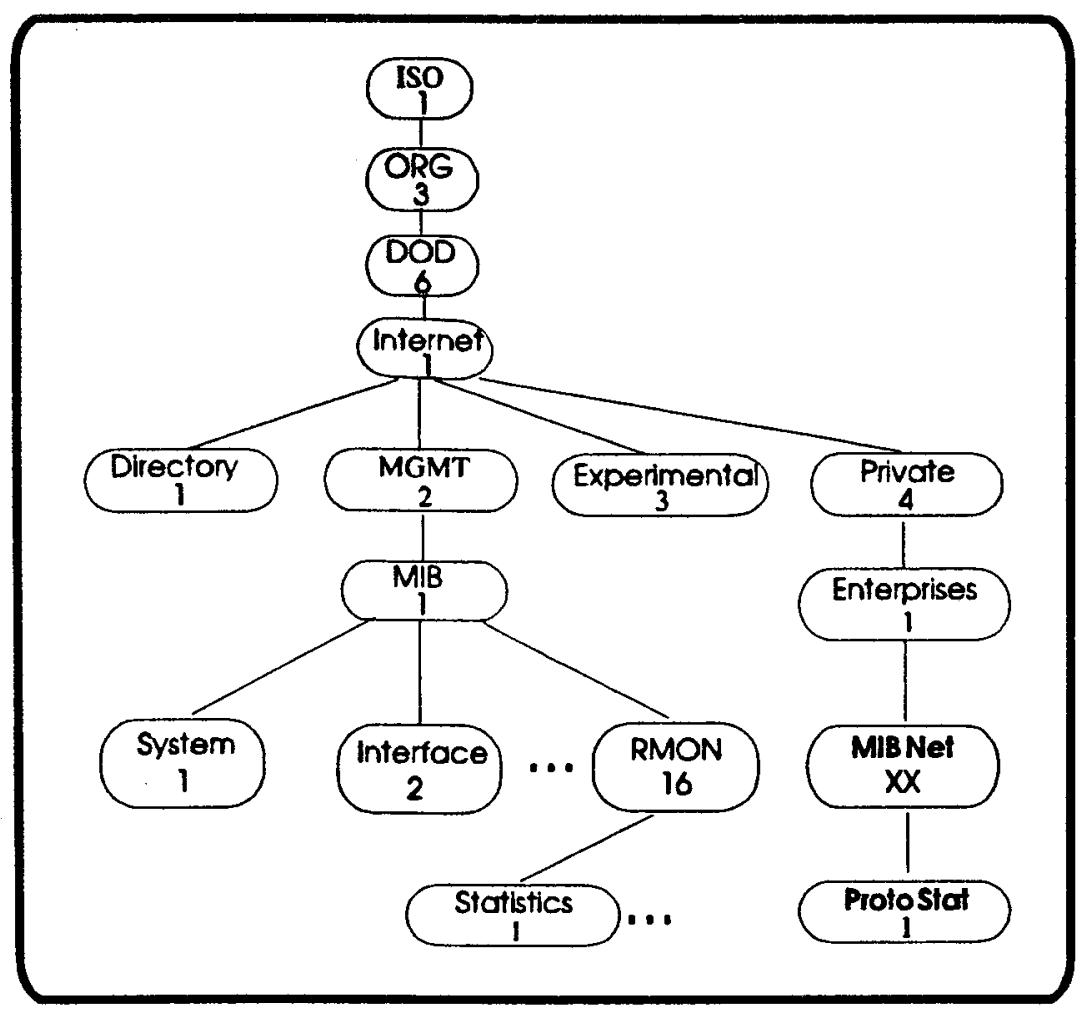

Figura 4.2: A MIB Net na Árvore de Identificação

O esqueleto definido para a MIB Net é o seguinte:

MIB-NET DEFINITIONS $::=$ BEGIN

IMPORTS

enterprises, Counter

FROM RFC1158-SMI;

OBJECT-TYPE

FROM RFC-1212;

- Esta MIB usa a definição da macro OBJECT-TYPE segundo [RO9Ib]

$-M M B N e t$

mibNet OBJECT IDENTIFIER $::=$ \{enterprises $X X\}$

$E N D$ 
A especificação dos objetos que constituem a MIB Net encontra-se no apêndice $A$, seguindo o SMI [RO90a] e as extensões especificadas em [R091b]. Tal especificação inclui:

- os grupos System e Interfaces da MIB II [MC91a];

- o grupo Statistics da MIB RMON [WA91] e

- o novo grupo, ProtoStat.

\subsection{Um Agente SNMP para Plataformas rodando DOS}

Este trabalho trata do desenvolvimento de um agente SNMP para plataformas rodando DOS. $O$ agente deve desempenhar algumas funções básicas:

- a obtenção de informações previstas na MIB Net, definida na seção 4.4;

- a apresentação das informações obtidas na tela da máquina onde está instalado;

- o fornecimento destas informações ao gerente; devendo ser capaz de responder às requisições do mesmo, segundo o protocolo de gerenciamento por ele utilizado; no caso, o SNMP.

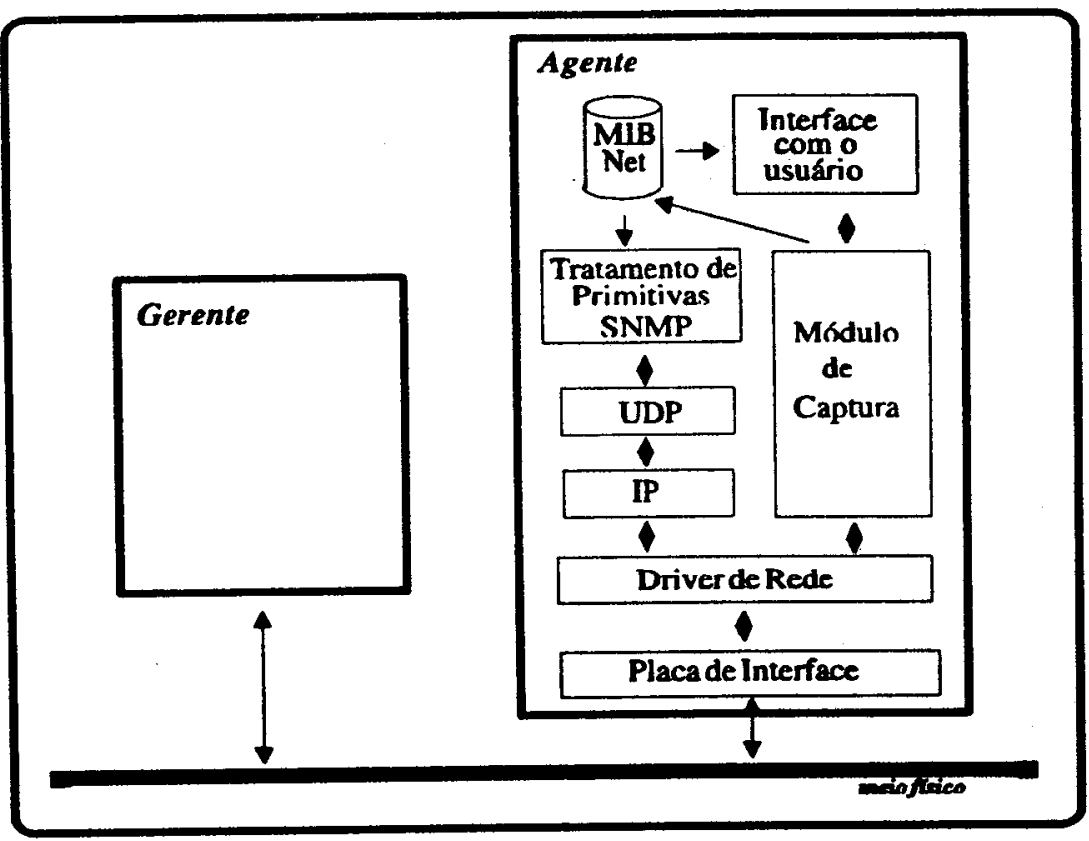

Figura 4.3: O Agente SNMP

A figura 4.3 ilustra o agente SNMP. O módulo de captura deve ser responsável por coletar as informações mantidas na MIB Net. Tais informações podem ser apresentadas localmente através do módulo de interface com o usuário. Como dito na seção 4.4, a MIB Net é formada pelo grupo adicional ProtoStat, pelos grupos System e Interfaces da MIB II e pelo grupo Statistics da MIB RMON.

A obtenção dos dados do grupo ProtoStat, leva em conta a existência do modo de recepção promiscuo de mensagens, implementado na maioria das placas ethernet disponiveis no 
mercado. Através da inicialização da placa em modo promiscuo, todos os pacotes que passam pela rede são detectados pela estação. A partir de então, deve-se armazenar tais pacotes numa lista para processamento posterior, que consiste em desmontar os pacotes analisando os cabeçalhos para a avaliação dos protocolos. $O$ algoritmo em alto nivel correspondente a tal tarefa é apresentado a seguir:

\section{Inicio}

Inicializar a placa de interface em Modo de Recep̧̧ão Promíscuo "Escutar" a rede recebendo e armazenando os pacotes recebidos numa fila Analisar os pacotes recebidos, checando os cabeçalhos dos

Fim protocolos e fazendo a contabilização dos pacotes

As informações dos grupos System e Interfaces podem ser obtidas através de arquivo de configuração, de funções do sistema, ou ainda da análise de pacotes recebidos.

Os dados do grupo Statistics da RMON devem ser obtidos com a placa em modo promíscuo também, visto que a definição de tal grupo ressalta a manutenção de estatísticas sobre todos os pacotes que passam pela interface. Algumas dessas informações podem ser obtidas de registradores da placa de interface, como por exemplo o total de pacotes com erros de CRC, enquanto que outras exigem a análise dos pacotes, como por exemplo o total de pacotes recebidos com endereşo broadcast.

Considerando a estrutura modular do agente, percebe-se que novas funçб̃es podem ser incorporadas ao módulo de captura com o objetivo de coletar outros dados que futuramente possam ser incorporados à MIB Net. Do mesmo modo, o módulo de captura pode ser substituido por outro módulo capaz de se comunicar com algum dispositivo conectado à rede, originando um agente proxy para o dispositivo em questão.

O mecanismo de transporte adotado no projeto segue o padrão especificado pelo SNMP, usando o serviço de transporte sem conexão fornecido pelo protocolo UDP. Considerou-se também o mapeamento direto sobre a ethernet, no entanto, este tipo de implementação não permite o roteamento, deixando as tarefas de gerenciamento confinadas à uma única sub-rede [R091a]. Considera-se então, que o trabalho adicional exigido na implementação dos protocolos UDP e IP seja compensador pois, possibilita a transmissão de informações de gerência para as demais sub-redes que porventura estejam separadas por roteadores. 
A codificação dos dados para a transmissão da resposta, assim como a decodificação necessária na chegada de uma requisição, são feitas de acordo com o esquema de codificação usado no modelo Internet e descrito sucintamente na seção 3.3.2. 


\section{Capítulo 5}

\section{Implementação}

\subsection{Introdução}

Neste capitulo são abordados aspectos de implementação do agente cujo projeto foi apresentado no capítulo 4, incluindo o ambiente de desenvolvimento formado pelos softwares utilizados na implementação do agente.

\subsection{Ambiente de Desenvolvimento}

O agente foi projetado para computadores com sistema operacional DOS e conectados em rede Ethernet. Como driver de rede utiliza-se o Packet Driver, descrito na seção 5.2.1, adequado à placa Ethernet usada, dentre os diversos drivers que constituem a coleção de Packet Drivers da Universidade de Clarkson [CL89]. 
Desenvolveu-se um agente para computadores rodando DOS, basicamente devido aos seguintes fatores:

- disponibilidade de equipamento: muitas redes não possuem como estações de trabalho máquinas do tipo SUN ou Risc IBM rodando UNIX, enquanto que computadores pessoais são equipamentos mais baratos e encontrados em abundância;

- maior facilidade de implementação de sistemas que manipulam dados a baixo nível, visto que neste tipo de máquina o acesso ao hardware é facilitado.

A implementação das primitivas SNMP baseia-se na biblioteca SNMPLIB, desenvolvida por Robert Crosson do National Institute of Standards and Technology [CR91a, CR91b, CR91c] e descrita na seção 5.2.2. A SNMPLIB dá suporte à implementação de sistemas monitores e não de agentes, como é o caso do presente trabalho. No entanto, decidiu-se utilizar a SNMPLIB como base, alterando o software sempre que necessário para adequá-lo ao desenvolvimento de um agente SNMP. A SNMPLIB atende às necessidades do projeto, pois:

- trata-se de um software de domínio público, logo tem-se total acesso aos códigos fonte e permissão para alterá-los;

- oferece a infra-estrutura básica que interessa ao projeto: implementa as funções básicas necessárias à implementação de primitivas SNMP no ambiente considerado, além de suportar a implementação de novas MIBs.

Utiliza-se como mecanismo de transporte o protocolo UDP, cuja implementação faz parte do pacote da SNMPLIB, assim como o protocolo IP. A coleção de Packet Drivers de Clarkson e a biblioteca SNMPLIB são softwares de domínio público e podem ser obtidos por Anonymous FTP no endereço sun.soe.clarkson.edu, diretório /pub/mail.archives/drivers. Os arquivos correspondentes ao Packet Driver são: drivers.zip, driversl zip e drivers2.zip; enquanto que os referentes à biblioteca SNMPLIB são: snmp.not, snmpsrc.zip e snmpsup.zip.

\subsubsection{O Packet Driver}

O Packet Driver foi especificado pela FTP Software com o objetivo de interagir com as interfaces de rede e fornecer uma interface padrão versátil às aplicações.

A utilização do Packet Driver, como o conceito de driver determina, faz com que a aplicação fique independente da interface de rede utilizada, pois a troca de interfaces de rede implica apenas na substituição do Packet Driver. Por exemplo, uma aplicação $\mathrm{Z}$ desenvolvida sobre o Packet Driver não precisa sofrer nenhuma alteração quando a interface de rede $\mathrm{X}$ for trocada pela Y, basta apenas substituir o Packet Driver por um outro adequado à nova rede, como ilustrado na figura 5.1. 


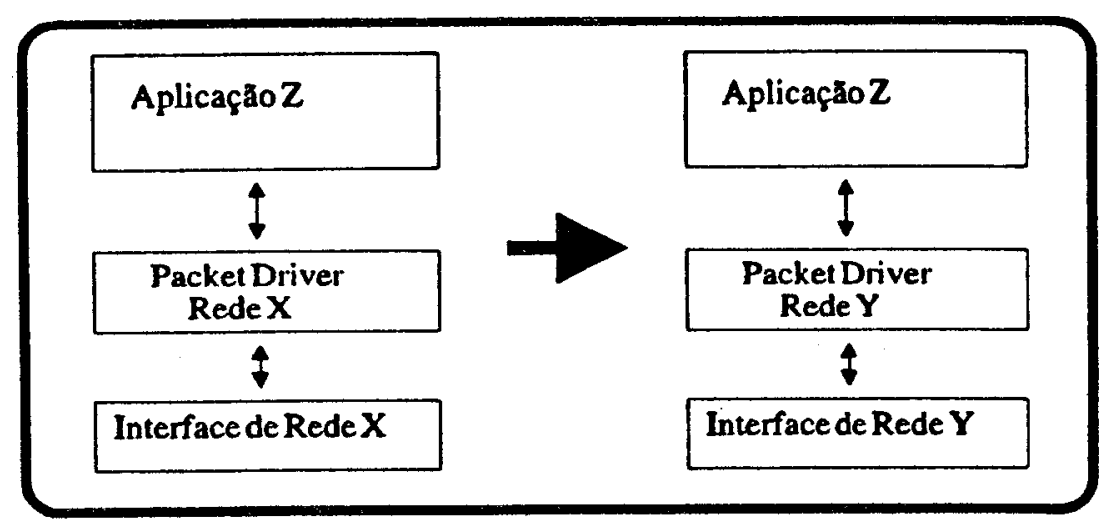

Figura 5.1: Os efeitos da utilização do Packet Driver na substituição de interfaces de rede

Existem drivers implementados para placas de várias classes, por exemplo: para placas Ethernet, como a NE1000 e NE2000 da Novell; para placas token ring, tais como a IBM token ring adapter; dentre outras.

O packet driver fornece uma interface de programação simples e padronizada, permitindo que várias aplicações compartilhem a mesma interface de rede no nivel da camada de enlace de dados [CL89]. A figura 5.2 exemplifica este fato mostrando as aplicą̧ões $\mathrm{Z}$ e W sobre uma mesma interface de rede $\mathrm{X}$, utilizando o packet driver X. Para tanto, o packet driver é capaz de fazer a demultiplexação dos pacotes recebidos entre as aplicações. Protocolos que usam o packet driver podem coexistir numa mesma máquina; por exemplo, um determinado usuário pode executar TCP/IP, NOVELL e um protocolo proprietário qualquer sobre a mesma interface de rede.

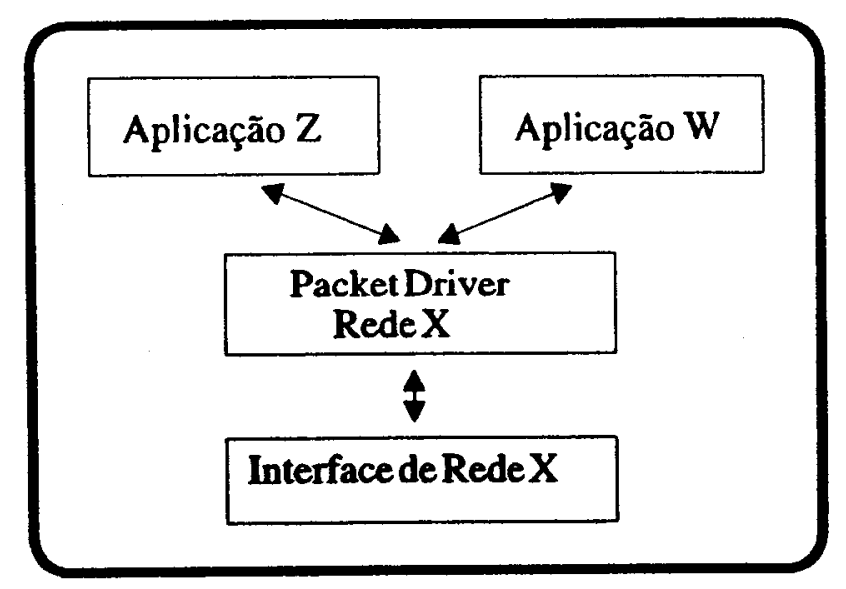

Figura 5.2: Duas aplicações sobre uma mesma placa de interface de rede, usando o Packet Driver

A figura 5.3 ilustra um caso que também deve ser considerado: a existência de duas placas diferentes numa mesma máquina. Neste caso, deve-se ter dois packet drivers diferentes, um para cada placa. Assim, uma aplicação $Z$ pode utilizar as duas placas de uma forma padrão. Tal aplicação poderia ser um roteador, por exemplo. 


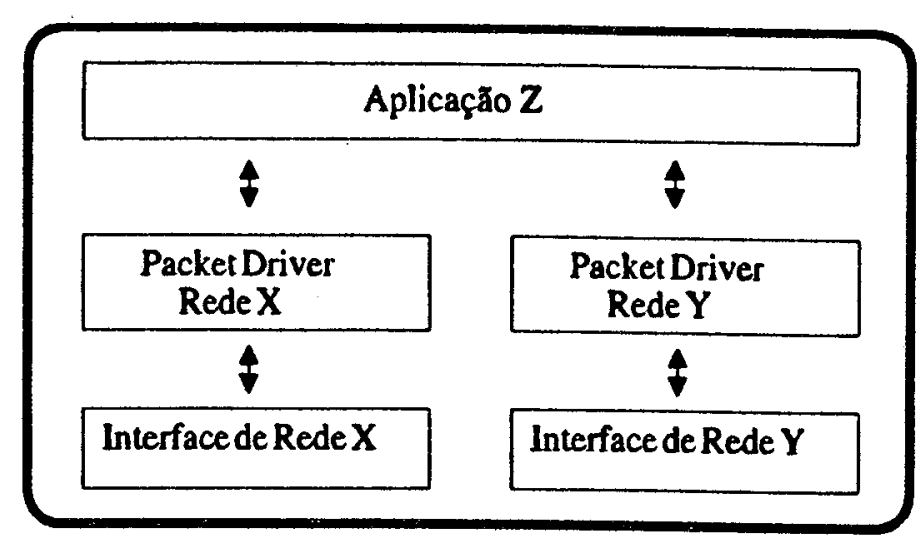

Figura 5.3: Uma aplicação sobre duas placas de interface de rede diferentes, usando o Packet Driver

O packet driver apresenta uma interface padrão para a aplicação através de um conjunto de funções pré-definidas, dentre as quais pode-se destacar [CL89]:

- DRIVER_INFO, responsável por fornecer informações sobre a placa de interface; como por exemplo a classe e a versão do driver;

- ACCESS_TYPE, responsável por iniciar o acesso aos pacotes do tipo especificado como um dos parâmetros, sendo outro parâmetro relevante um ponteiro para a rotina de recepção que deve ser acionada na recep̧̧ão de pacotes pelo packet driver;

- RELEASE_TYPE, encerra o acesso aos pacotes de um determinado tipo;

- SEND_PKT, responsável por transmitir um pacote armazenado no buffer passado como parâmetro para a função.

As funções do Packet Driver, residentes em memória, e a aplicação desenvolvida sobre ele são processos distintos que se comunicam através de interrupção, como descrito a seguir. Para acionar as funçōes do Packet Driver torna-se necessário o desenvolvimento de pequenas rotinas de interface. Uma rotina de interface, basicamente, inicializa determinados registradores com os parâmetros correspondentes à função a ser chamada, executa a interrupção e lê os valores dos registradores depois da execução das funções, retornando os resultados para a aplicação. Os registradores e os respectivos parâmetros são definidos na especificação do Packet Driver [CL89]. Assim, uma aplicação sobre o Packet Driver acessa as funções do mesmo através de tais rotinas de interface, como ilustrado na figura 5.4. 


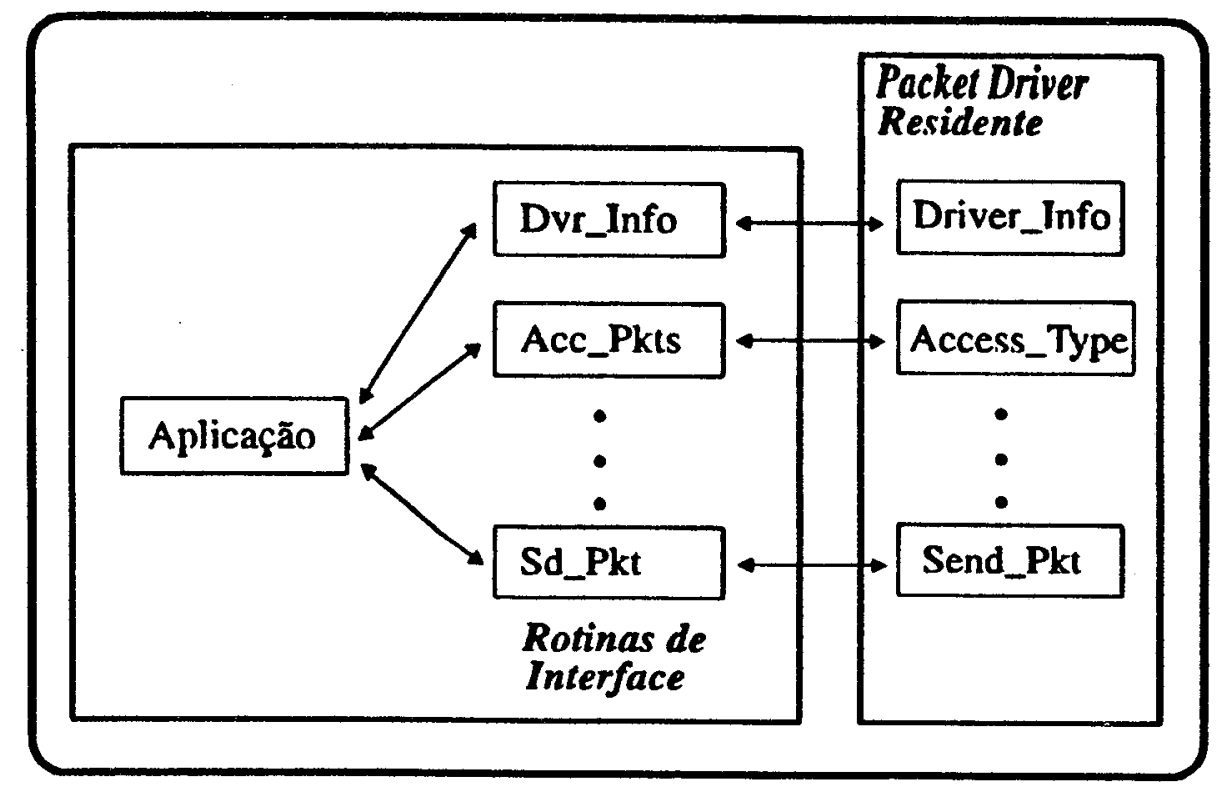

Figura 5.4: 0 Acesso às Rotinas do Packet Driver [CL89]:

Um exemplo é a função send @pkt, cuja especificação é mostrada abaixo extraída de send pkt ()

$$
\begin{array}{cl}
\text { int send pkt (buffer, length) } & A H==4 \\
\text { char far *buffer; } & D S: S I \\
\text { unsigned length; } & C X
\end{array}
$$

error return:

carry flag set

error code

DH

possible errors:

CANT_SEND

non-error return:

carry flag clear

A rotina de interface usada para acionar a função send _pkt deve então:

- inicializar os registradores:

- $\quad$ AH com o código da função, no caso 4;

- DS:SI com o endereço da variávél que contém o pacote a ser transmitido e

- CX com o tamanho do pacote.

- executar a interrupção, cujo número é especificado na ocasião da instalação do Packet Driver, podendo assumir um valor entre $0 \times 60$ e $0 \times 80$;

- e obter o resultado da operação lendo o registrador DH, após a execução da mesma. 
O código em liguagem $C$ da rotina de interface para a função send pkt é mostrado abaixo:

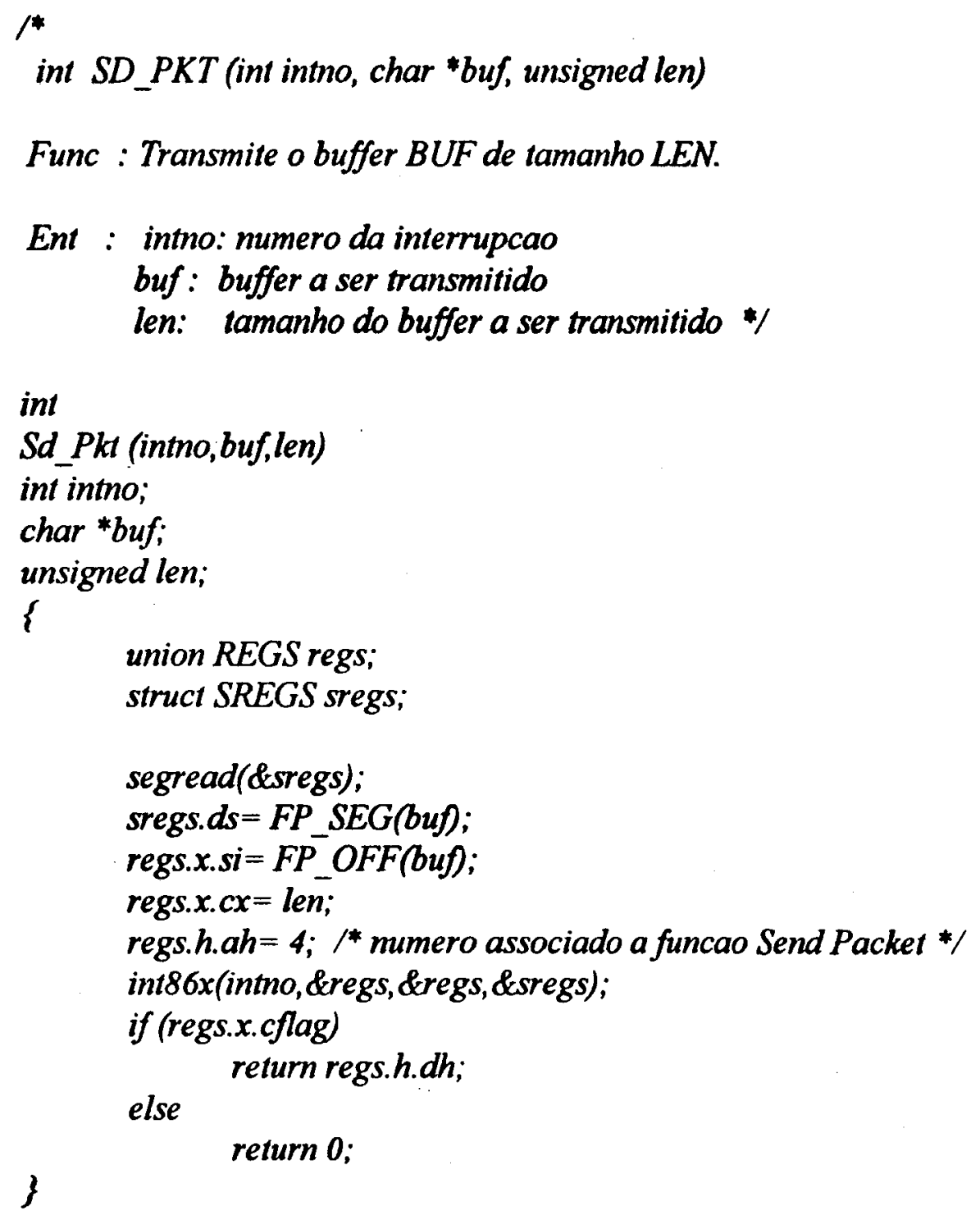

O packet driver é especificado em niveis. O primeiro nivel constitui o packet driver básico, fornecendo funcionalidade minima, implementação simples, sem exigir muitos recursos da máquina; suporta funções de transmissão e recepção de pacotes, por exemplo. $O$ segundo nivel constitui o packet driver estendido, que implementa funções menos usadas, tais como multicast e obtenção de dados estatísticos. $O$ terceiro nível engloba as funções de alta performance capazes de melhorar a performance da aplicação. O packet driver extendido é formado pela funções básicas e pelas funções adicionais especificadas como extensão. As funções de alta performance podem estar presentes tanto no packet driver básico como no estendido.

Descreve-se a seguir o funcionamento do packet driver na transmissão e recepção de pacotes. Na transmissão, o programa usuário monta o buffer de transmissão na memória e chama a rotina de interface para enviar o pacote, passando como parâmetro o endereço do buffer em questão. Então, a rotina de interface inicializa os registradores especificados com o endereço do buffer e o número da rotina correspondente do packet driver, a qual executa de fato a 
operação: configura a placa e transmite os dados do buffer de transmissão da memória para a placa.

A recepção é um processo um pouco mais complexo. Quando um pacote chega na placa, é gerada uma interrupção acionando o packet driver. Este por sua vez, já possui o endereço da rotina de recepção, obtido através da função ACCESS_TYPE do packet driver. A rotina de recepção é chamada duas vezes: na primeira, é responsável por retornar o endereço de memória de um buffer de recepção, onde o packet driver colocará o pacote recebido; e na segunda, apenas inicializa uma variável do programa usuário, indicando a chegada do pacote.

\subsubsection{A Biblioteca SNMPLIB}

A biblioteca SNMPLIB foi desenvolvida para computadores pessoais IBM PC ou compativeis, com interfaces de rede Ethernet e packet driver. Dessa forma, o software pode ser executado sobre qualquer interface Ethernet, desde que se utilize o packet driver adequado [CR91a]. niveis:

A SNMPLIB, ilustrada na figura 5.5, inclui a implementação de softwares em vários

- os protocolos IP e UDP, que é utilizado como mecanismo de transporte;

- algumas primitivas SNMP, que possibilitam a implementação de sistemas capazes de monitorar variáveis de gerenciamento e

- programas capazes de gerar a estrutura de uma MIB.

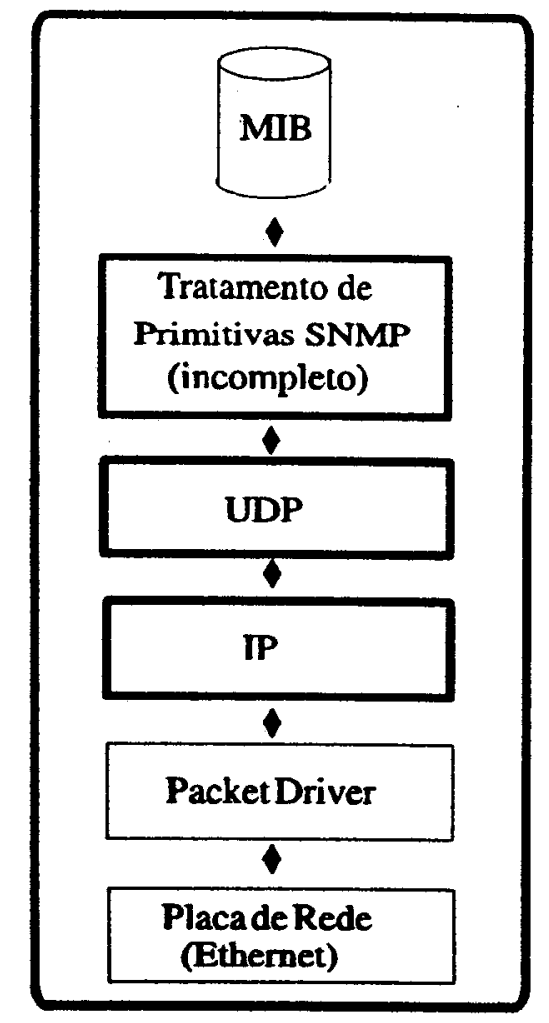

Figura 5.5: A Biblioteca SNMPLIB 
A SNMPLIB não suporta todas as primitivas definidas pelo protocolo SNMP, implementando apenas a primitiva GetRequest e rotinas de tratamento da recepção das primitivas GetResponse e Trap, através de:

- uma rotina responsável por montar o datagrama GetRequest, de acordo com dados especificados, tais como: 0 endereço do agente que deve ser consultado, sua comunidade, a lista de variáveis desejadas e informações de configuração da rede na qual encontra-se a aplicação (endereço local, máscara de rede e endereço do gateway);

- uma rotina capaz de analisar e extrair os dados de um datagrama GetResponse recebido;

- e rotinas de recepção de datagramas de notificação de eventos, as chamadas Traps.

Algumas rotinas são usadas para auxiliar na realização dessas atividades, sendo responsáveis por codificar os datagramas de GetRequest para a transmissão, ou ainda decodificar os datagramas GetResponse e Trap recebidos.

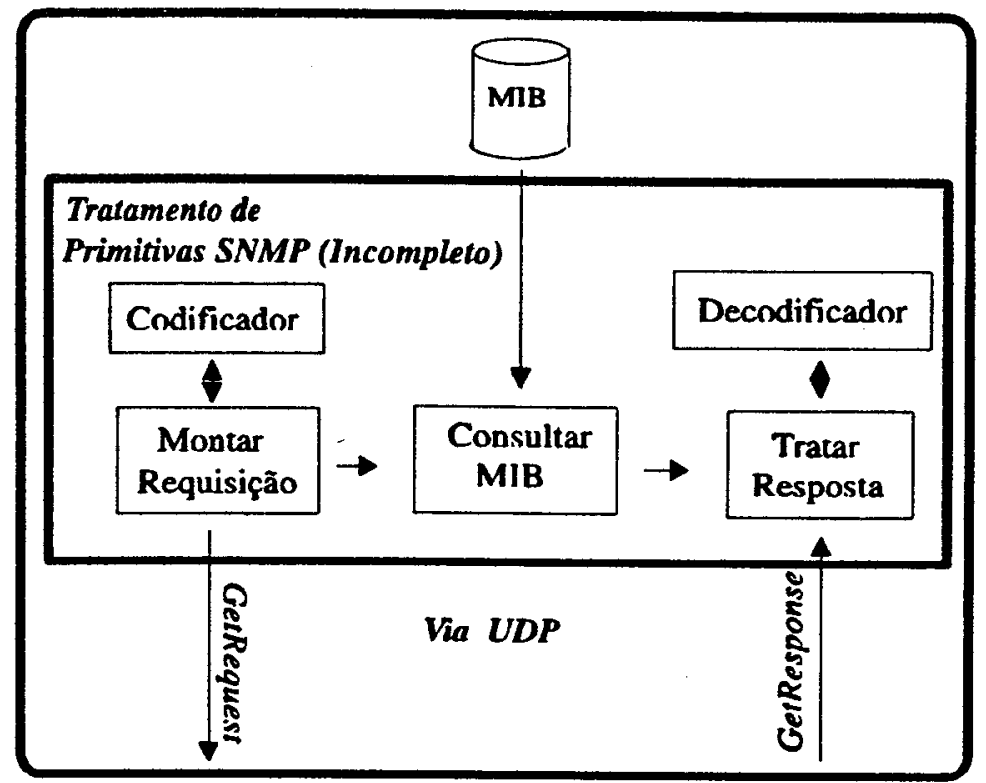

Figura 5.6: Tarefas Básicas de um Sistema de Monitoração

O envio de requisições e o tratamento de respostas constituem as tarefas básicas de um sistema de monitoração e são ilustradas na figura 5.6. Tais tarefas são suportadas pela SNMPLIB através do módulo de tratamento de primitivas SNMP na figura 5.5, o qual está referenciado como incompleto pois não implementa o mecanismo necessário para o desenvolvimento de agentes, como será visto na seção 5.3.

Um programa exemplo é distribuído com a biblioteca: o SNMPMON. Trata-se de um programa que tem por finalidade acessar dispositivos de rede, ler valores de variáveis específicas de tal dispositivo e imprimir esses valores na tela [CR91b]. Os dispositivos de rede podem ser quaisquer equipamentos que mantenham variáveis numa MIB, como definida no modelo de gerenciamento Internet e que suportem SNMP. Para desempenhar suas funções, o SNMPMON utiliza as funções implementadas pela SNMPLIB para gerar requisi̧̧ões, baseadas em dados especificados pelo usuário num arquivo de entrada, e imprimir na tela os resultados obtidos através das respostas enviadas pelo agente consultado [CR91a]. 
Para que as funções da SNMPLIB possam gerar corretamente as requisições para os dispositivos, precisa-se de determinadas informações sobre as variáveis a serem acessadas. Tais informações são obtidas da MIB definida para cada dispositivo, a qual deve ser codificada de modo a permitir o acesso pelas funçōes da SNMPLIB. Assim, a biblioteca traz programas em linguagem $C$ capazes de gerar a estrutura da MIB e escrevê-la num arquivo binário da forma reconhecida pelas funções da biblioteca. Dois programas exemplificam esse processo: um que gera a MIB padrão Internet, MIB I, e o outro que gera uma MIB particular para um dispositivo Cabletron. Os passos necessários para a geração de uma nova MIB na SNMPLIB são abordados em [CR91c].

\subsection{Implementação de um Agente SNMP para Plataformas rodando DOS}

A figura 5.7 ilustra a implementação do agente SNMP, mostrando os módulos utilizados e destacando com contornos fortes os módulos desenvolvidos. O presente trabalho implementa:

- parte do módulo de captura, coletando algumas das informações previstas na MIB Net, como descrito na seção 5.3.2;

- as rotinas acrescentadas no módulo de tratamento de primitivas SNMP, visando dar suporte à implementação de agentes, descritas na seção $5.3 .3 \mathrm{e}$

- o módulo de interface com o usuário, que mostra os dados coletados na tela da máquina onde se encontra o agente;

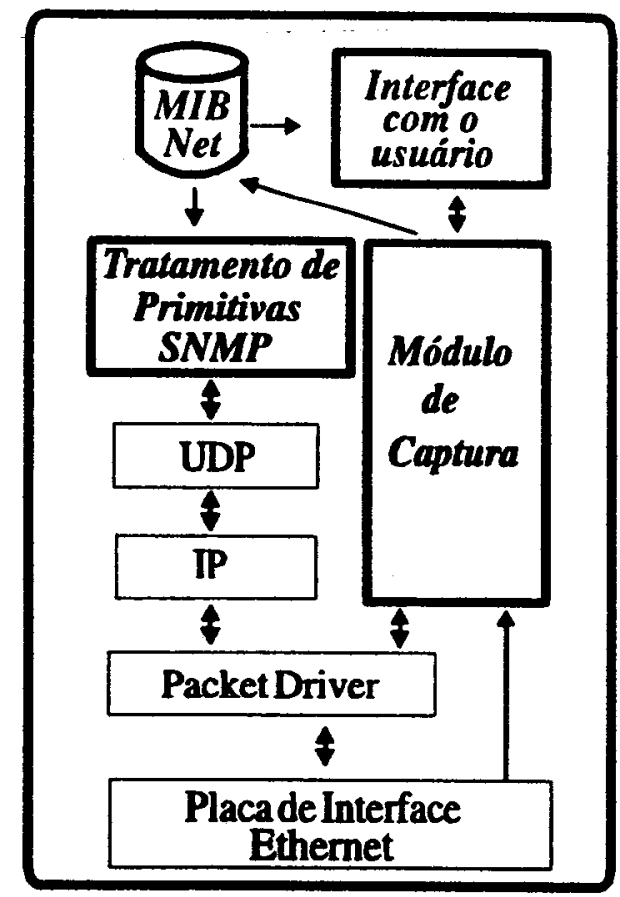

Figura 5.7: A Implementação do Agente SNMP 


\subsubsection{Implementação da MIB Net}

A MIB Net é a MIB particular definida pelo agente SNMP, tema deste trabalho. A MIB Net, especificada no apêndice A, é formada pelos grupos System e Interfaces da MIB padrão Internet, MIB II; pelo grupo Statistics da MIB RMON; e pelo grupo ProtoStat. Definida desta maneira, a MIB Net fica especificada segundo o modelo de gerenciamento Internet, podendo ser incorporada a qualquer implementação do mesmo, bastando ser gerada de acordo com as especificações de tal implementação.

$O$ agente SNMP é implementado com base na biblioteca SNMPLIB. Para se gerar uma nova MIB a ser reconhecida pela SNMPLIB, deve-se escrever um programa em linguagem $C$ que, quando executado, cria a estrutura da MIB em questão armazenando-a num arquivo binário, 0 qual será carregado para a memória no momento da execução do aplicativo desenvolvido sobre a SNMPLIB [CR91c]. A SNMPLIB possui o arquivo para a geração da MIB padrão Internet, MIB I. Assim, a solução para se implementar a MIB Net na SNMPLIB, inclui a definição de um arquivo .C para a geração da MIB II, outro para a geração da MIB RMON e, finalmente, outro para a geração do grupo ProtoStat. Compilando-se estes arquivos .C, obtém-se os correspondentes executáveis. Após a execução destes últimos, como resultado são gerados os três arquivos binários correspondentes a cada uma das "partes" da MIB Net. Tais arquivos binários deverão ser especificados na ocasião da execução do agente. Desta forma, o agente será capaz de suportar várias MIBs simultaneamente, como definido pelo modelo Internet.

Considere como exemplo a incorporação da MIB Net por um sistema de gerenciamento desenvolvido sobre o pacote de domínio público 4BSD/ISODE SNMP, que implementa o modelo de gerenciamento Internet para sistemas Berkeley Unix [RO91a]. Neste caso, o 4BSD/ISODE SNMP já possui devidamente geradas algumas MIBs, dentre as quais encontram-se a MIB padrão MIB II e a MIB RMON, restando apenas gerar a parte adicional da MIB Net, o grupo ProtoStat, o que é feito através da compilação da especificação, apresentada no apêndice $A$, no compilador de MIBs do 4BSD/ISODE SNMP. Feito isto, o sistema de gerenciamento desenvolvido sobre o 4BSD/ISODE SNMP suporta a MIB Net, o que lhe permite consultar as informações mantidas por um agente do tipo considerado neste trabalho. $O$ sistema de gerenciamento desenvolvido no ICMSC utiliza o 4BSD/ISODE SNMP.

\subsubsection{O Módulo de Captura}

A obtenção das informações mantidas na MIB Net é tarefa do módulo de captura. Este trabalho não implementa a coleta de todas as informações previstas na MIB Net. Assim, apresenta-se a seguir exemplos e sugestōes para a implementação de algumas das informações de cada grupo que compõe a MIB Net.

\section{Obtenção das Informações do novo grupo: ProtoStat}

Na implementação do grupo ProtoStat, o novo conjunto de objetos definido na MIB Net, utiliza-se o chamado modo promiscuo de recepção da interface ethernet, o qual permite a recepção de todos os pacotes da rede. A grande maioria das placas de interface de rede suporta 
este tipo de recepção, no entanto, algumas ainda não o implementam. Para saber se a placa que se está utilizando suporta ou não modo promíscuo pode-se usar a rotina Driver-Info do Packet Driver. 0 Packet Driver permite alterar o modo de recepção da interface através da rotina SetRcv-Mode. Os modos permitidos são:

Modo 1: recepção desabilitada;

Modo 2: somente a recepção dos pacotes enviados para esta interface;

Modo 3: modo 2 e recepção de pacotes broadcast;

Modo 4: modo 3 e recepção limitada de pacotes multicast;

Modo 5: modo 3 e recepção de todos os pacotes multicast;

Modo 6: todos os pacotes;

Assim, a inicialização da placa em modo promiscuo é feita acionando-se a rotina Set-rcvmode do Packet Driver com o modo de recepção 6. A figura abaixo ilustra o processo de captura e análise dos pacotes na implementação do grupo ProtoStat.

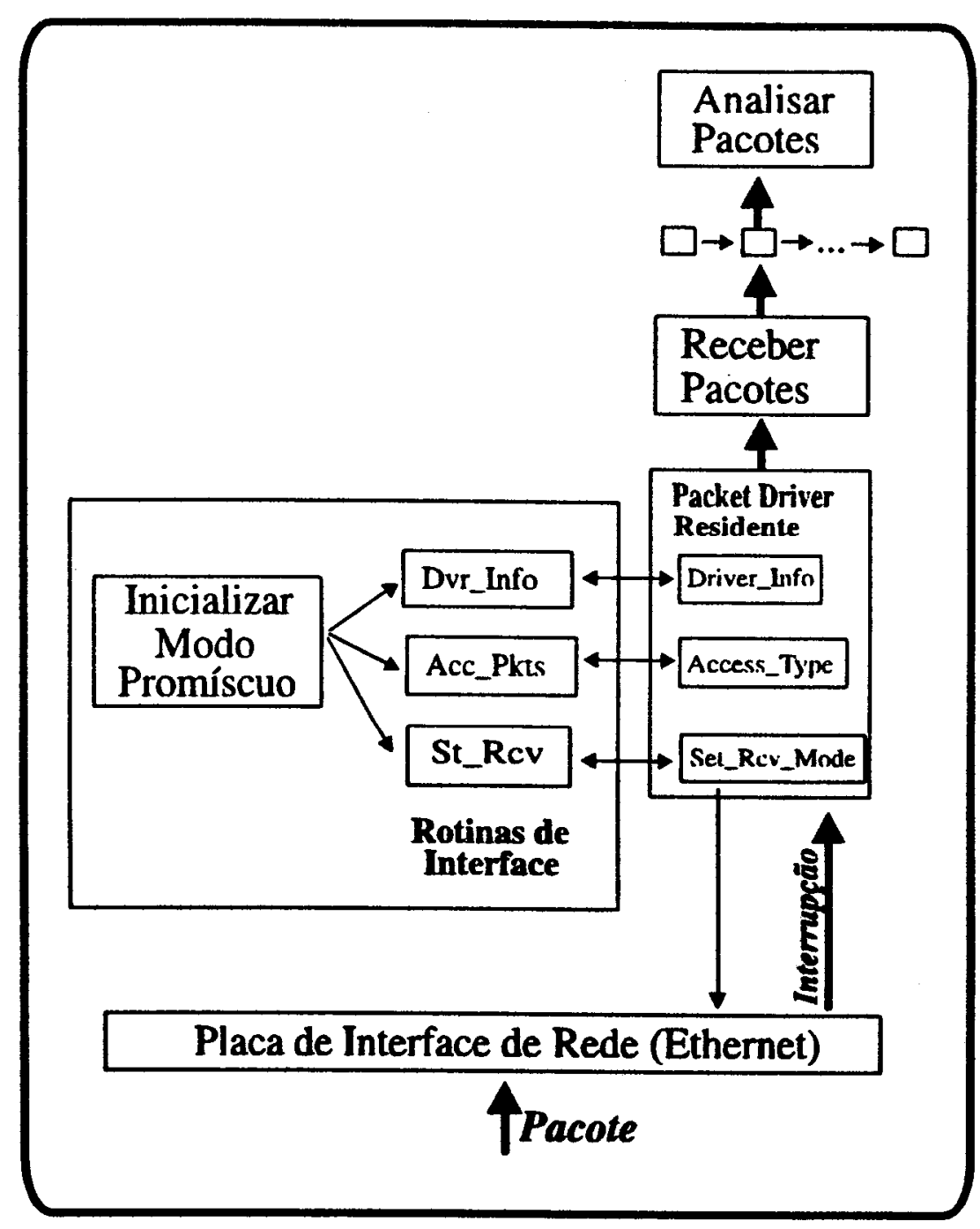

Figura 5.8: A Implementação da Captura das Informações do Grupo ProtoStat 
Após inicializar a placa em modo promiscuo, são recebidos e enfileirados todos os pacotes que passam no meio fisico. A recepção dos pacotes dá-se através do Packet Driver. 0 próximo passo é feito pela rotina de análise dos pacotes. Nesse caso, analisar um pacote significa:

- checar o campo TYPE do cabeçalho ethernet:

TYPE $=0 \times 800$, trata-se de um pacote IP;

TYPE $=0 \times 806$, trata-se de um pacote ARP;

TYPE = outro, trata-se de um pacote considerado com protocolo desconhecido.

- caso seja um pacote IP, checar o cabeçalho IP, verificando se o pacote pertence ao protocolo UDP, TCP ou ICMP.

- caso seja UDP, verificar se o pacote é para o protocolo SNMP. Caso contrário, descarta-se o pacote.

Tal análise é feita para todos os pacotes da fila, atualizando-se os contadores. No final, obtém-se os resultados que revelam o fluxo de pacotes por protocolo na sub-rede.

\section{Obtenção das Informaçōes do Grupo Statistics da RMON}

Como o grupo Statistics é definido com relação a todos os pacotes que passam na rede, sua implementação também deve usar o modo promíscuo de recepção, como descrito anteriormente. $O$ agente em questão não implementa a obtenção de todas as informações definidas no grupo Statistics. No entanto, algumas destas podem ser obtidas diretamente de registradores da placa de interface, justificando o acesso do módulo de captura à placa, mostrado na figura 5.7. Um exemplo deste tipo de informação inclui o total de pacotes recebidos com erros de CRC e erros de alinhamento (FCS), definido no objeto etherStatsCRCAlignErrors. Tal informação pode ser obtida através de dois registradores da placa de interface responsáveis por armazenar estes dados [NA90].

\section{Obtenção das Informações do Grupo System da MIB II}

Considerando as informações do grupo System da MIB padrão MIB II, sua implementação envolve um arquivo de configuração, de onde grande parte delas pode ser obtida. Estas informações incluem:

- a descrição do dispositivo, sysDescr;

- a identificação do agente, sysObjectID;

- o nome da pessoa responsável, sysContact;

- o nome do dispositivo, sysName;

- a localização física do dispositivo, sysLocation;

- os serviços oferecidos pelo agente, sysServices.

Um exemplo de tal arquivo de configuração seria:

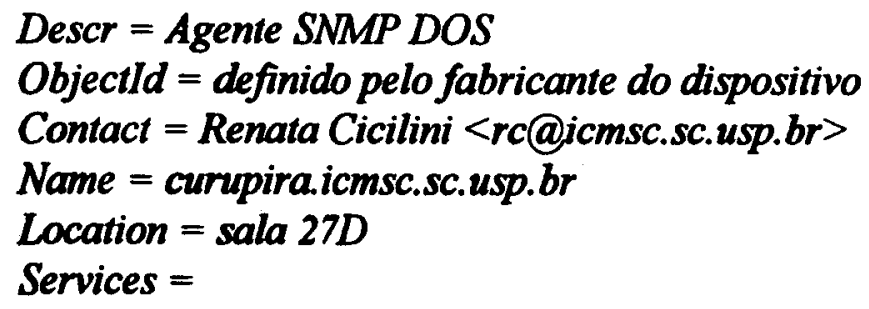


Resta ainda um objeto: o sysUpTime, que diz há quanto tempo o agente está em execução. Este dado é obtido através de funções relacionadas com a hora do sistema operacional.

\section{Obtenção das Informaçōes do Grupo Interfaces da MIB II}

Algumas informações do grupo Interfaces podem ser obtidas através da análise dos pacotes recebidos pela interface, como por exemplo o total de pacotes unicast passados para 0 protocolo da camada superior, ifInUcastPhts. Já o endereço fisico da interface, ifPhysAddress, pode ser obtido utilizando-se a função Get Address do Packet Driver.

O processo de coleta de uma dada informação pode ser efetuado para atender a um pedido do usuário local ou para responder a uma requisição SNMP feita por um sistema de gerenciamento. No primeiro caso, o sistema estará desempenhando a função de auxiliar na detecção de problemas na sub-rede onde está conectado, sendo que o usuário escolhe a informação que lhe interessa, a qual é obtida e mostrada na tela. No segundo caso entra em cena o agente SNMP propriamente dito, onde o sistema aguarda a chegada das requisições SNMP, obtendo as informações requisitadas e gerando as correspondentes respostas SNMP ao sistema de gerenciamento que as pediu. A estrutura da MIB é utilizada na checagem das identificações dos objetos pedidos nas requisições SNMP recebidas, assim como na obtenção dessas mesmas identificações para a montagem das correspondentes respostas.

\subsubsection{O Módulo de Tratamento de Primitivas SNMP}

O módulo de tratamento de primitivas SNMP é formado por:

- rotinas implementadas pela SNMPLIB, que permitem a implementação de sistemas monitores, como mostrado na figura 5.6;

- e novas rotinas, incorporadas com o objetivo de dar suporte ao desenvolvimento de agentes, como ilustrado na figura 4.3.

As novas rotinas englobam a implementação dos mecanismos de recepção de GetRequests e de geração de GetResponses, exatamente o processo inverso ao considerado pela SNMPLIB. A seguir apresenta-se os passos básicos seguidos nos dois casos:

\section{Na recepção de um $\mathrm{PDU}$ de GetRequest:}

- depois de um tempo de espera, o módulo agente recebe um datagrama UDP;

- confere o cabeçalho do datagrama, verificando tratar-se do protocolo SNMP;

- após a retirada do cabeçalho UDP, tem-se a mensagem SNMP. A partir dai, cada campo é devidamente decodificado, segundo o mecanismo descrito na seção 3.3 .2 , interpretado e checado.

- checa-se a versão e a comunidade;

- verifica-se o campo de identificação: caso não seja a constante que define um PDU de GetRequest, o pacote é descartado; 
- verifica-se o Requestld, campo que identifica a requisição, armazenando-o para a geração da resposta;

- verifica-se a lista de variáveis requisitadas.

\section{Na geração de um PDU de GetResponse:}

- os campos de versão, comunidade e Requestld são os mesmos do PDU de GetRequest correspondente;

- caso não tenha sido detectado erro, os demais campos são também idênticos aos do PDU de GetRequest correspondente, exceto por conter os valores das variáveis requisitadas; os quais foram obtidos, percorrendo-se a MIB na memória.

- caso tenha sido detectado um erro, este é notificado através dos campos error-status e errorindex, como mostrado na seção 3.3.5.

- após a codificação do PDU de GetResponse, este é passado para o protocolo UDP, para a transmissão.

\subsubsection{O Módulo de Interface com o Usuário}

Este módulo fornece uma interface simples constituída por menus através dos quais o usuário pode requisitar as informações definidas na MIB Net. As informações pedidas são mostradas na tela. 


\section{Capítulo 6}

\section{Conclusões e Trabalhos Futuros}

O gerenciamento tornou-se uma tarefa vital na área de redes de computadores, motivando o desenvolvimento de diversas aplicações de gerência. $\mathbf{O}$ trabalho descrito nesta dissertação trata de um agente para computadores rodando DOS, o qual deve obter informaçðes sobre a sub-rede à qual está conectado, deixando-as disponiveis para o acesso por sistemas de gerenciamento, através do protocolo SNMP. O desenvolvimento de agentes torna-se essencial, servindo como base para a elaboração de diversas aplicaç̃es de gerência, ou ainda sendo um importante componente no escopo dos modelos de gerenciamento. $O$ agente foi implementado em computadores rodando DOS, por ser este tipo de equipamento mais comum e barato em redes e por facilitar o acesso à mesma a baixo nivel.

O protocolo de gerenciamento usado é o SNMP pois as redes do campus USP de São Carlos são baseadas nos protocolos Internet e o agente deverá comunicar-se com o sistema de gerenciamento em desenvolvimento no ICMSC: um sistema de gerenciamento de redes com recursos multimidia, o MultiView, que também utiliza SNMP.

Foi apresentada uma solução para o desenvolvimento de agentes, baseada em softwares de domínio público: o Packet Driver, usado como driver de rede e a biblioteca SNMPLIB, usada como base para a implementą̧ão das primitivas SNMP. 
Pode-se ressaltar os seguintes pontos no sistema desenvolvido:

- a implementação de primitivas SNMP capazes de auxiliar no desenvolvimento de aplicações de gerenciamento em computadores rodando DOS. A união das rotinas da SNMPLIB com as rotinas desenvolvidas resulta numa biblioteca contendo rotinas de: geração e recebimento de primitivas GetRequest e GetResponse, e recebimento de Traps. Desta forma, tal biblioteca pode ser usada no desenvolvimento de sistemas monitores, de agentes e de agentes proxy.

- a definição de uma nova MIB, a MIB Net, especificada segundo o modelo de gerenciamento Internet, permitindo a incorporação de novos objetos e a implementação por quaisquer sistemas que sigam tal modelo. A MIB Net inclui alguns grupos da MIB padrão, um grupo da MIB RMON e define um novo grupo de objetos relacionados com o fluxo de pacotes por protocolo na sub-rede, considerado para efeito de teste do sistema. A definição e implementação de MIBs particulares torna-se importante devido à grande quantidade de dispositivos gerenciados através de MIBs particulares e também para definir novos objetos que representem informações obtidas e não definidas nas MIBs já existentes, deixando-as disponiveis para a consulta via SNMP.

- a disponibilidade de uma infra-estrutura para o desenvolvimento de agentes proxy, visto que o próprio sistema desenvolvido pode ser visto como um agente proxy da sub-rede à qual está conectado. Um agente proxy pode ser implementado utilizando-se o agente SNMP desenvolvido, necessário para que o proxy fale com o gerente SNMP; o módulo de captura, que pode ser substituído por um outro módulo qualquer responsável por acessar um determinado dispositivo da rede que não implemente o protocolo SNMP; e os mecanismos básicos para a construção de MIBs particulares, caso a MIB para o dispositivo em questão não tenha sido definida ainda.

- a consulta por sistemas de gerenciamento que implementem a MIB Net. Mantendo-se um agente que implemente a MIB Net em cada sub-rede, um sistema de gerenciamento é capaz de, consultando tais agentes, apresentar dados sobre todas as sub-redes fornecendo ao administrador uma visão global da rede, através da análise das sub-redes que a compõe.

- a exibição local dos dados obtidos, auxiliando na deteç̧ão no local, de problemas ou na depuração da sub-rede.

\section{Sugestōes para Trabalhos Futuros}

As seguintes sugestões podem gerar trabalhos futuros que darão continuidade ao sistema em questão, ou ainda motivar o desenvolvimento de outros sistemas:

- visando completar a biblioteca de primitivas SNMP para computadores rodando DOS, restaria ainda implementar as seguintes primitivas SNMP: Get-Next-Request, Set-Request e a geração de Traps. 
- visando completar a implementação da MIB Net como definida neste projeto, restaria implementar a coleta das informações restantes, como discutido no capitulo 5.

- implementação completa da estrutura da MIB Net na SNMPLIB;

- no que diz respeito à definição da MIB Net, várias melhorias poderiam ser feitas, tais como: - a implementação de outros grupos da MIB II, visto que a MIB Net considera apenas os grupos System e Interfaces;

- a implementação de outros grupos da MIB RMON, pois a MIB Net considera apenas o grupo Statistics. Deve-se observar que a MIB RMON inclui dados importantes sobre a monitoração da rede à baixo nivel, assim, a incorporação de outros grupos da RMON no agente ajudaria, por exemplo, a detectar as máquinas conectadas à sub-rede onde se encontra o agente;

- o levantamento de novos conjuntos de dados considerados importantes e não definidos nas MIBs existentes.

- o desenvolvimento de uma interface gráfica para a exibição dos dados localmente;

- uma tarefa a ser considerada, de acordo com o panorama mundial atual, seria migração do sistema para a versão 2 do modelo de gerenciamento Internet, SNMPV2;

Este trabalho é o ponto de partida para a implementação de agentes proxy e sistemas de monitoração de sub-redes, modularizando a tarefa do gerenciamento e reduzindo o tráfego de gerenciamento na rede, a medida que tais agentes e monitores mantenham dados sobre os dispositivos presentes nas sub-redes onde se encontram, reduzindo o número de máquinas a serem consultadas pelo sistema de gerenciamento. 


\section{Apêndice A}

\section{A Especificação da MIB Net}

Este apêndice apresenta a especificação da MIB Net segundo o SMI Internet [R090a] e as extensões definidas em [RO91b]. A especificação inclui

- os grupos System e Interfaces da MIB padrão Internet, MIB II, como definidos em [MC91a];

- o grupo Statistics da MIB RMON, como definido em [WA91];

- o novo grupo definido na MIB Net, o ProtoStat. 
A seguir tem-se a especificação dos grupos System e Interfaces da MIB II, extraida do RFC 1213 [MC91a]:

\section{RFC1213-MIB DEFINITIONS ::= BEGIN}

\section{IMPORTS}

mgmt, NetworkAddress, IpAddress, Counter, Gauge, TimeTicks

FROM RFC1155-SMI

OBJECT-TYPE

FROM RFC-1212;

-- This MIB module uses the extended OBJECT-TYPE macro as

-- defined in [RO91b];

-- MIB-II (same prefix as MIB-I)

mib-2 OBJECT IDENTIFIER ::=\{mgmt 1$\}$

-- textual conventions

DisplayString ::= OCTET STRING

-- This data type is used to model textual information taken

-- from the NVT ASCIl character set. By convention, objects

-- with this syntax are declared as having

$-$

-- SIZE (0..255)

PhysAddress ::=

OCTET STRING

-- This data type is used to model media addresses. For many

-- types of media, this will be in a binary representation.

-- For example, an ethernet address would be represented as

- a string of 6 octets.

- groups in MIIB-II

system OBJECT IDENTIFIER ::=\{ mib-2 1$\}$

interfaces OBJECT IDENTIFIER $::=\{$ mib-2 2$\}$ 


\title{
-- the System group
}

-- Implementation of the System group is mandatory for all

-- systems. If an agent is not configured to have a value

- for any of these variables, a string of length 0 is

-- returned.

\author{
sysDescr OBJECT-TYPE \\ SYNTAX DisplayString (SIZE (0..255)) \\ ACCESS read-only \\ STATUS mandatory \\ DESCRIPTION \\ "A textual description of the entity. This value \\ should include the full name and version \\ identification of the system's hardware type, \\ software operating-system, and networking \\ software. It is mandatory that this only contain \\ printable ASCII characters." \\ $::=\{$ system 1$\}$

\section{sysObjectID OBJECT-TYPE \\ SYNTAX OBJECT IDENTIFIER \\ ACCESS read-only \\ STATUS mandatory \\ DESCRIPTION} \\ "The vendor's authoritative identification of the \\ network management subsystem contained in the \\ entity. This value is allocated within the SMI \\ enterprises subtree (1.3.6.1.4.1) and provides an \\ easy and unambiguous means for determining "what \\ kind of box' is being managed. For example, if \\ vendor 'Flintstones, Inc.' was assigned the \\ subtree 1.3.6.1.4.1.4242, it could assign the \\ identifier 1.3.6.1.4.1.4242.1.1 to its 'Fred \\ Router'." \\ $::=\{$ system 2$\}$

\section{sysUpTime OBJECT-TYPE \\ SYNTAX TimeTicks \\ ACCESS read-only \\ STATUS mandatory \\ DESCRIPTION \\ "The time (in hundredths of a second) since the network management portion of the system was last}




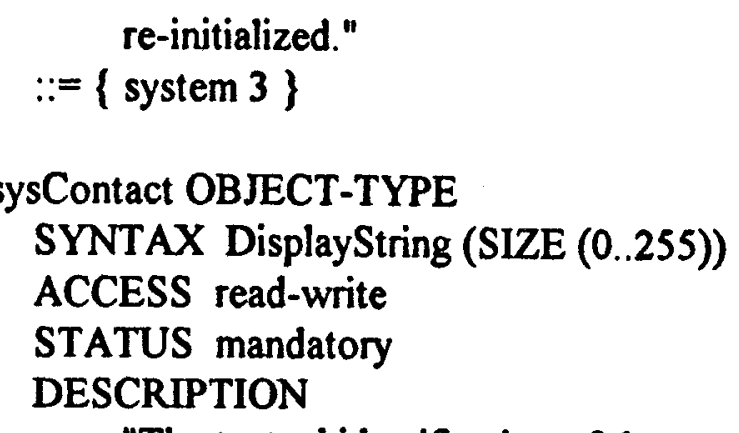

"The textual identification of the contact person for this managed node, together with information on how to contact this person."

$::=\{$ system 4$\}$

sysName OBJECT-TYPE

SYNTAX DisplayString (SIZE (0..255))

ACCESS read-write

STATUS mandatory

DESCRIPTION

"An administratively-assigned name for this

managed node. By convention, this is the node's

fully-qualified domain name."

$::=\{$ system 5$\}$

sysLocation OBJECT-TYPE

SYNTAX DisplayString (SIZE (0..255))

ACCESS read-write

STATUS mandatory

DESCRIPTION

"The physical location of this node (e.g., 'telephone closet, 3rd floor')."

$::=\{$ system 6$\}$

sysServices OBJECT-TYPE

SYNTAX INTEGER (0..127)

ACCESS read-only

STATUS mandatory

DESCRIPTION

"A value which indicates the set of services that this entity primarily offers.

The value is a sum. This sum initially takes the value zero, Then, for each layer, $L$, in the range 1 through 7, that this node performs transactions for, 2 raised to $(L-1)$ is added to the sum. For example, a node which performs primarily routing 
functions would have a value of $4(2 \wedge(3-1))$. In contrast, a node which is a host offering application services would have a value of 72

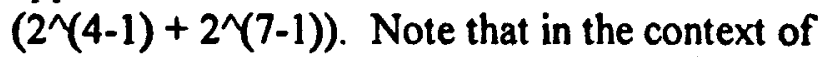
the Internet suite of protocols, values should be calculated accordingly:

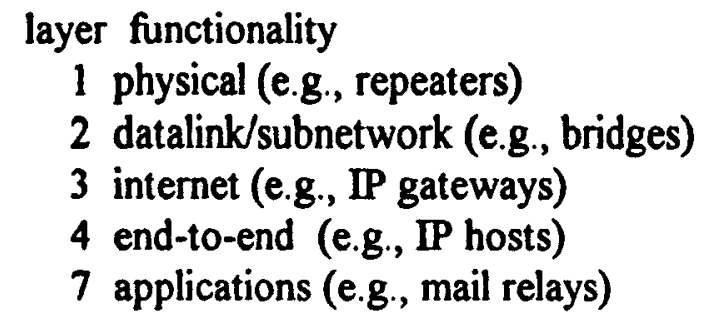

For systems including OSI protocols, layers 5 and 6 may also be counted."

$::=\{$ system 7$\}$

-- the Interfaces group

-- Implementation of the Interfaces group is mandatory for -- all systems.

ifNumber OBJECT-TYPE

SYNTAX INTEGER

ACCESS read-only

STATUS mandatory

DESCRIPTION

"The number of network interfaces (regardless of their current state) present on this system."

$::=\{$ interfaces 1$\}$

-- the Interfaces table

-- The Interfaces table contains information on the entity's

- interfaces. Each interface is thought of as being

-- attached to a 'subnetwork'. Note that this term should

-- not be confused with 'subnet' which refers to an

-- addressing partitioning scheme used in the Internet suite

-- of protocols.

\section{ifTable OBJECT-TYPE \\ SYNTAX SEQUENCE OF IfEntry \\ ACCESS not-accessible \\ STATUS mandatory}




\section{DESCRIPTION}

"A list of interface entries. The number of entries is given by the value of ifNumber."

$::=\{$ interfaces 2$\}$

\section{ifEntry OBJECT-TYPE \\ SYNTAX IfEntry \\ ACCESS not-accessible \\ STATUS mandatory \\ DESCRIPTION}

"An interface entry containing objects at the subnetwork layer and below for a particular interface."

INDEX \{ iflndex

$::=\{$ ifTable 1$\}$

\section{IfEntry $::=$ \\ SEQUENCE \{ \\ ifIndex \\ INTEGER, ifDescr \\ DisplayString, \\ ifType \\ INTEGER, ifMtu \\ INTEGER, ifSpeed \\ Gauge, \\ ifPhysAddress \\ PhysAddress, \\ ifAdminStatus \\ INTEGER, \\ ifOperStatus \\ INTEGER, \\ iflastChange \\ TimeTicks, \\ iflnOctets \\ Counter, ifInUcastPkts \\ Counter, ifInNUcastPkts \\ Counter, ifInDiscards \\ Counter,}




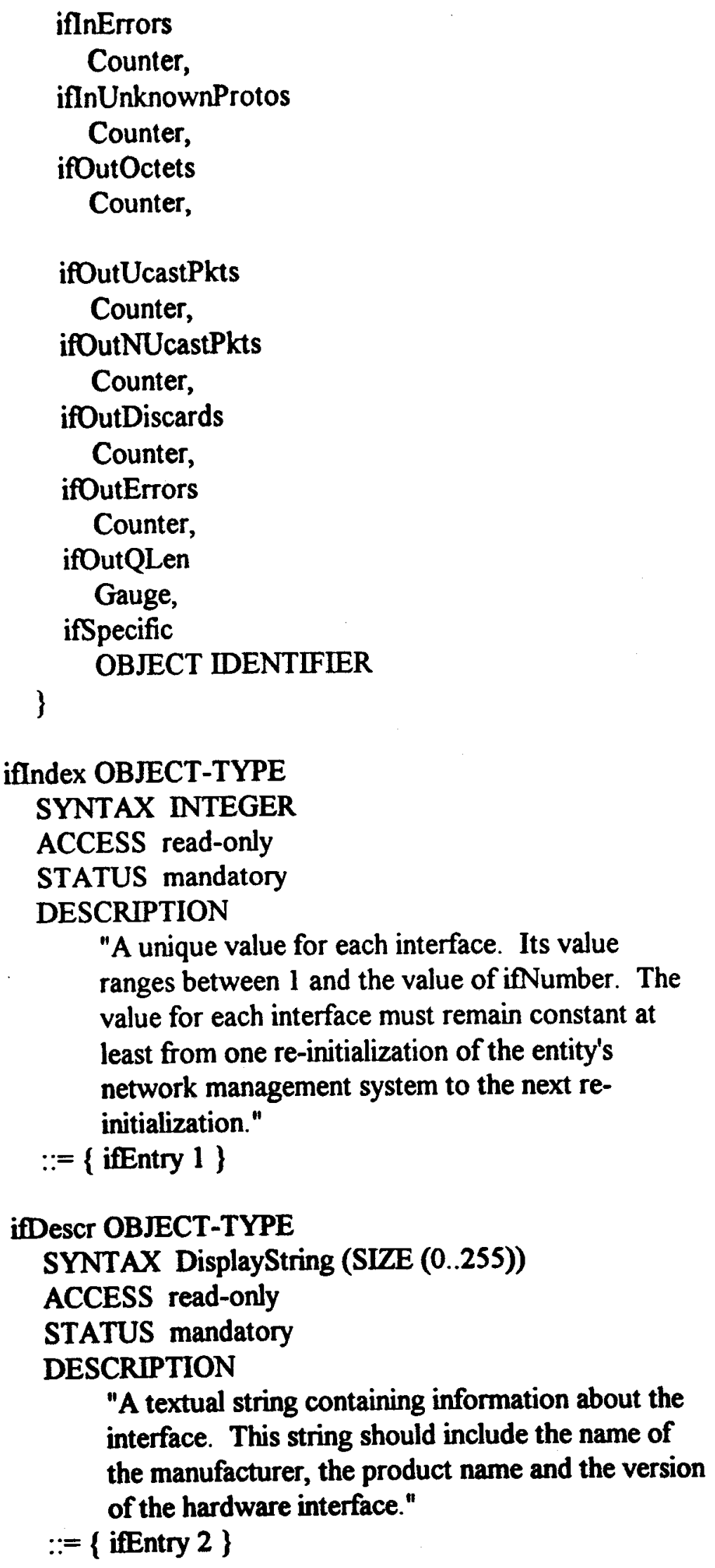




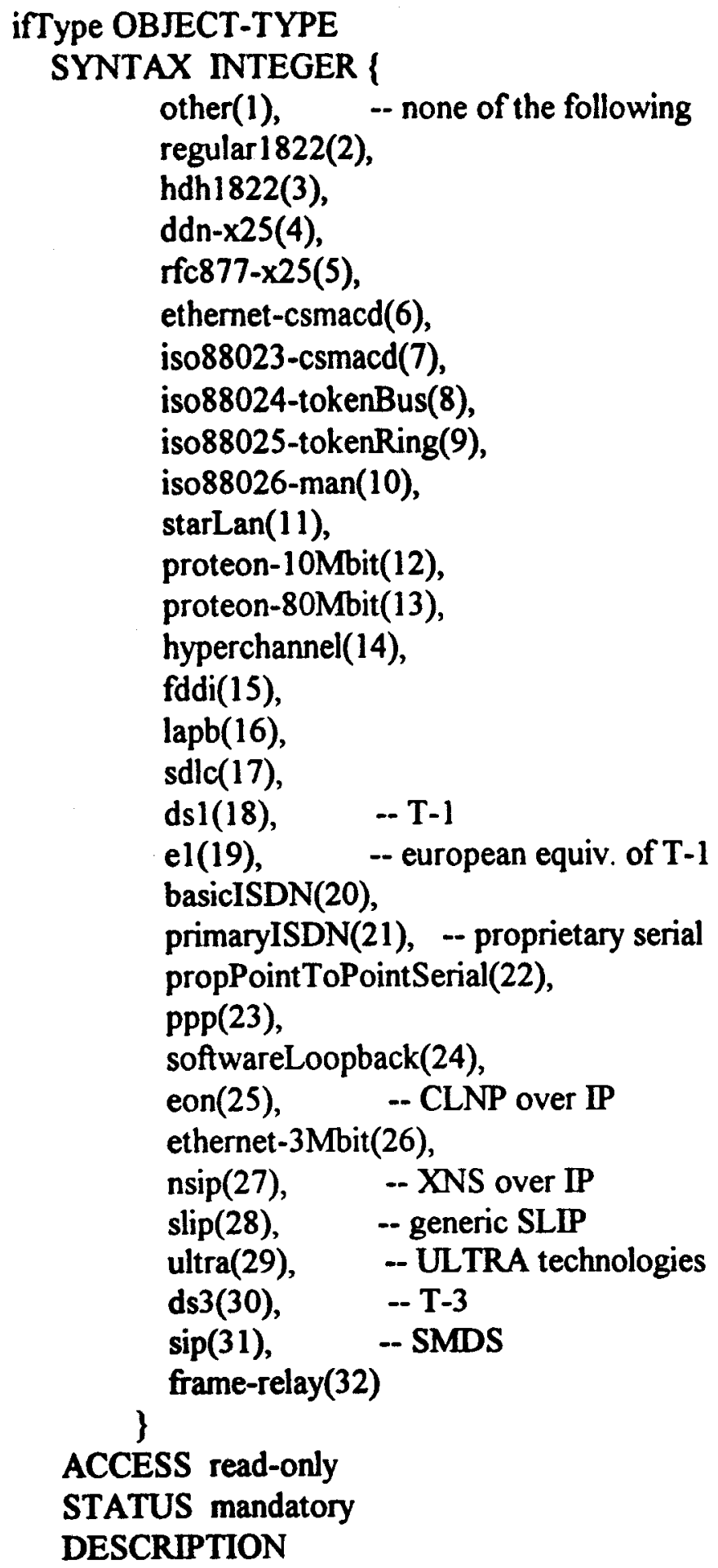

"The type of interface, distinguished according to the physical/link protocol(s) immediately 'below' the network layer in the protocol stack."

$::=\{$ ifEntry 3$\}$

ifMtu OBJECT-TYPE

SYNTAX INTEGER 


\section{ACCESS read-only \\ STATUS mandatory \\ DESCRIPTION}

"The size of the largest datagram which can be sent/received on the interface, specified in octets. For interfaces that are used for transmitting network datagrams, this is the size of the largest network datagram that can be sent on the interface."

$::=\{$ ifEntry 4$\}$

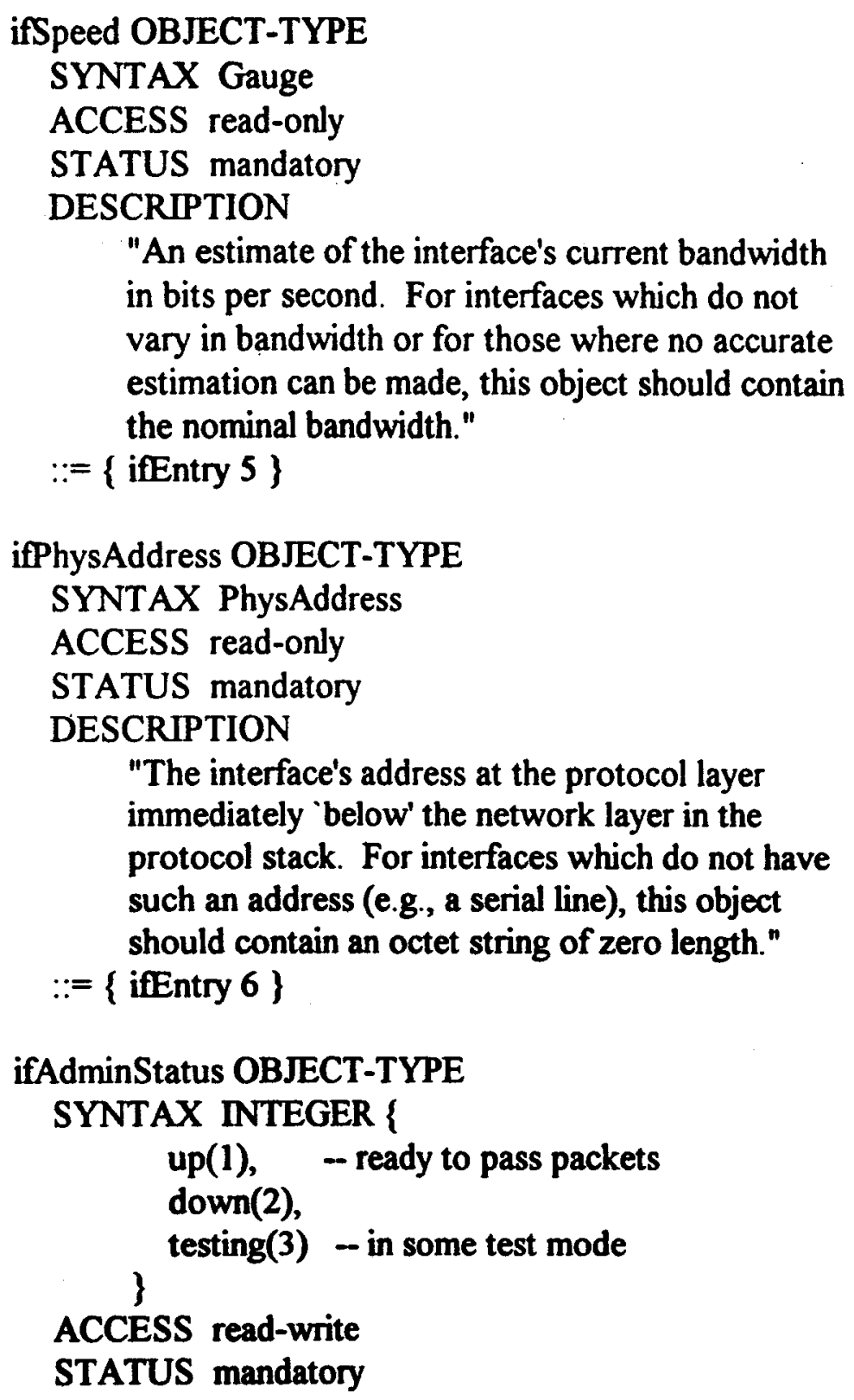




\section{DESCRIPTION}

"The desired state of the interface. The

testing(3) state indicates that no operational

packets can be passed."

$::=\{$ ifEntry 7$\}$

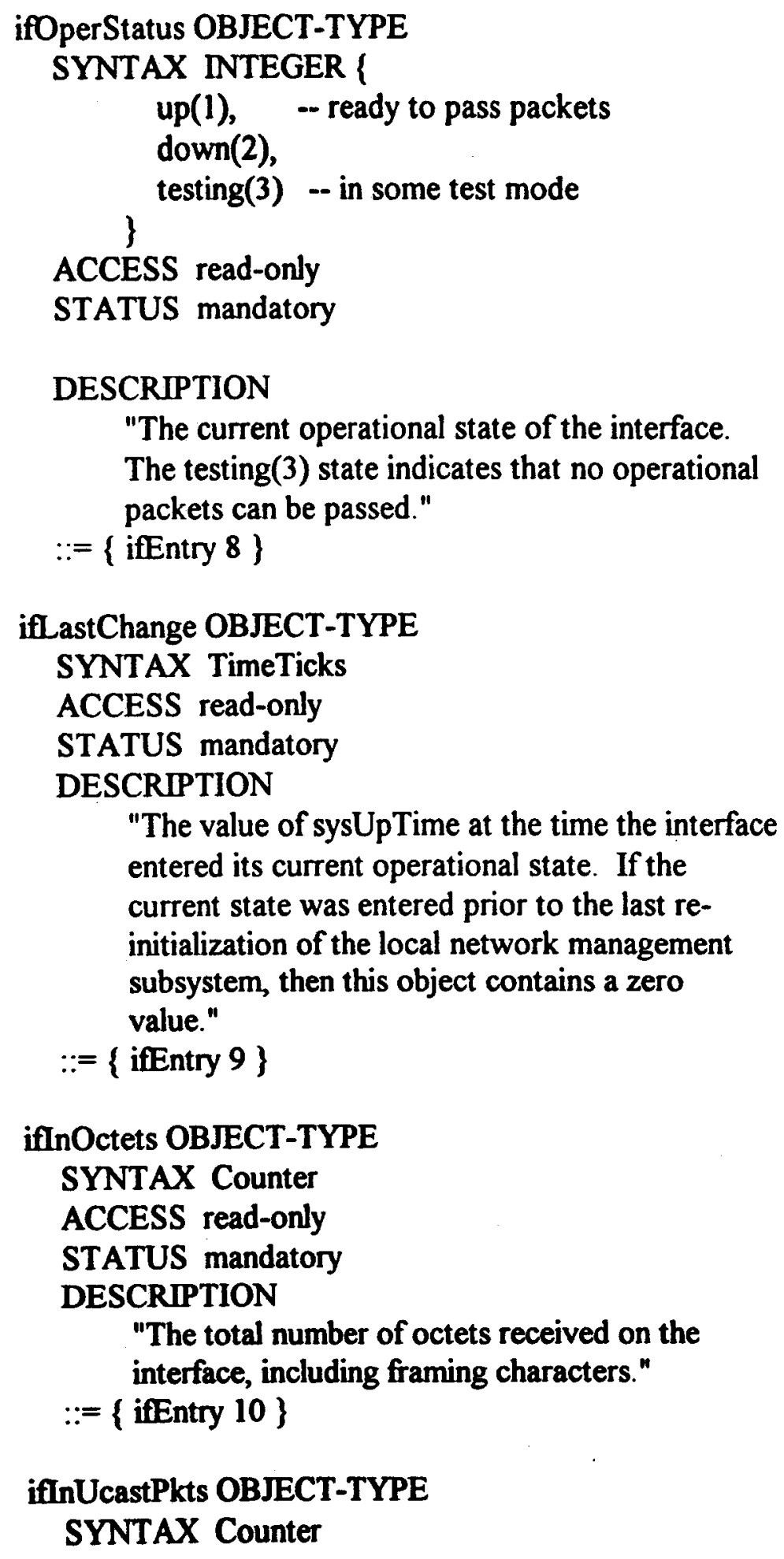




\section{ACCESS read-only \\ STATUS mandatory \\ DESCRIPTION}

"The number of subnetwork-unicast packets

delivered to a higher-layer protocol."

$::=\{$ ifEntry 11$\}$

\section{iflnNUcastPkts OBJECT-TYPE \\ SYNTAX Counter \\ ACCESS read-only \\ STATUS mandatory \\ DESCRIPTION}

"The number of non-unicast (i.e., subnetworkbroadcast or subnetwork-multicast) packets delivered to a higher-layer protocol."

$::=\{$ ifEntry 12$\}$

\section{ifInDiscards OBJECT-TYPE \\ SYNTAX Counter \\ ACCESS read-only \\ STATUS mandatory \\ DESCRIPTION}

"The number of inbound packets which were chosen to be discarded even though no errors had been detected to prevent their being deliverable to a higher-layer protocol. One possible reason for discarding such a packet could be to free up buffer space."

$::=\{$ ifEntry 13$\}$

\section{ifInErrors OBJECT-TYPE \\ SYNTAX Counter \\ ACCESS read-only \\ STATUS mandatory \\ DESCRIPTION}

"The number of inbound packets that contained errors preventing them from being deliverable to a higher-layer protocol."

$::=\{$ ifEntry 14$\}$

\section{iflnUnknownProtos OBJECT-TYPE \\ SYNTAX Counter \\ ACCESS read-only \\ STATUS mandatory}




\section{DESCRIPTION}

"The number of packets received via the interface which were discarded because of an unknown or unsupported protocol."

$::=\{$ ifEntry 15$\}$

\section{ifOutOctets OBJECT-TYPE \\ SYNTAX Counter \\ ACCESS read-only \\ STATUS mandatory \\ DESCRIPTION}

"The total number of octets transmitted out of the interface, including framing characters."

$::=\{$ ifEntry 16$\}$

\section{ifOutUcastPkts OBJECT-TYPE}

SYNTAX Counter

ACCESS read-only

STATUS mandatory

DESCRIPTION

"The total number of packets that higher-level protocols requested be transmitted to a subnetwork-unicast address, including those that were discarded or not sent."

$::=\{$ ifEntry 17$\}$

\section{ifOutNUcastPkts OBJECT-TYPE \\ SYNTAX Counter \\ ACCESS read-only \\ STATUS mandatory \\ DESCRIPTION}

"The total number of packets that higher-level protocols requested be transmitted to a nonunicast (i.e., a subnetwork-broadcast or subnetwork-multicast) address, including those that were discarded or not sent."

$::=\{$ ifEntry 18$\}$

\section{ifOutDiscards OBJECT-TYPE \\ SYNTAX Counter \\ ACCESS read-only \\ STATUS mandatory \\ DESCRIPTION}

"The number of outbound packets which were chosen to be discarded even though no errors had been 
detected to prevent their being transmitted. One possible reason for discarding such a packet could be to free up buffer space."

$::=\{$ ifEntry 19$\}$

\section{ifOutErrors OBJECT-TYPE \\ SYNTAX Counter \\ ACCESS read-only \\ STATUS mandatory \\ DESCRIPTION}

"The number of outbound packets that could not be transmitted because of errors."

$::=\{$ ifEntry 20$\}$

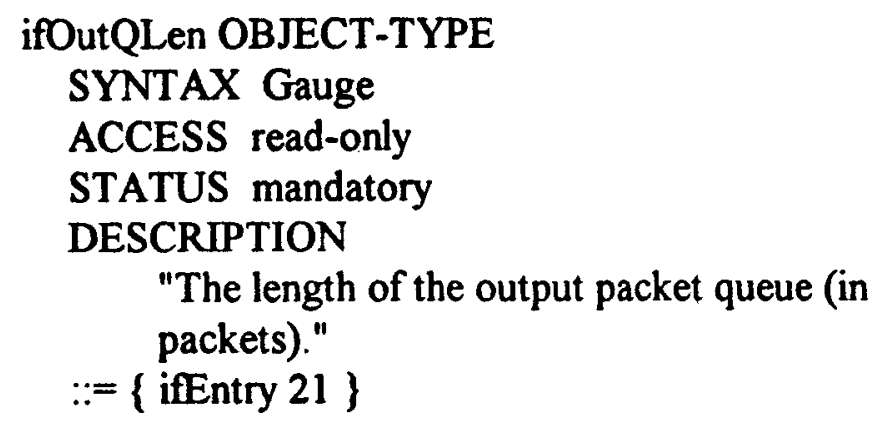

\section{ifSpecific OBJECT-TYPE}

SYNTAX OBJECT IDENTIFIER

ACCESS read-only

STATUS mandatory

DESCRIPTION

"A reference to MIB definitions specific to the particular media being used to realize the interface. For example, if the interface is realized by an ethernet, then the value of this object refers to a document defining objects specific to ethernet. If this information is not present, its value should be set to the OBJECT IDENTIFIER $\left\{\begin{array}{lll}0 & 0\end{array}\right\}$, which is a syntatically valid object identifier, and any conformant implementation of ASN.1 and BER must be able to generate and recognize this value."

$::=\{$ ifEntry 22$\}$ 
A seguir encontra-se a especificação do grupo Statistics da MIB RMON, extraida do RFC 1271 [WA91]:

RFC1271-MIB DEFINITIONS ::= BEGIN

\section{IMPORTS}

Counter

DisplayString

mib-2

OBJECT-TYPE
FROM RFC1155-SMI

FROM RFC1158-MIB

FROM RFC1213-MIB

FROM RFC-1212;

-- This MIB module uses the extended OBJECT-TYPE macro as

-- defined in [RO91b].

-- Remote Network Monitoring MIB

rmon OBJECT IDENTIFIER $:=\{$ mib-2 16$\}$

-- textual conventions

OwnerString ::= DisplayString

-- This data type is used to model an administratively

-- assigned name of the owner of a resource. This

-- information is taken from the NVT ASCII character set.

-- It is suggested that this name contain one or more

-- of the following:

-- IP address, management station name, network manager's

-- name, location, or phone number.

-- In some cases the agent itself will be the owner of

- an entry. In these cases, this string shall be set

- to a string starting with 'monitor'.

- SNMP access control is articulated entirely in terms of

- the contents of MIIB views; access to a particular SNMP

-- object instance depends only upon its presence or

- absence in a particular MIB view and never upon its

- value or the value of related object instances. Thus,

- objects of this type afford resolution of resource

- contention only among cooperating managers; they

- realize no access control function with respect

- to uncooperative parties. 
-- By convention, objects with this syntax are declared

-- as having

--

-- SIZE (0..127)

EntryStatus ::= INTEGER

( valid(1), createRequest(2), underCreation(3), invalid(4)

)

-- The status of a table entry.

$-$

-- Setting this object to the value invalid(4) has the

-- effect of invalidating the corresponding entry.

-- That is, it effectively disassociates the mapping

-- identified with said entry.

-- It is an implementation-specific matter as to whether

-- the agent removes an invalidated entry from the table.

- Accordingly, management stations must be prepared to

- receive tabular information from agents that corresponds

- to entries currently not in use. Proper

-- interpretation of such entries requires examination

-- of the relevant EntryStatus object.

$\cdots$

-- An existing instance of this object cannot be set to

-- createRequest(2). This object may only be set to

-- createRequest(2) when this instance is created. When

-- this object is created, the agent may wish to create

-- supplemental object instances to complete a conceptual

-- row in this table. Immediately after completing the

- create operation, the agent must set this object to

-- underCreation(3).

$-$

- Entries shall exist in the underCreation(3) state until

- the management station is finished configuring the

-- entry and sets this object to valid(1) or aborts,

-- setting this object to invalid(4). If the agent

-- determines that an entry has been in the

-- underCreation(3) state for an abnormally long time,

- it may decide that the management station has

-- crashed. If the agent makes this decision,

- it may set this object to invalid(4) to reclaim the

- entry. A prudent agent will understand that the 
- management station may need to wait for human input

-- and will allow for that possibility in its

-- determination of this abnormally long period.

statistics OBJECT IDENTIFIER ::=\{rmon 1$\}$

\section{-- The Statistics Group}

$+$

-- Implementation of the Statistics group is optional.

$-$

-- The statistics group contains statistics measured by the

-- probe for each monitored interface on this device. These

-- statistics take the form of free running counters that

-- start from zero when a valid entry is created.

$-$

-- This group currently has statistics defined only for

-- Ethernet interfaces. Each etherStatsEntry contains

-- statistics for one Ethernet interface. The probe must

-- create one etherStats entry for each monitored Ethernet

-- interface on the device.

\section{etherStatsTable OBJECT-TYPE}

SYNTAX SEQUENCE OF EtherStatsEntry

ACCESS not-accessible

STATUS mandatory

DESCRIPTION

"A list of Ethernet statistics entries."

$::=\{$ statistics 1$\}$

etherStatsEntry OBJECT-TYPE

SYNTAX EtherStatsEntry

ACCESS not-accessible

STATUS mandatory

DESCRIPTION

"A collection of statistics kept for a particular

Ethernet interface."

INDEX \{ etherStatsIndex \}

$::=\{$ etherStatsTable 1$\}$

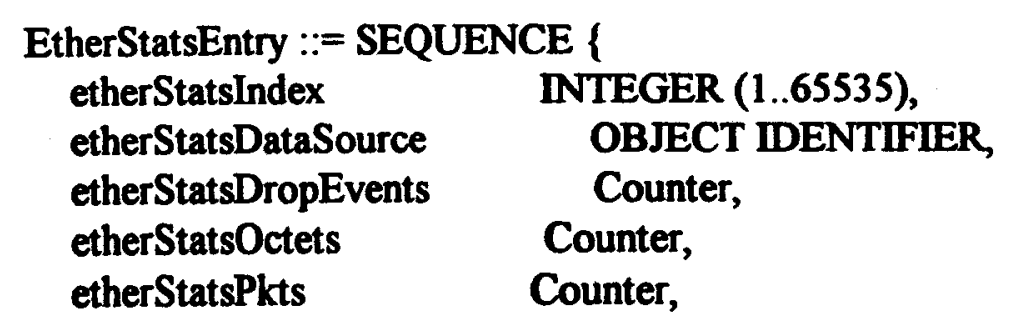




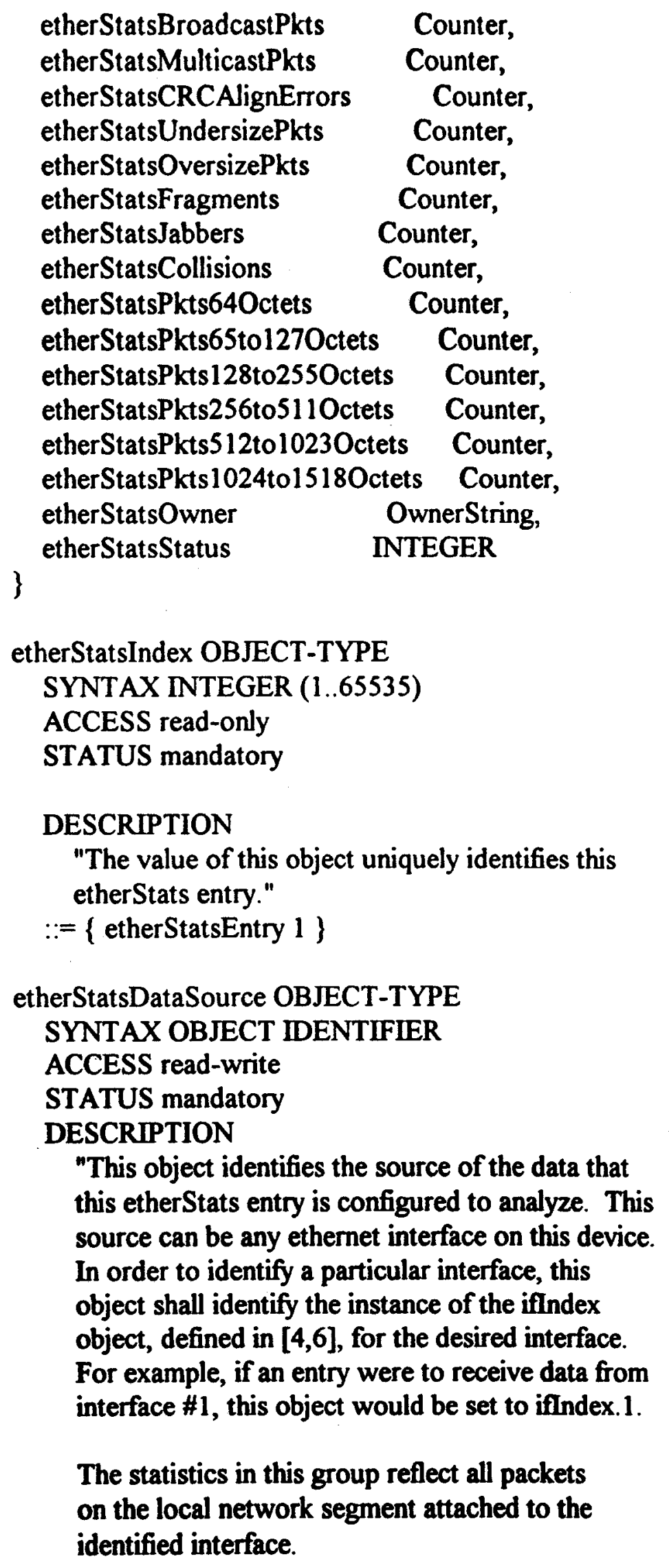

"This object identifies the source of the data that this etherStats entry is configured to analyze. This source can be any ethernet interface on this device. In order to identify a particular interface, this object shall identify the instance of the iflndex object, defined in $[4,6]$, for the desired interface. For example, if an entry were to receive data from interface \#1, this object would be set to iflndex.1.

The statistics in this group reflect all packets on the local network segment attached to the identified interface. 
This object may not be modified if the associated etherStatsStatus object is equal to valid(1)."

$::=\{$ etherStatsEntry 2$\}$

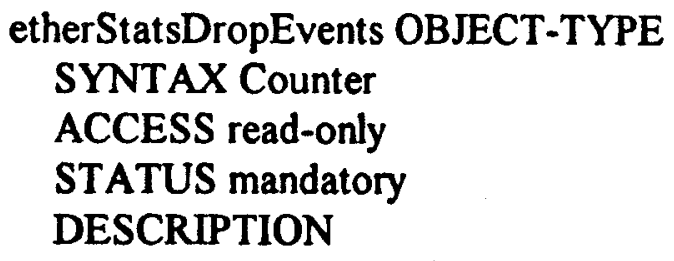

"The total number of events in which packets were dropped by the probe due to lack of resources.

Note that this number is not necessarily the number of packets dropped; it is just the number of times this condition has been detected."

$::=\{$ etherStatsEntry 3$\}$

\section{etherStatsOctets OBJECT-TYPE \\ SYNTAX Counter \\ ACCESS read-only \\ STATUS mandatory \\ DESCRIPTION}

"The total number of octets of data (including

those in bad packets) received on the

network (excluding framing bits but including

FCS octets)."

$::=\{$ etherStatsEntry 4$\}$

\section{etherStatsPkts OBJECT-TYPE \\ SYNTAX Counter \\ ACCESS read-only \\ STATUS mandatory \\ DESCRIPTION}

"The total number of packets (including error packets) received."

$::=\{$ etherStatsEntry 5$\}$

\section{etherStatsBroadcastPkts OBJECT-TYPE}

SYNTAX Counter

ACCESS read-only

STATUS mandatory

DESCRIPTION

"The total number of good packets received that were directed to the broadcast address."

$::=\{$ etherStatsEntry 6$\}$ 


\section{etherStatsMulticastPkts OBJECT-TYPE \\ SYNTAX Counter \\ ACCESS read-only \\ STATUS mandatory \\ DESCRIPTION}

"The total number of good packets received that were

directed to a multicast address. Note that this

number does not include packets directed to the

broadcast address."

$::=\{$ etherStatsEntry 7$\}$

\section{etherStatsCRCAlignErrors OBJECT-TYPE \\ SYNTAX Counter \\ ACCESS read-only \\ STATUS mandatory \\ DESCRIPTION}

"The total number of packets received that

had a length (excluding framing bits, but

including FCS octets) of between 64 and 1518

octets, inclusive, but were not an integral number

of octets in length or had a bad Frame Check

Sequence (FCS)."

$::=\{$ etherStatsEntry 8$\}$

etherStatsUndersizePkts OBJECT-TYPE

SYNTAX Counter

ACCESS read-only

STATUS mandatory

DESCRIPTION

"The total number of packets received that were less than 64 octets long (excluding framing bits, but including FCS octets) and were otherwise well formed."

$::=\{$ etherStatsEntry 9$\}$

\section{etherStatsOversizePkts OBJECT-TYPE \\ SYNTAX Counter \\ ACCESS read-only \\ STATUS mandatory \\ DESCRIPTION}

"The total number of packets received that were longer than 1518 octets (excluding framing bits, but including FCS octets) and were otherwise well formed."

$::=\{$ etherStatsEntry 10$\}$ 


\section{etherStatsFragments OBJECT-TYPE \\ SYNTAX Counter \\ ACCESS read-only \\ STATUS mandatory \\ DESCRIPTION}

"The total number of packets received that were not an

integral number of octets in length or that had a bad

Frame Check Sequence (FCS), and were less than 64

octets in length (excluding framing bits but

including FCS octets)."

$::=\{$ etherStatsEntry 11$\}$

etherStatsJabbers OBJECT-TYPE

SYNTAX Counter

ACCESS read-only

STATUS mandatory

DESCRIPTION

"The total number of packets received that were longer than 1518 octets (excluding framing bits, but including FCS octets), and were not an integral number of octets in length or had a bad Frame Check Sequence (FCS)."

$::=\{$ etherStatsEntry 12$\}$

etherStatsCollisions OBJECT-TYPE

SYNTAX Counter

ACCESS read-only

STATUS mandatory

DESCRIPTION

"The best estimate of the total number of collisions

on this Ethernet segment."

$::=\{$ etherStatsEntry 13$\}$

\section{etherStatsPkts640ctets OBJECT-TYPE}

SYNTAX Counter

ACCESS read-only

STATUS mandatory

DESCRIPTION

"The total number of packets (including error packets) received that were 64 octets in length (excluding framing bits but including FCS octets)."

$::=\{$ etherStatsEntry 14$\}$ 
etherStatsPkts65to 1270 ctets OBJECT-TYPE

SYNTAX Counter

ACCESS read-only

STATUS mandatory

DESCRIPTION

"The total number of packets (including error

packets) received that were between

65 and 127 octets in length inclusive

(excluding framing bits but including FCS octets)."

$::=\{$ etherStatsEntry 15$\}$

etherStatsPkts128to2550ctets OBJECT-TYPE

SYNTAX Counter

ACCESS read-only

STATUS mandatory

DESCRIPTION

"The total number of packets (including error

packets) received that were between

128 and 255 octets in length inclusive

(excluding framing bits but including FCS octets)."

$::=\{$ etherStatsEntry 16$\}$

etherStatsPkts256to5110ctets OBJECT-TYPE

SYNTAX Counter

ACCESS read-only

STATUS mandatory

DESCRIPTION

"The total number of packets (including error packets) received that were between 256 and 511 octets in length inclusive

(excluding framing bits but including FCS octets)."

$:=\{$ etherStatsEntry 17$\}$

etherStatsPkts512to10230ctets OBJECT-TYPE

SYNTAX Counter

ACCESS read-only

STATUS mandatory

DESCRIPTION

"The total number of packets (including error

packets) received that were between

512 and 1023 octets in length inclusive

(excluding framing bits but including FCS octets)."

$::=\{$ etherStatsEntry 18$\}$ 


\section{etherStatsPkts 1024to15180ctets OBJECT-TYPE \\ SYNTAX Counter \\ ACCESS read-only \\ STATUS mandatory \\ DESCRIPTION}

"The total number of packets (including error packets) received that were between

1024 and 1518 octets in length inclusive

(excluding framing bits but including FCS octets)."

$::=\{$ etherStatsEntry 19$\}$

\section{etherStatsOwner OBJECT-TYPE}

SYNTAX OwnerString

ACCESS read-write

STATUS mandatory

DESCRIPTION

"The entity that configured this entry and is

therefore using the resources assigned to it."

$::=\{$ etherStatsEntry 20$\}$

etherStatsStatus OBJECT-TYPE

SYNTAX EntryStatus

ACCESS read-write

STATUS mandatory

DESCRIPTION

"The status of this etherStats entry."

$::=\{$ etherStatsEntry 21$\}$

END

Finalmente, apresenta-se a especificação do novo grupo definido na MIB Net, o ProtoStat:

MIB-NET DEFINITIONS ::= BEGIN

\section{IMPORTS}

enterprises, Counter, TimeTicks

FROM RFC1155-SMI;

OBJECT-TYPE

FROM RFC-1212; 
-- Esta MIB usa a definição da macro OBJECT-TYPE segundo [RO91b]

-- MIB Net

mibNet OBJECT IDENTIFIER ::= enterprises XX $\}$

-- Grupos da MIB Net

protoStat OBJECT IDENTIFIER ::= $\{$ mibNet 1$\}$

\section{-- The ProtoStat Group}

-- This group is related to the flow of packets per protocol on a subnetwork

-- on which agent is conected. It is consisted of several packet counters

-- storing the total number of packets for each protocol. At this moment,

-- it is detected only protocols of the TCP/IP suite: ARP, ICMP, TCP,

-- UDP and SNMP, treating others as unknown protocols.

-- The suported counters permit to obtain an estimative of management traffic

-- (SNMP packets counter) or traffic per transport protocols (UDP and TCP

-- packets counters). However, in the future this group may include other

-- protocols, like Novell. This feature would provide a traffic evaluation per

-- protocol suite on the subnetwork.

$-$

-- Implementation of ProtoStat group is optional.

statArpPkts OBJECT-TYPE

SYNTAX Counter

ACCESS read-only

STATUS mandatory

DESCRIPTION

" The total number of ARP packets detected on the subnetwork. " $::=\{$ protoStat 1$\}$

statIcmpPkts OBJECT-TYPE

SYNTAX Counter

ACCESS read-only

STATUS mandatory

DESCRIPTION

" The total number of ICMP packets detected on the subnetwork. " $::=\{$ protoStat 2$\}$ 
statTcpPkts OBJECT-TYPE

SYNTAX Counter

ACCESS read-only

STATUS mandatory

DESCRIPTION

" The total number of TCP packets detected on the subnetwork." $::=\{$ protoStat 3$\}$

statUdpPkts OBJECT-TYPE

SYNTAX Counter

ACCESS read-only

STATUS mandatory

DESCRIPTION

" The total number of UDP packets detected on the subnetwork. " $::=\{$ protoStat 4$\}$

statSnmpPkts OBJECT-TYPE

SYNTAX Counter

ACCESS read-only

STATUS mandatory

DESCRIPTION

"The total number of SNMP packets detected on the subnetwork."

$:=\{$ protoStat 5$\}$

statUnknownProtoPkts OBJECT-TYPE

SYNTAX Counter

ACCESS read-only

STATUS mandatory

DESCRIPTION

" The total number of unknown protocols packets, non-TCP/IP packets, detected on the subnetwork. "

$::=\{$ protoStat 6$\}$ 


\section{Glossário}

Abstract Syntaxe Notation One (ASN.1): a linguagem OSI para descrever sintaxe abstrata.

Association Control Service Element (ACSE): elemento do serviço de aplicação responsável pelo estabelecimento e liberação de conexões.

Address Resolution Protocol (ARP): o protocolo do conjunto de protocolos Internet utilizado para mapear endereços IP em endereços fisicos.

Agente de gerenciamento de rede: a implementação de um protocolo de gerenciamento de rede que troca informações de gerenciamento com uma estação de gerenciamento de rede.

Asynchronous Transfer Mode (ATM): uma técnica de multiplexação e chaveamento, onde as conexões são multiplexadas através de pequenos pacotes de tamanho fixo. É a estrutura de transporte usada pela B-ISDN.

Basic Encoding Rules (BER): a linguagem OSI para descrição da sintaxe de transferência.

Broadband ISDN (B-ISDN): uma evolução da ISDN, desenvolvida com o objetivo de dar suporte à transmissão de diversas mídias (som, imagem e dados).

Checksum: uma soma aritmética utilizada para se verificar a integridade de dados.

CMIP over TCP/IP (CMOT): o mapeamento do modelo de gerenciamento de redes OSI para o gerenciamento de redes baseadas no conjunto de protocolos Internet.

Commom Management Information Protocol (CMIP): o protocolo OSI para gerenciamento de redes.

Commom Management Information Service (CMIS): o serviço oferecido pelo CMIP.

Commom Management Information Service Element (CMISE): o elemento de serviço de aplicação responsável pela troca de informações de gerenciameto de redes.

Comunidade: uma relação administrativa entre entidades SNMP. 
Conjunto de protocolos Internet: uma coleção de protocolos de comunicação originalmente desenvolvidos sob responsabilidade da DARPA. O conjunto de protocolos Internet, ou TCP/IP, é atualmente a solução de facto para redes abertas.

Defense Advanced Research Projects Agency (DARPA): uma agência do Departamento de Defesa dos Estados Unidos que financia pesquisas de alto risco e custo elevado. 0 conjunto de protocolos Internet foi desenvolvido pela DARPA. A DARPA era conhecida como ARPA (Advanced Research Projects Agency), quando a ARPANET foi construida.

Distributed Queue Dual Bus (DQDB): padrão IEEE 802.6 para redes metropolitanas (MANs).

Endereço broadcast: endereço IP ou específico do meio referindo-se a todas as estações no meio.

Estação de gerenciamento de rede: o sistema responsável pelo gerenciamento da rede.

Exterior Gateway Protocol (EGP): um protocolo de alcançabilidade utilizado por roteadores em uma internet de dois niveis.

File Transfer Protocol (FTP): o protocolo de aplicação que oferece o serviço de arquivos no conjunto de protocolos Internet.

Gateway: o roteador, seguindo a terminologia Internet. É também usado como entidade responsável por mapeamentos complexos, geralmente a nível de camada de aplicação.

High-level Entity Management System (HEMS): um primeiro experimento no gerenciamento de redes.

Interface Message Processors (IMPs): elementos chaveadores, usados para conectar dois ou mais canais de transmissão, recebendo e transmitindo dados através da linha correta.

Institute of Electrical and Electronics Engineers (IEEE): uma organização profissional, que, como parte de seus serviços para a comunidade, realiza alguns trabalhos de prépadronizações para a OSI.

Integrated Services Digital Network (ISDN): definida pelo CCITT como uma rede que fornece conectividade end-to-end e suporta uma grande variedade de serviços, envolvendo ou não voz, a qual os usuários podem acessar através de um conjunto limitado de interfaces padrão usuário-rede.

IEEE 802.x: conjunto de padrões para redes locais desenvolvidos pelo IEEE. 
International Organization for Standardization (ISO): a organização que produz muitos dos padrōes mundiais. O OSI é somente uma das muitas áreas padronizadas pelo ISO/IEC.

International Telephone and Telegraph Consultative Committee (CCITT): uma organização compreendendo o Post, Telephone, and Telegraph (PTT).

Internet: uma grande coleção de redes conectadas, inicialmente nos Estados Unidos, rodando o conjunto de protocolos Internet. Às vezes referido como DARPA Internet, NSF/DARPA Internet, ou Federal Research Internet.

internet: fisicamente, uma coleção de redes de comutação de pacotes interconectadas por gateways juntamente com protocolos que permitem que funcionem logicamente como uma única rede virtual.

Internet Activities Board (IAB): a organização técnica que controla o desenvolvimento do conjunto de protocolos Internet.

Internet Control Message Protocol (ICMP): um protocolo simples de notificação para o IP.

Internet Protocol (IP): o protocolo de rede do conjunto de protocolos Internet que oferece o serviço de transporte não orientado a conexão.

ISO Development Environment (ISODE): uma ferramenta de pesquisa desenvolvida para o estudo das camadas superiores do OSI.

Layer Management Entity (LME): num sistema OSI, a entidade dentro de uma camada que interage com a SMAE.

Lightweight Presentation Protocol (LPP): um protocolo que implementa um serviço de apresentação OSI mínimo, usando um protocolo de propósito especial.

Logic Link Control (LLC): executa as funções de enlace de dados independente do meio e do controle de acesso ao meio.

Local Area Network (LAN): uma rede de computadores que fornece alta velocidade, transferência com baixa latência e é limitada geograficamente.

Management Information Base (MIB): uma coleção de objetos que podem se acessados via um protocolo de gerenciamento de rede.

Maximum Transmission Unit (MTU): a maior quantidade de dados do usuário (ex. o tamanho máximo de um datagrama IP) que pode ser enviado num único frame sobre um meio particular. 
Medium Access Control (MAC): define o método de acesso ao meio, comunicando-se com as camadas superiores através do LLC.

Metropolitan Area Network (MAN): uma rede de computadores que interconecta LANs e outras máquinas abrangendo, tipicamente, uma área de $50 \mathrm{~km}$ de diâmetro.

Network File System (NFS): protocolo desenvolvido pela SUN Microsystems que utiliza o IP para permitir que um conjunto de computadores interligados em rede acessem os sistemas de arquivos uns dos outros. A vantagem principal do NFS sobre protocolos de transferência de arquivos convencionais é que o NFS esconde as diferenças entre arquivos remotos e locais colocando-os no mesmo espaço de nomes.

Nó gerenciado: um dispositivo de rede que contém uma implementação de um agente de gerenciamento de rede.

Open System Interconnection (OSI): um esforço internacional para facilitar a comunicação entre computadores de diferentes fabricantes e tecnologias.

Packet Driver: especificado pela FTP Software com o objetivo de interagir com as interfaces de rede $\mathrm{e}$ fornecer uma interface padrão às aplicações.

Protocol Data Unit (PDU): um objeto de dado trocado entre camadas contendo dados do usuário e informações de controle do protocolo.

Protocolo de gerenciamento de redes: o protocolo utilizado para transportar informações de gerenciamento.

Remote Operation Service Element (ROSE): elemento do serviço de aplicação responsável pelas interações de request/replay.

Request for Comments (RFC): uma série de documentos que descreve o conjunto de protocolos Internet e os experimentos relacionados.

Simple Gateway Monitoring Protocol (SGMP): o predecessor do SNMP.

Simple Network Management Protocol (SNMP): protocolo de aplicação do conjunto de protocolos Internet que oferece serviço de gerenciamento de rede

SNMPv2: segunda versão do modelo de gerenciamento de redes Internet.

Sintaxe abstrata: uma descrição de um tipo de dado que é independente de restrições e estruturas de máquinas.

Sintaxe de transferência: uma descrição de uma instância de um tipo de dado que é expresso como uma string de bits. 
Structure of Management Information (SMI): as regras usadas para definir os objetos que podem ser acessados via um protocolo de gerenciamento de rede.

Sub-rede: um segmento de uma rede.

Sub-rede de Comunicação: conecta os hospedeiros, tendo como tarefa a transferência de mensagens de um hospedeiro a outro.

System Management Application-Entity (SMAE): em um sistema OSI, o processo responsável pela coordenação entre as LMEs e o protocolo de gerenciamento.

TCP/IP : veja Conjunto de Protocolos Internet (Internet Suite of Protocols).

TELNET: o protocolo de aplicação que oferece um serviço de terminal virtual no conjunto de protocolos Internet.

Transmission Control Protocol (TCP): o protocolo do conjunto de protocolos Internet que oferece serviço de transporte orientado a conexão.

User Datagram Protocol (UDP): protocolo do conjunto de protocolos Internet que oferece serviço de transporte não orientado a conexão

Wide Area Network (WAN): qualquer número de tecnologias fornecendo transferência geograficamente distante. 


\section{Referências Bibliográficas}

[BA86] BACH, M. J. The Design of the UNIX Operating System. Englewood Cliffs, Prentice-Hall, 1986.

[BA93] BASTOS, C. A.; STANTON, M. Serviços e Redes de Comunicação em Alta Velocidade. In: SIMPÓSIO BRASILEIRO DE REDES DE COMPUTADORES, 11., Campinas, 1993. Tutoriais e Minicursos.

[BE88] BENHAMOU, E. Integrating Bridges and Routers in a Large Internetwork. IEEE Network, v.2, n.1, p. 69-71, 1988.

[BE90] BEN_ARTZ, A; CHANDNA, A; WARRIER, U. Network Management of TCP/IP Networks: Present and Future. IEEE Network, v.4, n.4. p.35-43, 1990.

[BI92] BISDIKIAN, C. A Performance Analysis of the IEEE 802.6 (DQDB) Subnetwork with the Bandwidth Balancing Mechanism. Computer Networks and ISDN Systems, n. 24, p. 367-385, 1992.

[B092] LE BOUDEC, J.-Y. The Asynchronous Transfer Mode: a Tutorial. Computer Network and ISDN Systems, n. 24, p. 279-309, 1992.

[BR93] BRISA. Gerenciamento de Redes - Uma Abordagem de Sistemas Abertos. São Paulo, Makron Books, 1993.

[BY91] BYRNE, W. R. et. al. Evolution of Metropolitan Area Networks to Broadband ISDN. IEEE Communications Magazine, v.29, n. 1, p. 69-82, 1991.

[CA90] CASE, J. et. al. A Simple Network Management Protocol (SNMP). Network Working Group, (DDN Network Information Center, SRI International), Request for Comments 1157, 1990.

[CA93a] CASE, J. et. al. Introduction to version 2 of the Internet-standard Network Management Framework. SNMP Research, Inc., Hughes LAN Systems, Dover Beach Consulting, Inc., Carnegie Mellon University, Request for Comments 1441, 1993. 
[CA93b] CASE, J. et. al. Coexistence between version 1 and version 2 of the Internetstandard Network Management Framework. SNMP Research, Inc., Hughes LAN Systems, Dover Beach Consulting, Inc., Carnegie Mellon University, Request for Comments 1452, 1993.

[CA93c] CASE, J. et. al. Structure of Management Information for version 2 of the Simple Network Management Protocol (SNMPy2). SNMP Research, Inc., Hughes LAN Systems, Dover Beach Consulting, Inc., Carnegie Mellon University, Request for Comments 1442, 1993.

[CA93d] CASE, J. et. al. Textual Conventions for version 2 of the Simple Network Management Protocol (SNMPv2). SNMP Research, Inc., Hughes LAN Systems, Dover Beach Consulting, Inc., Carnegie Mellon University, Request for Comments 1443, 1993.

[CA93e] CASE, J. et. al. Protocol Operations for version 2 of the Simple Network Management Protocol (SNMPv2). SNMP Research, Inc., Hughes LAN Systems, Dover Beach Consulting, Inc., Carnegie Mellon University, Request for Comments 1448, 1993.

[CA93f] CASE, J. et. al. Transport Mappings for version 2 of the Simple Network Management Protocol (SNMPv2). SNMP Research, Inc., Hughes LAN Systems, Dover Beach Consulting, Inc., Carnegie Mellon University, Request for Comments 1449, 1993.

[CA93g] CASE, J. et. al. Management Information Base for version 2 of the Simple Network Management Protocol (SNMPv2). SNMP Research, Inc., Hughes LAN Systems, Dover Beach Consulting, Inc., Carnegie Mellon University, Request for Comments 1450, 1993.

[CA93h] CASE, J. et. al. Manager-to-Manager Management Information Base. SNMP Research, Inc., Hughes LAN Systems, Dover Beach Consulting, Inc., Carnegie Mellon University, Request for Comments 1451, 1993.

[CI91] CICILINI, R.; MOREIRA, E. S. Desenvolvimento de um Conjunto de Utilitários para Testes em Redes Ethernet. In: REUNIÃO ANUAL DA SBPC, 43., Rio de Janeiro, 1991. Anais. v. 43, n.7, p. 117-118.

[CL89] User Documentation for the Packet Driver Collection. Version 1.09, US Clarckson University, 1989.

[CO84] COMER, D. E. Operating System Design: The XINU Approach. Englewood Cliffs, Prentice-Hall, 1984. v.1. 
[CO87] COMER, D. E. Operating System Design: Internetworking with XINU. Englewood Cliffs, Prentice-Hall, 1987. v.2.

[CO91a] COMER, D. E. Internetworking with TCP/PP - Principles, Protocols, and Architecture. 2.ed. Englewood Cliffs, Prentice- Hall, 1991. v.1.

[CO91b] COMER, D. E.; STEVENS, D. L. Internetworking with TCP/IP - Design, Implementation, and Internals. Englewood Cliffs, Prentice- Hall, 1991. v.2.

[CR91a] CROSSON, R. SNMPLIB: A Simple Network Management Protocol Function Library for IBM PC Compatible Computers. Documentações obtidas com 0 software via Anonymous FTP em sun.soe.clarkson.edu; 1991.

[CR91b] CROSSON, R. SNMPMON: Introduction. Documentações obtidas com o software via Anonymous FTP em sun. soe.clarkson.edu; 1991.

[CR91c] CROSSON, R. Making a Management Information Base File for SNMPLIB. Documentações obtidas com o software via Anonymous FTP em sun. soe.clarkson.edu; 1991.

[FI91] FISHER, S. Dueling Protocols. BYTE, v.16, n.3, p. 183-190, 1991.

[GA93a] GALVIN, J.; McCLOGHRIE, K. Administrative Model for version 2 of the Simple Network Management Protocol (SNMPv2). Trusted Information Systems, Hughes LAN Systems, Request for Comments 1445, 1993.

[GA93b] GALVIN, J.; McClOGHRIE, K. Security Protocols for version 2 of the Simple Network Management Protocol (SNMPv2). Trusted Information Systems, Hughes LAN Systems, Request for Comments 1446, 1993.

[GE89] GECHTER, J.; OREILLY, P. Conceptual Issues for ATM. IEEE Network, v. 3, n. 1, p. 14-16, 1989.

[GI86] GIOZZA, W. F. et. al. Redes Locais de Computadores - Tecnologia e Aplicações. São Paulo, McGraw-Hill, 1986.

[HA89] HANDEL, $R$. Evolution of ISDN Towards Broadband ISDN. IEEE Network, $v$. 3, n. 1, p. 7-13, 1989.

[KE90] KESSLER, G. C. ISDN : Concepts, Facilities and Services. McGraw-Hill, 1990.

[KL86] KLESSIG, R. W. Overview of Metropolitan Area Networks. IEEE Communications Magazine, v.24, n.1, 1986. 
[KL88] KLERER, S. M. The OSI Management Architecture: an Overview. IEEE Network, v.2, n. 2, p. 20-29, 1988.

[KN88] KNIGTHSON , K. G.; KNOWLES, T.; LARMOUTH, J. Standards for Open Systems Interconnections. McGraw- Hill, 1988.

[KR93] KRISHNAN, R.; MAXEMCHUK, N. Life Beyond Linear Topologies. IEEE Network Magazine, Março, 1993.

[MC90a] McClOGHRIE, K.; ROSE, M. Management Information Base for TCP/IP-based internets. (DDN Network Information Center, SRI International), Request for Comments 1156, 1990.

[MC90b] McMASTER, D. DAVID ExpressNet SNMP MIB for TCP/IP Networks Release 1.0. Definição de uma MIB obtida via Anonymous FTP em venera. isi.edu; 1990.

[MC91a] McCLOGHRIE, K.; ROSE, M. Management Information Base for Network Management of TCP/IP- based internets: MIB-II. Hughes LAN Systems, Performance Systems International, Request for Comments 1213, 1991.

[MC91b] McCLOGHRIE, K. Extensions to the Generic-Interface MIB. Hughes LAN Systems, Request for Comments 1229, 1991.

[MC93] McClOGHRIE, K.; GALVIN, J. Party MIB for version 2 of the Simple Network Management Protocol (SNMPv2). Hughes LAN Systems, Trusted Information Systems, Request for Comments 1447, 1993.

[ME76] METCALFE, R. M.; BOGGS, D. R. Distributed Packet Switching for Local Computer Networks. Communications of $A C M$, v. 19, n. 7, p. 395-404, 1976.

[MI90a] MICROSOFT C MANUAL. Reference. Microsoft Corporation, 1990.

[MI90b] MICROSOFT C MANUAL. Advanced Programming Techniques. Microsoft Corporation, 1990.

[MO94] MOREIRA, E. S; ODA, C. S.; CICILINI, R. Um Sistema Gerenciador de Redes de Computadores com Recursos de Multimídia. In: SEMINFO, 5, Salvador, Bahia, 1994. Anais.

[NA90] NATIONAL MANUAL. Data Communications, Local Area Networks, UARTs. NATIONAL Semiconductor, 1990.

[NI90] NITZAN, R.; GROSS, P. The Role of the GOSIP. Computer Networks and ISDN Systems, v.19, p. 270-274, 1990. 
[OD91] ODA, C. S.; MOREIRA, E. S. Um Ambiente Gráfico para Monitoração de Redes Locais. In: REUNIÃO ANUAL DA SBPC, 43., Rio de Janeiro, 1991. Anais. v. 43, n. 7, p.121-122.

[PE85] PETERSON, J. L.; SILBERSCHATZ, A. Operating System Concepts. 2.ed. Addison-Wesley Publishing Company, 1985.

[PL82] PLUMMER, D. C. Ethernet Address Resolution Protocol. Request for Comments 826, (DDN Network Information Center, SRI International), 1982.

[PO81] POSTEL, J. Internet Protocol. Request for Comments 79], (DDN Network Information Center, SRI International), 1981.

[RI89] RIDER, M. J. Protocols for ATM Access Networks. IEEE Network, v. 3, n. 1, p. 17-22, 1989.

[RO90a] ROSE, M.; MCCLOGHRIE, K. Structure and Identification of Management Information for TCP/IP-based internets. (DDN Network Information Center, SRI International), Request for Comments 1155, 1990.

[RO90b] ROSS, F. E.; HAMSTRA, J. R.; FINK, R. L. FDDI: a LAN among MANs. Computer Communications Review, v.20, n.3, p. 16-31, 1990.

[RO90c] RODRIGUES, M. A. Evaluating Perfomance of High-Speed Multiaccess Networks. IEEE Network Magazine, Maio, 1990.

[RO91a] ROSE, M. T. The Simple Book- An Introduction to Management of TCP/IP- based Internet. Englewood Cliffs, Prentice- Hall, 1991.

[RO91b] ROSE, M.; McCLOGHRIE, K. Concise MIB Definitions. Performance Systems International, Hughes LAN Systems, Request for Comments 1212, 1991.

[SA94] SADIKU, M. N. O.; ARVIND, A. S. Annotated Bibliography On Distributed Queue Dual Bus (DQDB). Computer Communication Review, v.24, n.1, 1994.

[SC88] SCHWARTZ, M. Telecommunication Networks- Protocols, Modeling and Analysis. Addison-Wesley Publishing Company, 1988.

[SC89] SCHOFFSTALL, M. L. et. al. SNMP over Ethernet. (DDN Network Information Center, SRI International), Request for Comments 1089, 1989.

[SC90a] SCHILDT, H. C Completo e Total. Makron Books, McGraw-Hill, 1990.

[SC90b] SCHNAIDT, P. Keep It Simple. Lan Magazine; p. 82-92, julho 1990. 
[SE88] SEIFERT, W. M. Bridges and Routers. IEEE Network Magazine, v.2, n.1, p. 5764, 1988.

[SK89] SKOV, M. Implementation of Physical and Media Access Protocols for HighSpeed Networks. IEEE Communications Magazine, v.27, n.6, p. 45-53, 1989.

[SO91] SOCOLOFSKY, T.; KALE, C. A TCP/IP Tutorial. (DDN Network Information Center, SRI International), Request for Comments 1180, 1991.

[SO92] SOARES, L. F. G. et. al. Fundamentos de Sistemas Multimídia. In: ESCOLA DE COMPUTAÇÃO, VIII., Gramado, 1992.

[SP93] SPECIALSKI, E. S. Arquitetura OSI de Gerenciamento. /Apresentado à XI SBRC, Campinas, 1993/.

[ST84a] STALLINGS, W. Local Networks. Computing Surveys, v. 16, n. 1, p.3-27, 1984.

[ST84b] STALLINGS, W. Local Networks - An Introduction. New York, Macmillan Publishing Company, 1984.

[ST91] STEPHENSON, P. Mixing and Matching LANs. BYTE, v. 16, n. 3, p. 157-164, 1991.

[SU90a] SUN MANUAL. SunOS Reference Mamual-Maintenance commands. Sun Microsystems, 1990. v. 3.

[SU90b] SUN MANUAL. Writing Device Drivers. Sun Microsystems, 1990.

[TA87] TANENBAUM, A. S. Operating Systems- Design and Implementation. Englewood Cliffs, Prentice-Hall, 1987.

[TA89] TANENBAUM, A. S. Computer Networks. 2.ed. Englewood Cliffs, PrenticeHall, 1989.

[TA92] TANENBAUM, A. S. Modern Operating Systems. Englewood Cliffs, PrenticeHall, 1992.

[WA91] WALDBUSSER, S. Remote Network Monitoring Management Information Base. Carnegie Mellon University, Request for Comments 1271, 1991.

[WA89] WARRIER, V.; BESAW, L. The Common Management Information Services and Protocol over TCP/IP (CMOT). (DDN Network Information Center, SRI International), Request for Comments 1095, 1989. 
[WA90] WARRIER, U. et. al. The Common Management Information Services and Protocols for the Internet (CMOT and CMIP). (DDN Network Information Center, SRI International), Request for Comments J189, 1990

[YA93] YAP, M; HUTCHISON, D. An Emulator for Evaluating DQDB Performance. Computer Networks and ISDN Systems, n. 25, p. 1177-1204, 1993.

[ZU90] ZUKERMAN, M; POTTER, P. G. The DQDB Protocol and its Performance under Overload Traffic Conditions. Computer Networks and ISDN Systems, n. 20, p. 261-270, 1990. 